\title{
Stratigraphische Begriffe für das Quartär des norddeutschen Vereisungsgebietes
}

\author{
Thomas Litt, Karl-Ernst Behre, Klaus-Dieter Meyer, Hans-Jürgen Stephan \& Stefan Wansa*)
}

Einleitung: Norddeutschland und angrenzende Gebiete, beeinflusst durch die skandinavischen Inlandvereisungen, sind klassische Regionen der Quartärgeologie und -stratigraphie. Der Schweizer Geologe vON MORLOT (1844) vermutete bereits, dass die nordischen Vergletscherungen das Erzgebirge in Sachsen erreicht haben könnten. Die Entdeckung der Gletscherschrammen auf triassischem Muschelkalk in Rüdersdorf bei Berlin durch TorRell (1875) führte zur generellen Akzeptanz der Glazialtheorie in Deutschland. PENCK (1879) vermutete, dass Norddeutschland durch drei voneinander getrennte Vergletscherungen beeinflusst wurde. Die Kartierung der pleistozänen Ablagerungen durch den Preußischen Geologischen Dienst seit 1910 war ein Meilenstein für die Quartärstratigraphie, und die Begriffe „Elster“, „Saale“ und „Weichsel“" wurden in die wissenschaftliche Literatur eingeführt. Quartärgeologen wie L. Siegert, W. Weissermel, K. Keilhack, R. Grahmann und P. Woldstedt beschrieben bereits Anfang des 20. Jahrhunderts fundamentale Zusammenhänge der Glazialgeschichte des nordmitteleuropäischen Tieflandes und ihre Korrelation mit fluvialen Prozessen. Die Quartärstratigraphie in Norddeutschland besitzt nicht zuletzt durch das dichte Netz an Bohrungen und durch die gut untersuchten Profilaufschlüsse in den Braunkohlentagebauen eine solide Basis. Von besonderer Bedeutung für die Stratigraphie ist in diesem Gebiet die Verzahnung von glaziärer und periglaziärer Fazies, d.h. die Beziehung zwischen Schotterterrassen, Moränenablagerungen und überdies zwischengeschalteten Interglazialsedimenten. In ihrer vertikalen Abfolge folgen sie in klassischer Weise dem stratigraphischen Grundgesetz.

Die Gliederung für den nicht glazial beeinflussten Zeitraum des Unterpleistozän und des unteren Mittelpleistozän (bis zur Elster-Kaltzeit) basiert in Norddeutschland auf langen kontinentalen Folgen wie Lieth in Schleswig-Holstein (Menke 1975) und Gorleben in Niedersachsen (Müller 1992). Die Kriterien für die paläoklimatologische Klassifikation in Kalt- und Warmzeiten (Abb. 1) werden vor allem durch die Palynologie bestimmt.

Das aussagefähigste Profil für das nahezu gesamte Unterpleistozän ist die Abfolge von Lieth (MENKE 1975), das in stratigraphischer Superposition den Zeitraum vom Beginn des Praetiglium (KaltenhörnKaltzeit) bis zum Bavel-Komplex (Pinneberg-Warmzeit) hervorragend dokumentiert. Insofern sind in Lieth die Befunde vollständiger als die der einzelnen nicht zusammenhängenden Typusprofile in den Niederlanden. Die Korrelation zwischen Norddeutschland und dem Niederrheingebiet wird von Menke (1975) sowie von Stephan \& Menke (1993) diskutiert (Abb. 2). Als palynologische Charakteristika für das Unterpleistozän in Norddeutschland beschreibt Menke (1975), dass die typische Pliozän-Flora bereits erloschen ist, jedoch einige Pliozänelemente wie Tsuga, Carya, Eucommia wichtige Differenzialformen gegenüber dem Mittel- und Oberpleistozän darstellen. Klimageschichtlich wird

\footnotetext{
*Anschrift der Verfasser: Prof. Dr. Thomas Litt, Institut für Paläontologie, Universität Bonn, Nussallee 8, 53115 Bonn, Email: t.litt@uni-bonn.de; Prof. Dr. KarL-Ernst Behre, Niedersächsisches Institut für historische Küstenforschung, Viktoriastr. 26/28, Postfach 2062, 26360 Wilhelmshaven, Email: behre@nihk.de; Prof. Dr. Klaus-Dieter Meyer, Engenser Weg 5, 30938 Burgwedel; Dr. Hans-JÜrgeN StePhan, Köhlstraße 3, 24159 Kiel, Email: h-j.stephan@freenet.de; Dr. Stefan Wansa, Landesamt für Geologie und Bergwesen Sachsen-Anhalt, Köthener Str. 34, Postanschrift: Postfach 156, 06118 Halle, Email: wansa@lagb.mw.lsa-net.de
} 
zwar ein vielfältiger Wechsel zwischen so genannten Kryo- und Thermomeren deutlich (Lieth als Typusprofil für die entsprechenden klimatostratigraphischen Einheiten), wobei jedoch die Kryomere noch nicht das Ausmaß der mittel- und oberpleistozänen Kaltzeiten bzw. Glaziale erreichten.

Insbesondere die Warmzeiten des oberen Unterpleistozän und des unteren Mittelpleistozän (BaveliumKomplex und Cromerium-Complex) wurden mittels Bohrungen durch das Deckgebirge des Salzstocks von Gorleben palynostratigraphisch erfasst (MüLLER 1986, 1992). Durch Überlappung ist der Anschluss an die Lieth-Sequenz gesichert (Abb. 3). Nach den Untersuchungen in Gorleben lassen sich allein für den Cromer-Komplex mindestens fünf Warmzeiten identifizieren (von alt nach jung: Osterholz-, Hunteburg-, zwei unbenannte Thermomere und abschließend die Rhume-Warmzeit, vgl. Abb. 3).

Während des Elster-Glazials ist das nordische Inlandeis bis an den Rand der Mittelgebirge von Sachsen und Thüringen vorgestoßen und hat den Unterharz teilweise überfahren. Der erste Elster-Eisvorstoß erreichte in Mitteldeutschland die größte Ausdehnung aller pleistozänen Vergletscherungen (Abb. 4). Der weitere Verlauf des Eisrandes nach Westen ist unsicher, da die elsterzeitlichen Ablagerungen während des Drenthe-Eisvorstoßes in Niedersachsen großflächig erodiert oder durch jüngere Sedimente überlagert wurden (CASPERS et al. 1995). Die glaziären Ablagerungen werden mit zwei großen Eisvorstößen in Verbindung gebracht, die jedoch nicht durch eine voll entwickelte Warmzeit unterbrochen sind.

Nach dem Zerfall des Elstereises bildeten sich in ehemaligen Rinnen, Exarationswannen und Toteislöchern Seen, in denen Sedimente der Holstein-Warmzeit akkumuliert wurden. Im Gebiet der nordischen Vereisungen sind zahlreiche Vorkommen des Holstein-Interglazials über elsterglazialen Bildungen bekannt, die durch ihre charakteristische Vegetationsentwicklung eine sichere Einstufung und Korrelation erlauben.

Der Saale-Komplex umfasst den Zeitraum vom Ende der Holstein-Warmzeit bis zum Beginn der Eem-Warmzeit (LitT \& TURNER 1993). Er ist eine komplexe stratigraphische Einheit mit mehrfachen Kälte- und Wärmeschwankungen, wobei letztere sogar Interglazialcharakter erreichen können (mindestens eine Warmzeit im Sinne von Dömnitz- bzw. Wacken-Warmzeit nach ERD 1965b bzw. MenKE 1968a. Urban 1995 vermutet die Existenz von zwei Warmzeiten). Diese liegen eindeutig vor der ersten saalezeitlichen Eisbedeckung (Drenthe-Stadium). Warmzeitliche Ablagerungen zwischen den einzelnen Eisvorstößen sind nicht nachweisbar. Die maximale Verbreitung des Drenthe-Inlandeises ist etwa markiert durch die Orte Düsseldorf - Paderborn - Hameln - Goslar - Eisleben - Zeitz - Meißen - Görlitz. Der jüngere markante Saale-Vorstoß wird als Warthe-Stadium bezeichnet (Abb. 4).

Im Gebiet der nordischen Vereisungen ist die Eem-Warmzeit das mit Abstand am besten erforschte Interglazial, dessen Sedimente unmittelbar über saalezeitlichen glaziären Bildungen liegen (sowohl über Drenthe als auch über Warthe). In der Typusregion (Amersfoort-Becken in den Niederlanden, aber auch im Amsterdam-Becken als Parastratotyp) liegen die klassischen Eem-Folgen über Ablagerungen des Drenthe-Vorstoßes. Im gesamten nordischen Vereisungsgebiet werden die Interglazialsedimente vom Eem-Typ von keinen weiteren glaziären Bildungen als denen aus der Weichsel-Kaltzeit überdeckt. Dass zwischen Eiszerfall der ersten saalezeitlichen Eisbedeckung (Drenthe-Stadium) und der Frühweichselzeit mit seinen beiden borealen Interstadialen (Brörup, Odderade) nur ein Interglazial - die Eem-Warmzeit - existiert hat, belegen zahlreiche lange kontinentale Pollenfolgen südlich der Warthe-Linie, die eine lückenlose Abfolge Spätsaale-Eem-Frühweichsel dokumentieren. Die Eem-Profile sowohl in Norddeutschland als auch im angrenzenden nördlichen Mitteleuropa zeigen eine erstaunliche palynologische Übereinstimmung in den Grundzügen der allgemeinen Waldentwicklung (MENKE \& TYNNI 1984).

Die Weichsel-Kaltzeit setzt palynostratigraphisch mit dem Wechsel zwischen borealer Vegetation am Ende der Eem-Warmzeit und subarktischer Vegetation ein. Das Früh- und das beginnende Hochweichsel sind durch den mehrfachen Wechsel von Stadialen und Interstadialen gekennzeichnet (Abb. 5), wobei in Norddeutschland noch keine sicheren Nachweise von Vereisungsspuren vorhanden sind. Am wahrscheinlichsten ist der Beginn der Vergletscherung ab ca. 25 ka v.h., möglicherweise drangen aber schon zwischen 70 und 50 ka v.h. Gletscher in den Bereich der westlichen Ostsee vor (STEPHAN 1995). Die Maximalausdehnung der Weichselvergletscherung erreichte den Raum Brandenburg im Osten, weiter westlich den nördlichen Randbereich von Hamburg und nur den östlichen Teil von 
Schleswig-Holstein (Abb. 4). Drei Vereisungsphasen sind durch Grundmoränen belegt (Brandenburg-, Pommern- und Mecklenburg-Phase). Mit dem Eiszerfall begann vor ca. 14.500 Jahren v.h. das Weichsel-Spätglazial, das durch einen mehrfachen Wechsel von Kälte- und Wärmeschwankungen gekennzeichnet ist (Abb. 6).

Das Holozän (Beginn vor 11.600 Jahren) wird als eigenständige Serie bzw. Epoche aufgefasst. Die Untergrenze ist mit dem Beginn der Birken-Kiefern-Bewaldung nach der noch spätweichselzeitlichen Jüngeren Dryaszeit definiert.

\title{
Stratigraphical Terms for the Quaternary of the North German Glaciation Area
}

\author{
Keywords: Stratotypes, Quaternary, North Germany
}

Northern Germany and neighbouring areas affected by the Scandinavian ice sheets are classic regions of Quaternary geology and stratigraphy. The Swiss geologist von MorLot (1844) had already presumed that the Nordic ice could have reached the Erzgbirge (Ore Mountains) in Saxony. The discovery of glacial striae on Triassic Muschelkalk in Rüdersdorf near Berlin by TorRELL (1875) led to wide acceptance of the glacial theory in Germany. PENCK (1879) surmised that three separate glaciations had occurred in northern Germany. The mapping of Pleistocene deposits by the Prussian Geological Survey since 1910 was a milestone for Quaternary stratigraphy, and the terms "Elsterian","Saalian" and "Weichselian" were introduced into scientific literature. At the start of the 20th century already, Quaternary geologists such as L. Siegert, W. Weissermel, K. Keilhack, R. Grahmann and P. WoLDSTEDT described the fundamental context of the glacial history of northern central Europe and its correlation with fluvial processes. Quaternary stratigraphy in Germany has solid foundations, not least due to a dense borehole network and intensively researched sections in open-cast lignite mines. A major stratigraphical factor in this region is the interlocking of glacial and periglacial facies, i.e. the relation between gravel terraces, till deposits, and intercalated interglacial sediments. Their vertical sequence is a classic illustration of key stratigraphical principles.

In northern Germany, subdivision of the non-glaciated period of the Lower Pleistocene and lower Middle Pleistocene (up to the Elsterian glacial stage) is based on long continental sequences like Lieth in Schleswig-Holstein (Menke 1975) and Gorleben in Lower Saxony (MüLLER 1992). The criteria for the palaeoclimatic classification into cold and warm stages (Fig. 1) largely derive from palynology.

The most informative section for almost the entire Lower Pleistocene is the Lieth sequence (MeNKE 1975), which supplies an excellent stratigraphical record of the period between the start of the Pretiglian (Kaltenhörn cold stage) and the Bavelian Complex (Pinneberg warm stage). In this respect the Lieth data are more complete than those from individual, unrelated type sections in the Netherlands. The correlation between northern Germany and the Lower Rhine region is discussed by both Menke (1975) and Stephan \& Menke (1993) (Fig. 2). According to Menke (1975) the palynological characteristics of the Lower Pleistocene in northern Germany are that the typical Pliocene flora is already extinct, but that some Pliocene elements such as Tsuga, Carya, or Eucommia distinguish it from the Middle and Upper Pleistocene. The climate varied repeatedly between so-called cryo- and thermomers (Lieth as type section for the corresponding climatostratigraphic units), but the cryomers in no way matched the Middle and Upper Pleistocene cold stages or glacials in magnitude.

Borehole samples from the sediments above the Gorleben salt dome were studied to establish the palynostratigraphy of the temperate stages of the late Lower Pleistocene and early Middle Pleistocene (Bavelian Complex and Cromerian Complex) (Müller 1986, 1992). These data overlap with those of the Lieth sequence (Fig. 3). The Gorleben results allow at least five warm stages to be identified for the Cromerian Complex alone (from old to young: Osterholz, Hunteburg, two unnamed thermomers and finally the Rhume warm stage, see Fig. 3). 
During the Elsterian glacial stage the Nordic ice sheet reached as far as the edge of the uplands in Saxony and Thuringia and partially overrode the lower Harz. In central Germany, the first Elsterian advance was the most far-reaching of all the Pleistocene glaciations (Fig. 4). It is unclear how the ice margin continued further westward because the Elsterian deposits were heavily eroded or overlain by younger sediments during the Drenthe advance in Lower Saxony (CASPERS et al. 1995). The Elsterian glacial deposits are associated with two major ice advances that were, however, not interrupted by a fully developed interglacial.

After the downmelting of the ice, lakes developed in former channels, exaration basins and dead-ice holes, where sediments of the Holstein interglacial were subsequently deposited. Above these Elsterian glacial features, numerous Holsteinian deposits have been found, which can be securely classified and correlated because of their typical vegetation record.

The Saalian Complex extends from the end of the Holstein warm stage to the start of the Eemian warm stage (LiTT \& TURNER 1993). It is a complex stratigraphical unit with several oscillations of cold and warm stages, with the latter sometimes approaching interglacial conditions (at least one warm stage like the Dömnitz or Wacken warm stage after ERd (1965b) and Menke (1968a); Urban (1995) presumes the existence of two warm stages). These clearly occurred prior to the first Saalian ice cover (Drenthe stage). There is no evidence of warm-stage deposits between the individual ice advances. The maximum extent of the Drenthe inland ice is roughly marked by the towns of Düsseldorf - Paderborn - Hameln - Goslar - Eisleben - Zeitz - Meißen - Görlitz. The younger distinctive Saalian glaciation is known as the Warthe stage (Fig. 4).

In the Nordic glaciation area the Eemian is easily the best researched interglacial; its sediments directly overlie Saalian glacial material (both Drenthe and Warthe). In the type region (Amersfoort Basin in the Netherlands, but also in the Amsterdam Basin as parastratotype), the classic Eemian sequences overlie deposits of the Drenthe ice advance. In the entire Nordic glaciation area, the Eemiantype interglacial sediments are not overlain by glacial sediments, except for those of the Weichselian glaciation. The occurrence of only one interglacial - the Eemian stage - between the ice decay of the first Saalian ice cover (Drenthe stage) and the early Weichselian with its two boreal interstadials (Brörup, Odderade) is confirmed by numerous long continental pollen sequences south of the Warthe line, which document a continuous late Saalian - Eemian - early Weichselian sequence. The Eemian sections in both northern Germany and neighbouring northern central Europe show an astonishing palynological agreement in their general forest development (MENKE \& TYNnI 1984).

In palynostratigraphical terms, the Weichselian cold stage starts with the change from boreal vegetation at the end of the Eemian warm stage to subarctic vegetation. The Lower and initial Pleni-Weichselian are characterised by the multiple alternation of stadials and interstadials (Fig. 5), whereby there is no securely based evidence of glaciation in northern Germany. Glaciation most probably started about $25 \mathrm{ka} \mathrm{BP}$; however, it is possible that glaciers already advanced into the western Baltic Sea area between 70 and $50 \mathrm{ka} \mathrm{BP}$ (STEPHAN 1995). The maximum limit of the Weichselian ice reached the Brandenburg region in the east, the northern periphery of Hamburg further westward, and only the eastern part of Schleswig-Holstein (Fig. 4). Till deposits provide evidence of three phases of glaciation (the Brandenburg, Pomeranian and Mecklenburg phases). When the ice melted 14,500 years ago, the Weichselian Late Glacial began, characterised by multiple oscillations between cold and warm conditions (Fig. 6).

The Holocene (starting 11,600 years ago) is considered to be an independent series (epoch). Its base is defined as the start of birch and pine forests after the Late Weichselian Younger Dryas.

\section{Altpleistozän \\ Känozän}

\section{Definition, Erstbeschreibung}

Dieser Begriff wurde erstmals von Menke (1972) vorgeschlagen und in Menke \& Behre (1973) mit 
einer kurzen pollenfloristischen Charakteristik für Nordwesteuropa ausgefüllt. Er bezeichnet den „stratigraphischen Großabschnitt vom Beginn des Prätegelen bis - vorläufig - zum Beginn der Kaltzeit prä Osterholz-Warmzeit (Elbe-Kaltzeit)“(MENKE 1975: 73). Es handelt sich um eine chronostratigraphische und geochronologische Einheit. Mit diesem Begriff wird das Ältestquartär vom folgenden Pleistozän s.str. abgetrennt und diesem als gleichwertige Abteilung gegenübergestellt. Es ist nicht identisch mit dem Begriff „Altquartär“. Der wesentlich weitere Begriff Känozoikum wird von dem Begriff Känozän nicht berührt. Eine Gliederung des Känozäns sowohl anhand der Lieth-Serie als auch nach den niederländischen Vorkommen findet sich bei Menke (1975).

\section{Bemerkungen}

Der Begriff Känozän wurde von MenKe (1972, 1975) vorgeschlagen, um den Übergangsbereich zwischen Pliozän und Pleistozän s.str. klar abzugrenzen. Er ist pollenfloristisch noch durch zahlreiche Tertiärelemente gekennzeichnet, während die Klimaentwicklung sehr ungleichmäßige Schwankungen zeigt, die eine Unterscheidung zwischen klaren Glazialen und Interglazialen oft schwierig macht. Als chronostratigraphische Einheit hat sich der Vorschlag von MENKE allerdings nicht durchgesetzt.

(BEHRE)

\section{Kaltenhörn-Kaltzeit}

\section{Definition, Erstbeschreibung}

Der Name „Kaltenhörn-Kaltzeit“ erscheint erstmals als neuer Stratotyp bei MENKE (1980) und ersetzt den bis dahin in der Lieth-Serie benutzten Begriff Prätegelen (vgl. auch STEPHAN \& MENKE 1993). Das Kaltenhörn bildet die Basis der quartären Schichtfolge. Die eigentliche Beschreibung dieser Kaltzeit innerhalb der Lieth-Serie erfolgte durch Menke (1975) als Prätegelen sensu ZaGwijn (1957, 1960). Die Pollenflora zeigt eine überwiegend waldlose, aber Ericaceen-reiche Vegetation von boreal-ozeanischem Klimatyp.

\section{Typuslokalität}

Als Typuslokalität für diesen Begriff hat nach MenKe (1975) Oldenswort in Eiderstedt zu gelten. Dort ist der damals noch Prätegelen genannte Abschnitt in zwei Bohrungen mit 40 bzw. 45 m Mächtigkeit in Form von Sand und Schluff mit z.T. erheblichem organischen Gehalt vorhanden. Das Kaltenhörn schließt dort unmittelbar an das Oberpliozän (Reuverien) an. Typuslokalität für das niederländische Prätegelen ist Meinweg (ZaGwiJn 1957).

\section{Vergleichbare Profile, Verbreitung}

Außer in Oldenswort ist die Kaltenhörn-Kaltzeit in Schleswig-Holstein in Lieth nachgewiesen, wo sie ebenfalls die Basis des Quartärs bildet, aber gestört ist. Aus der Korrelation mit dem niederländischen Prätegelen folgt, dass sie auch in Meinweg vorhanden ist.

\section{Datierung}

Mit numerischen Methoden der Altersbestimmung ermittelte absolute Daten liegen nicht vor. Aus Analogiegründen fällt der Anfang der Kaltenhörn-Kaltzeit mit dem Quartärbeginn zusammen (ca. 2,6 Ma v.h.).

\section{Bemerkungen}

Wenn sich in diesem Zeitbereich die Korrelation mit dem niederländischen Unterquartär weiterhin als richtig erweist, behält die Bezeichnung Prätegelen die Priorität. 


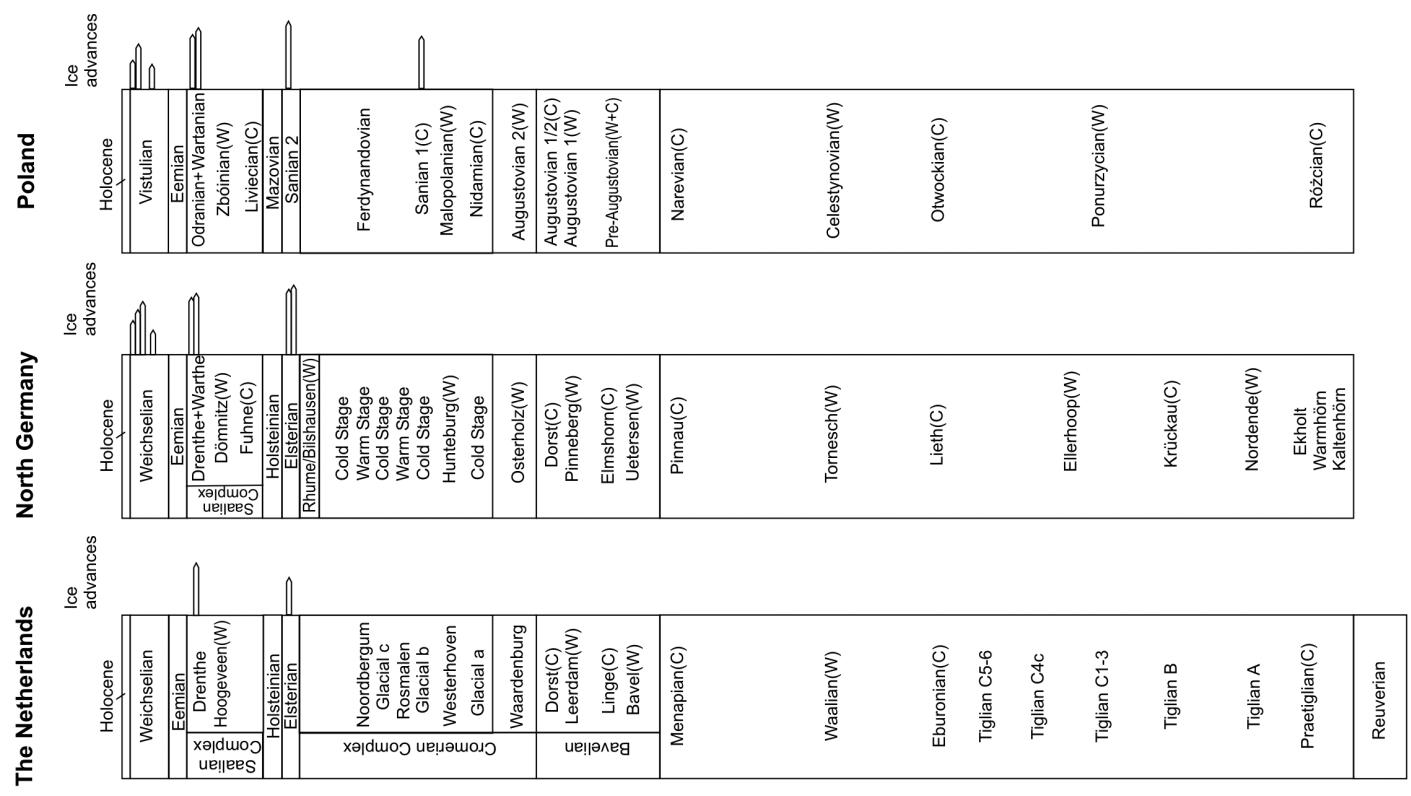

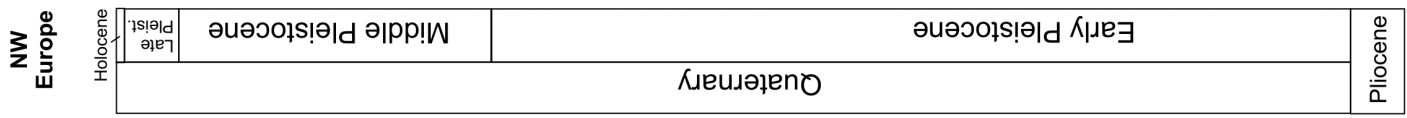

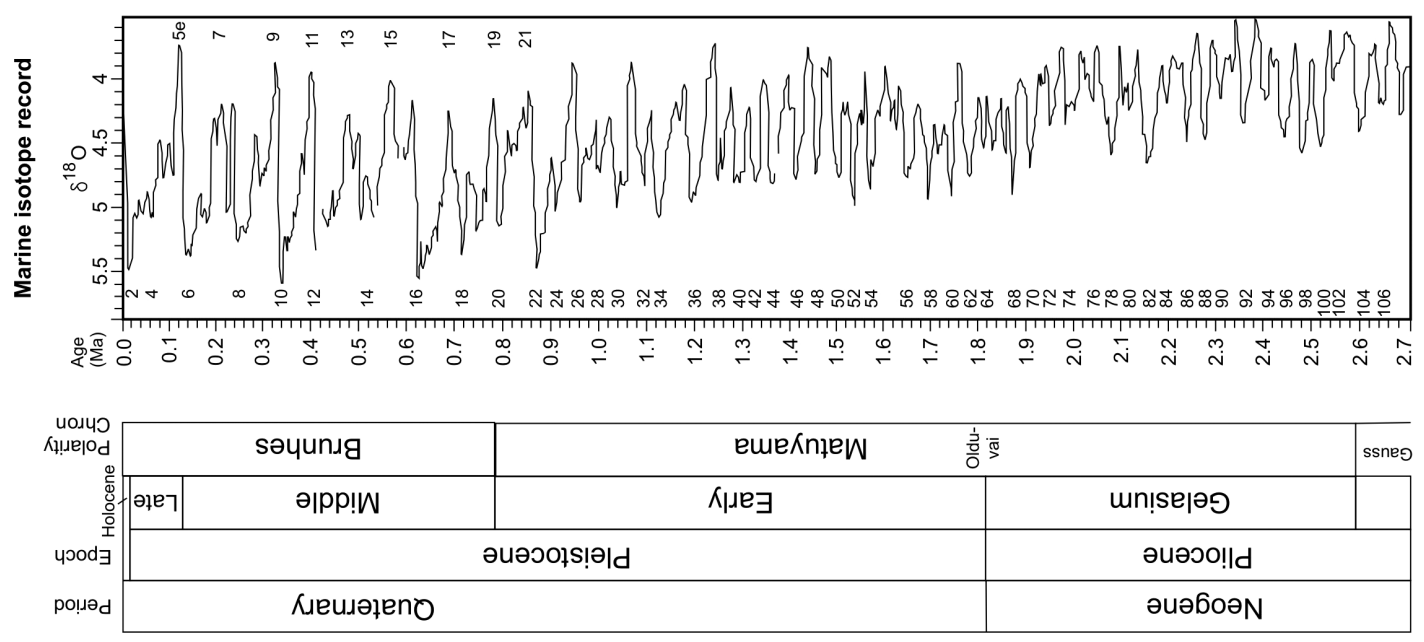

Abb. 1: Stratigraphische Gliederung des Quartärs im nördlichen Mitteleuropa (Norddeutschland und angrenzende Gebiete). Globale Chronostratigraphie und MIS verändert nach GIBBARD \& vAN Kolfschoten (2004), Gliederung in den Niederlanden nach ZaGwIJN (1989), in Norddeutschland nach LitT et al. (2005), in Polen nach Lindner et al. (2004) (aus LiTT 2007).

Fig. 1: Stratigraphic subdivision of the Quaternary in north-central Europe. Global chronostratigraphy and marine isotope record modified after GibBard \& Kolfschoten (2004), subdivision of the Quaternary sequences in the Netherlands after ZAGWIJN (1989), in N Germany after LiTT et al. (2005), in Poland after LinDNER et al. (2004) (from LitT 2007). 


\section{Warmhörn-Warmzeit}

\section{Definition, Erstbeschreibung}

Die erste Nennung dieser Warmzeit findet sich als „Meinweg-Thermomer“ in MenKe \& BeHRE (1973) als eine Erwärmungsphase am Ende des Prätegelen in Lieth. Die Beschreibung als „Meinweg-Warmzeit" erfolgte durch MenKe (1975) analog zu den Befunden von ZAGWIJN (1960), wobei sie zeitlich aus dem Tegelen sensu ZaGwiJn herausgelöst wurde. Menke (1980) benannte dann diesen Abschnitt in Warmhörn-Warmzeit um (vgl. auch Stephan \& Menke 1993). Menke (1975) nennt eine Anzahl thermophiler Pollentaxa, die sie als richtige Warmzeit ausweisen. Ein Pollendiagramm wurde bisher nicht veröffentlicht.

\section{Typuslokalität}

Als Typuslokalität hat der Bremsberg bei Lieth in Elmshorn/Schleswig-Holstein zu gelten. Die Warmhörn-Warmzeit wurde dort in Bohrung Lieth II in 55-59 m Tiefe erfasst. Nach MenKE (1980) ist sie dort jedoch gestört, während sie im benachbarten Oldenswort, wo sie ebenfalls auftritt, nicht vollständig ist.

\section{Vergleichbare Profile, Verbreitung}

Außer in Lieth und in Oldenswort ist die Warmzeit mit ähnlicher Pollenführung in Meinweg/Niederlande vertreten (ZAGWIJN 1960). Eine Korrelation mit Rippersroda (MAI et al. 1963) ist wahrscheinlich.

\section{Datierung}

Die Warmhörn-Warmzeit ist überdeckt von Ablagerungen der Ekholt-Kaltzeit und weiter von der vollständigen Lieth-Serie. Mit numerischen Methoden der Altersbestimmung ermittelte absolute Daten liegen nicht vor. Eine Zuordnung zur MIS-Zeitskala ist bisher nicht möglich.

\section{Bemerkungen}

Der Nachweis der Ekholt-Kaltzeit in Lieth hat Menke (1975) veranlasst, die darunterliegende WarmhörnWarmzeit vor das Tegelen zu stellen. Auf diesem Umweg löste MenKE auch die damit korrelierte, von ZAGWIJN (1960) beschriebene Warmzeit in Meinweg (die aber von diesem nicht mit Meinweg-Warmzeit benannt wurde) aus dem Tegelen A, in die sie ZAGwIJN (1963) in seiner Gliederung stellte, heraus.

(BEHRE)

\section{Ekholt-Kaltzeit}

\section{Definition, Erstbeschreibung}

Die Bezeichnung stammt von DüCKER \& Menke (1968) nach dem Bächlein Ekholter Au östlich Elmshorn (Lieth). Damit wurde der mehrere Meter mächtige Kaolinsand unter dem Kohleflöz der Nordende-Warmzeit an der Basis des Aufschlusses Lieth benannt. Das von Menke (1969) erstmals vorgelegte und in Menke (1975) erheblich verbesserte Pollendiagramm zeigt sehr hohe Nichtbaumpollenwerte und weist auf arktisches Klima hin. Es ist die ausgeprägteste Kaltzeit der ganzen Lieth-Serie.

\section{Typuslokalität}

Typuslokalität ist die Kalkgrube Meinert am Bremsberg bei Lieth in Elmshorn/Schleswig-Holstein. Dort ist ein Subrosionsbecken im Unterpleistozän aufgefüllt worden. Als Typusprofil hat das von Menke (1969) bearbeitete und mit einem detaillierten Pollendiagramm (MenKe 1975: Tafel 4) unterlegte Profil von Lieth zu gelten.

\section{Vergleichbare Profile, Verbreitung}

Da eine derart ausgeprägte Kaltzeit in der niederländischen Schichtenfolge bislang nicht bekannt ist, 
Schleswig-Holstein

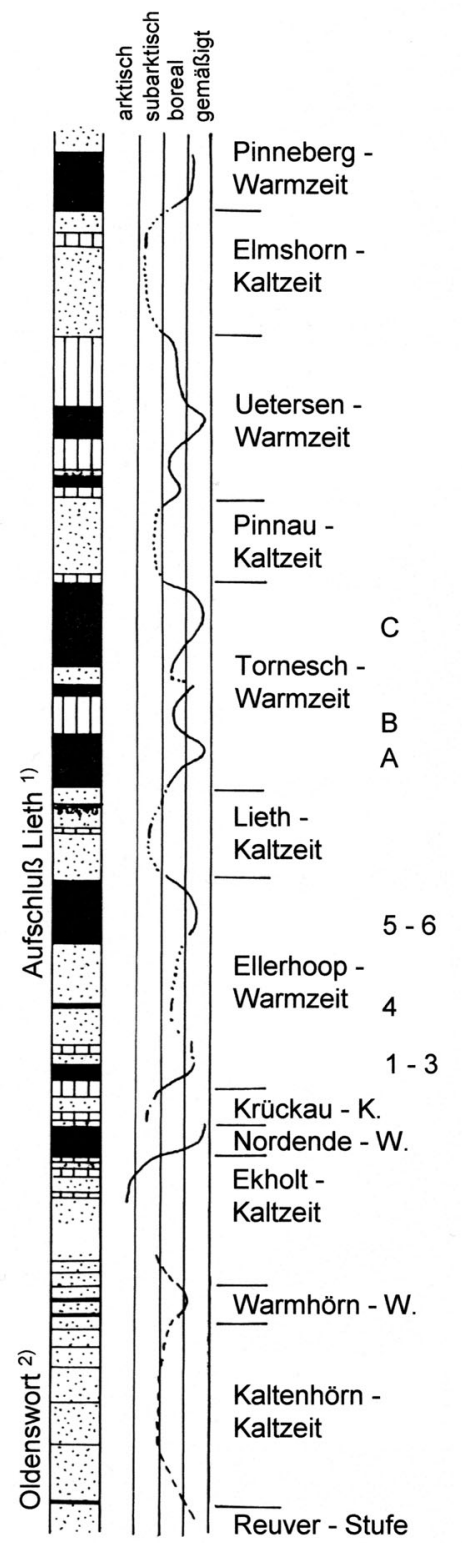

Niederlande

Leerdam -

Interglazial ${ }^{3)}$

Linge - Glazial ${ }^{3)}$

Bavel -

Interglazial ${ }^{3)}$

Menapian ${ }^{3,4)}$

C

Waalian 4)

B

A

Eburonian

5-6 Frechen - Interglazial III 6)

Tiglian C 4,5

4

Schotter $d^{6)}$

Frechen - Interglazial I| 6)

Schotter $c^{6)}$

Frechen - Interglazial I 6 )

Fortuna - Oszillation 6)

Niederrhein
Schotter b $2^{6)}$

? Tiglian 4)

Pretiglian 4)

Schotter b $1^{6)}$

Reuverian 4)

Reuverian 6)

\begin{abstract}
6) URAN (1978 a)
\end{abstract}
Tiglian A 4)

?
4) ZAGWIJN (1960)
5) ZAGWIJN (1963)
6) URBAN (1978 a)
1) MENKE (1975)
2) MENKE (1975) unveröff.; STREMME \& MENKE (1980)
3) ZAGWIJN \& DE JONG (1984)

Abb. 2: Stratigraphie des Altpleistozän in Schleswig-Holstein und Korrelation (aus StePHAn \& MenKe 1993).

Fig. 2: Stratigraphy of the Early Pleistocene in Schleswig-Holstein and correlation (after STEPHAN \& MenKe 1993). 
schloss Menke (1975) eine Korrelation mit dem Prätegelen aus und stellte die Ekholt-Kaltzeit in ein gegenüber ZAGWIJN (1960) stärker differenziertes Tegelen A.

\section{Datierung}

Die Ekholt-Kaltzeit liegt im untersten Pleistozän. Mit numerischen Methoden der Altersbestimmung ermittelte absolute Daten liegen nicht vor. Eine Zuordnung zur MIS-Zeitskala ist bisher nicht möglich.

\section{Bemerkungen}

Eine genauere Korrelation mit der niederländischen Unterpleistozän-Gliederung hängt wesentlich davon ab, ob die in einer Bohrung in Lieth unter der Ekholt-Kaltzeit erfasste Meinweg (Warmhörn)Warmzeit sicher mit dem niederländischen Meinweg gleichgesetzt werden kann. Dafür spricht, dass die den beiden vorangehenden Kaltzeiten Prätegelen bzw. Kaltenhörn eine gleichartige subarktische Vegetation aufweisen. Dann muss die ausgeprägt arktische Ekholt-Kaltzeit im Tegelen A untergebracht werden.

(BEHRE)

\section{Nordende-Warmzeit}

\section{Definition, Erstbeschreibung}

Erstmalig wurde die „Nordende-Warmzeit“ von DüCKER \& MENKE (1968) aus kohligem Torf und Mudde im unteren Teil der Lieth-Serie beschrieben, der Name kommt von einer Ortschaft südlich Elmshorn (Lieth). Das Pollendiagramm von Menke (1975) zeigt eine voll ausgebildete Warmzeit mit warm-gemäßigtem Klima, in der u.a. Eucommia und Pterocarya sowie als besonderes Tertiärrelikt Symplocos auftreten. Nach unten und oben wird die Nordende-Warmzeit durch kaltzeitliche Sande begrenzt.

\section{Typuslokalität}

Typuslokalität ist die Kalkgrube Meinert am Bremsberg bei Lieth in Elmshorn/Schleswig-Holstein. Dort ist ein Subrosionsbecken im Unterpleistozän aufgefüllt worden. Als Typusprofil gilt das von Menke (1969) erstmals publizierte und von Menke (1975: Tafel 4) vervollständigte Profil mit detailliertem Pollendiagramm.

\section{Vergleichbare Profile, Verbreitung}

In dieser Form ist die Nordende-Warmzeit bisher nur aus Lieth bekannt. Menke (1975) korreliert sie mit dem niederländischen Tegelen A, löst sie aber wegen des subarktischen Charakters der folgenden Krückau-Kaltzeit aus dem Tegelen heraus.

\section{Datierung}

Mit numerischen Methoden der Altersbestimmung ermittelte absolute Daten liegen nicht vor. Eine Zuordnung zur MIS-Zeitskala ist bisher nicht möglich.

\section{Bemerkungen}

Wegen der in Superposition liegenden gesamten Lieth-Serie ist die stratigraphische Lage zwischen liegenden Sedimenten der Ekholt- und hangenden Ablagerungen der Krückau-Kaltzeit zweifelsfrei gegeben. 


\section{Krückau-Kaltzeit}

\section{Definition, Erstbeschreibung}

Der Begriff „Krückau“ wurde erstmals bei der Beschreibung der Lieth-Serie durch DüCKER \& MENKE (1968) verwendet, benannt nach einem Flüsschen, an dem Elmshorn liegt. Er kennzeichnet die auf die Nordende-Warmzeit folgende Kaltphase. In der ersten eingehenden pollenanalytischen Untersuchung der Lieth-Serie wurde das Krückau von Menke (1969) als lange Kaltphase mit einem eingeschalteten längeren Interstadial (Ellerhoop) beschrieben. Dieses wurde in der endgültigen Bearbeitung der LiethSerie durch MenKe (1975) revidiert, indem das 1969 definierte Krückau in die Folge Krückau-EllerhoopLieth aufgeteilt wurde und die Krückau-Kaltzeit auf die Zone K 0 in MENKE (1969) beschränkt worden ist. Es liegt damit zwischen den Warmzeiten Nordende und Ellerhoop. Das Pollendiagramm im nunmehr gültigen Krückau-Bereich wird von Nichtbaumpollen beherrscht, der Baumpollenanteil ist gering.

\section{Typuslokalität}

Typuslokalität ist die Kalkgrube Meinert am Bremsberg in Lieth bei Elmshorn/Schleswig-Holstein. Dort ist ein Subrosionsbecken im Unterpleistozän aufgefüllt worden. Als Typusprofil gilt die Abfolge mit dem Pollendiagramm in Menke (1975: Tafel 4). Petrographisch besteht sie aus Sand und limnischer Schluffmudde.

\section{Vergleichbare Profile, Verbreitung}

In dieser Form ist die Krückau-Kaltzeit bisher nur aus Lieth bekannt. Nach der stratigraphischen Position wird sie von MENKE (1975) mit dem Tegelen B nach ZAGWIJN (1963) korreliert, ihm entspricht wahrscheinlich auch Donau III nach LonA \& BERTOLDI (1973).

\section{Datierung}

Mit numerischen Methoden der Altersbestimmung ermittelte absolute Daten liegen nicht vor. Eine Zuordnung zur MIS-Zeitskala ist bisher nicht möglich.

\section{Bemerkungen}

Wegen der in Superposition liegenden gesamten Lieth-Serie ist die stratigraphische Lage zwischen den liegenden Sedimenten der Nordende- und den hangenden Ablagerungen der Ellerhoop-Warmzeit zweifelsfrei gegeben.

(BEHRE)

\section{Ellerhoop-Warmzeit}

\section{Definition, Erstbeschreibung}

Die Bezeichnung „Ellerhoop“ findet sich erstmals bei Menke (1969) als Ellerhoop-Interstadial innerhalb der in dieser Publikation noch weit gefassten Krückau-Kaltzeit in der Lieth-Serie. Bei der endgültigen Bearbeitung der Lieth-Serie durch Menke (1975) wurde das Ellerhoop zur Warmzeit aufgewertet und dabei ihr pollenanalytisch bestimmter zeitlicher Umfang vergrößert. Per Definition liegt die Ellerhoop-Warmzeit zwischen der 1975 neu definierten, liegenden Krückau-Kaltzeit und der hangenden Lieth-Kaltzeit. Petrographie und Pollenanalysen zeigen eine Abkühlung etwa in der Mitte der Warmzeit. Der Name kommt von einer Ortschaft östlich Elmshorn (Lieth).

\section{Typuslokalität}

Typuslokalität ist die Kalkgrube Meinert am Bremsberg in Lieth bei Elmshorn/Schleswig-Holstein. Dort ist ein Subrosionsbecken im Unterpleistozän aufgefüllt worden. Als Typusprofil gilt die Abfolge mit dem Pollendiagramm in Menke (1975: Tafel 4). Petrographisch besteht sie aus Braunkohle mit sandigen und schluffigen Einlagerungen. 


\section{Vergleichbare Profile, Verbreitung}

In dieser Form ist die Ellerhoop-Warmzeit bisher nur aus Lieth bekannt. Nach der stratigraphischen Position und wegen der Unterbrechung durch ein Kryomer wird sie von MenKE (1975) mit dem Tegelen C nach ZAGWIJN (1963) korreliert, ihm entspricht der Umfang des Tegelen an dessen Typuslokalität Tegelen (VAN DER VLERK \& FlORSCHÜTZ 1950).

\section{Datierung}

Mit numerischen Methoden der Altersbestimmung ermittelte absolute Daten liegen nicht vor. Eine Zuordnung zu der MIS-Zeitskala ist bisher nicht möglich.

\section{Bemerkungen}

Wegen der in Superposition liegenden gesamten Lieth-Serie ist die stratigraphische Lage zwischen den liegenden Sedimenten der Krückau- und den hangenden Ablagerungen der Lieth-Kaltzeit zweifelsfrei gegeben.

(BEHRE)

\section{Lieth-Kaltzeit}

\section{Definition, Erstbeschreibung}

Erstmalig wurde der Begriff „Lieth-Kaltzeit“ von GRUBE (1968) für einen Würgeboden in der LiethSerie benutzt. Bei der ersten Bearbeitung der Lieth-Serie hat Menke (1969) diese periglaziale Schicht zusammen mit den liegenden Schichten in die Krückau-Kaltzeit einbezogen. Mit der Auftrennung dieser Periode durch Menke (1975) wurde deren jüngerer Teil wiederum als Lieth-Kaltzeit bezeichnet. Stratigraphisch ist sie definiert als Sandschicht mit eingeschlossenem Würge- bzw. Tropfenboden zwischen der Ellerhoop-Warmzeit und dem untersten Flöz der Tornesch-Warmzeit.

\section{Typuslokalität}

Typuslokalität ist die Kalkgrube Meinert am Bremsberg in Lieth bei Elmshorn/Schleswig-Holstein. Dort ist ein Subrosionsbecken im Unterpleistozän aufgefüllt worden. Als Typusprofil gilt die Abfolge mit dem Pollendiagramm in Menke (1975: Tafel 5).

\section{Vergleichbare Profile, Verbreitung}

In dieser Form ist die Lieth-Kaltzeit bisher nur aus Lieth bekannt. Nach der stratigraphischen Position wird sie von MenKe (1975) mit der Eburon-Kaltzeit nach ZaGWIJN (1957, 1963) korreliert. Wegen der Lückenhaftigkeit des von ZaGwiJn (1960) vorgeschlagenen Typusprofils Veghel schlägt MenKE (1975) Lieth als Neotypusprofil für das Eburon vor.

\section{Datierung}

Mit numerischen Methoden der Altersbestimmung ermittelte absolute Daten liegen nicht vor. Eine Zuordnung zur MIS-Zeitskala ist bisher nicht möglich.

\section{Bemerkungen}

Wegen der in Superposition liegenden gesamten Lieth-Serie ist die stratigraphische Lage zwischen den liegenden Sedimenten der Ellerhoop- und den hangenden Ablagerungen der Tornesch-Warmzeit zweifelsfrei gegeben. 


\section{Tornesch-Warmzeit}

\section{Definition, Erstbeschreibung}

Die Bezeichnung „Tornesch-Warmzeit“s stammt von Menke (1969), sie wurde von Menke (1975) weiter differenziert. Der Name kommt von einer Ortschaft südöstlich Elmshorn (Lieth). Diese Warmzeit ist ein Teil der Lieth-Serie und kann nach den pollenanalytischen Untersuchungen von MenKE (1975) in drei Thermomere mit zwei darin eingeschlossenen Kryomeren untergliedert werden. Die Thermomere sind als Braunkohle, die Kryomere als sandiger Detritus oder Sand ausgebildet.

\section{Typuslokalität}

Typuslokalität ist die Kalkgrube Meinert am Bremsberg in Lieth bei Elmshorn/Schleswig-Holstein. Dort ist ein Subrosionsbecken im Unterpleistozän aufgefüllt worden. Als Typusprofil gilt die Abfolge mit dem Pollendiagramm in Menke (1975: Tafel 5).

\section{Vergleichbare Profile, Verbreitung}

In dieser Form ist die Tornesch-Warmzeit bisher nur aus Lieth bekannt. Nach der stratigraphischen Position wird sie von Menke (1975) mit der Waal-Warmzeit nach ZAGWIJN $(1957,1960,1963)$ korreliert. Wegen der Lückenhaftigkeit des von ZAGWIJN (1960) vorgeschlagenen Typusprofils Veghel schlägt MenKe (1975) Lieth als Neotypusprofil für das Waal vor.

\section{Datierung}

Mit numerischen Methoden der Altersbestimmung ermittelte absolute Daten liegen nicht vor. Eine Zuordnung zur MIS-Zeitskala ist bisher nicht möglich.

\section{Bemerkungen}

Wegen der in Superposition liegenden gesamten Lieth-Serie ist die stratigraphische Lage zwischen den liegenden Sedimenten der Lieth- und den hangenden Ablagerungen der Pinnau-Kaltzeit zweifelsfrei gegeben.

(BEHRE)

\section{Pinnau-Kaltzeit}

\section{Definition, Erstbeschreibung}

Der Name „Pinnau-Kaltzeit“ erscheint ohne weitere Erklärung erstmals bei MENKE (1970), die Erstbeschreibung erfolgte durch MenKe (1975), etwas ausführlicher danach in MenKE (1980). Benannt ist sie nach einem Flüsschen südlich Elmshorn (Lieth). Es handelt sich um eine relativ dünne Sandschicht zwischen der Tornesch- und der Uetersen-Warmzeit. In den Pollenanalysen fehlen thermophile Sippen.

\section{Typuslokalität}

Typuslokalität ist die Kalkgrube Meinert am Bremsberg bei Lieth in Elmshorn/Schleswig-Holstein. Dort ist ein Subrosionsbecken im Unterpleistozän aufgefüllt worden. Typusprofil ist der Aufschluss in Lieth (Zustand 1970) mit dem Pollenprofil in Menke (1975: Tafel 5).

\section{Vergleichbare Profile, Verbreitung}

In Deutschland ist die Pinnau-Kaltzeit bisher nur aus Lieth bekannt. MENKE (1975) korreliert sie mit dem in ZAGWIJN (1974a) dargestellten Menap I und mit „Günz III“ in Leffe (LoNA 1950).

\section{Datierung}

Mit numerischen Methoden der Altersbestimmung ermittelte absolute Daten liegen nicht vor. Eine Zuordnung zur MIS-Zeitskala ist bisher nicht möglich. 


\section{Bemerkungen}

Wegen der in Superposition liegenden gesamten Lieth-Serie ist die stratigraphische Lage zwischen den liegenden Sedimenten der Tornesch- und den hangenden Ablagerungen der Uetersen-Warmzeit zweifelsfrei gegeben.

(BEHRE)

\section{Uetersen-Warmzeit}

\section{Definition, Erstbeschreibung}

Erstmals ist der Name „Uetersen-Warmzeit“ ohne weitere Erklärung bei MenKE (1970) genannt. Der Name kommt von einer Ortschaft südlich Elmshorn (Lieth). Die Warmzeit ist ein Teil der Lieth-Serie, die Erstbeschreibung erfolgte durch Menke (1975). Die Pollendiagramme von Menke (1975) zeigen zu Beginn und zum Ende jeweils ein Thermomer mit thermophilen Pflanzen, das von einem Kryomer unterbrochen wird, in dem jedoch ein subarktischer Zustand nicht erreicht wird.

\section{Typuslokalität}

Typuslokalität ist die Kalkgrube Meinert am Bremsberg bei Lieth in Elmshorn/Schleswig-Holstein. Dort ist ein Subrosionsbecken im Unterpleistozän aufgefüllt worden. Typusprofil ist der Aufschluss in Lieth (Stand 1968) und die dortige Bohrung I, aus denen Pollendiagramme (MEnKE 1975: Tafel 3, Tafel 6) vorliegen. Die Warmzeit ist aus zwei Mudde- und Braunkohleschichten aufgebaut, zwischen denen eine sandige Schicht des Kryomers liegt. Nach unten und oben wird dieses Schichtpaket von Sanden der Pinnau- bzw. Elmshorn-Kaltzeit begrenzt.

\section{Vergleichbare Profile, Verbreitung}

MenKE (1975) korrelierte die Uetersen-Warmzeit ursprünglich mit dem bei ZAGWIJN (1974a) nicht näher begründeten Menap II in den Niederlanden. Mit der Beschreibung des Bavel-Interglazials durch ZAGWIJN \& DE JONG (1984) ist die Uetersen-Warmzeit mit diesem zu korrelieren. In Deutschland ist sie außerdem durch MüLLER (1992) in Gorleben nachgewiesen, dort wurde der Lokalname „Marleben“ dafür verwendet.

\section{Datierung}

Mit numerischen Methoden der Altersbestimmung ermittelte absolute Daten liegen nicht vor. Eine Zuordnung zur MIS-Zeitskala ist bisher nicht möglich.

\section{Bemerkungen}

Wegen der in Superposition liegenden gesamten Lieth-Serie ist die stratigraphische Lage zwischen den Sedimenten der liegenden Pinnau- und den hangenden Ablagerungen der Elmshorn-Kaltzeit zweifelsfrei gegeben.

\section{EImshorn-Kaltzeit}

\section{Definition, Erstbeschreibung}

Der Name „Elmshorn-Kaltzeit“ findet sich ohne nähere Beschreibung erstmals bei MENKE (1970), benannt nach der Stadt Elmshorn in Schleswig-Holstein. Er ist nicht identisch mit der ebenfalls von dort beschriebenen, aber nicht genau definierten Elmshorner Serie (GRUBE 1968). Die Erstbeschreibung erfolgte durch Menke (1975) ursprünglich als „Menap-Kaltzeit ZaGWIJN (1957) n. emend.“ in der Erwartung der Veröffentlichung einer Menap-Neugliederung, die jedoch nicht erfolgte. Damit wird die Menkesche Option (1975) der Elmshorn-Kaltzeit n.strat. gültig, die dieser seit 1980 auch anwendete. Die sandigen 
Schichten dieser Kaltzeit sind von den warmzeitlichen Ablagerungen der Uetersen- und Pinneberg-Interglaziale unter- und überlagert. Eine eingeschaltete Schluffmudde weist subarktische Pollenspektren auf.

\section{Typuslokalität}

Typuslokalität ist die Kalkgrube Meinert am Bremsberg bei Lieth in Elmshorn/Schleswig-Holstein. Dort ist ein Subrosionsbecken im Unterpleistozän aufgefüllt worden. Typusprofil ist die Bohrung Lieth I mit dem Pollendiagramm bei MenKe (1975: Tafel 6).

\section{Vergleichbare Profile, Verbreitung}

Nach der Beschreibung des Linge-Glazials im Bavelian durch ZAGWIN \& DE Jong (1984) kann die Elmshorn-Kaltzeit damit korreliert werden. In Deutschland ist sie außerdem in Gorleben durch MÜLLER (1992) nachgewiesen worden.

\section{Datierung}

Mit numerischen Methoden der Altersbestimmung ermittelte absolute Daten liegen nicht vor. Eine Zuordnung zur MIS-Zeitskala ist bisher nicht möglich.

\section{Bemerkungen}

Wegen der in Superposition liegenden gesamten Lieth-Serie ist die stratigraphische Lage zwischen der liegenden Uetersen- und der hangenden Pinneberg-Warmzeit zweifelsfrei gegeben.

\section{Pinneberg-Warmzeit}

\section{Definition, Erstbeschreibung}

Erstmalig wird der Name „Pinneberg-Warmzeit“ noch ohne weitere Erklärung bei MeNKE (1970) genannt, namengebend ist das südöstlich von Elmshorn (Lieth) gelegene Städtchen Pinneberg. Die Erstbeschreibung findet sich bei MENKE (1975); die Pinneberg-Warmzeit bildet als Baunkohleschicht den oberen Abschluss der Lieth-Serie und liegt dabei auf den Sanden der Elmshorn-Kaltzeit. Die Pollenanalysen zeigen die Entwicklung bis zu thermophiler Waldvegetation, dann bricht das Profil ab.

\section{Typuslokalität}

Typuslokalität ist die Kalkgrube Meinert am Bremsberg bei Lieth in Elmshorn/Schleswig-Holstein. Dort ist ein Subrosionsbecken im Unterpleistozän aufgefüllt worden. Typusprofil ist die Bohrung Lieth I mit dem Pollendiagramm bei MenKe (1975: Tafel 6).

\section{Vergleichbare Profile, Verbreitung}

Seit der Beschreibung des Leerdam-Interglazials durch ZAGWIJN \& DE JONG (1984) in den Niederlanden kann die Pinneberg-Warmzeit mit diesem korreliert werden. In Deutschland konnte sie durch MüLLER (1992) außerdem in Gorleben nachgewiesen werden.

\section{Datierung}

Mit numerischen Methoden der Altersbestimmung ermittelte absolute Daten liegen nicht vor. Eine Zuordnung zur MIS-Zeitskala ist bisher nicht möglich.

\section{Bemerkungen}

Als Abschluss der Lieth-Serie an der Typuslokalität sowie durch die Position in der wohl vollständigen Gorleben-Serie unterhalb der Osterholz-Warmzeit ist die stratigraphische Lage der PinnebergWarmzeit unmittelbar vor dem Cromer-Komplex sichergestellt. 

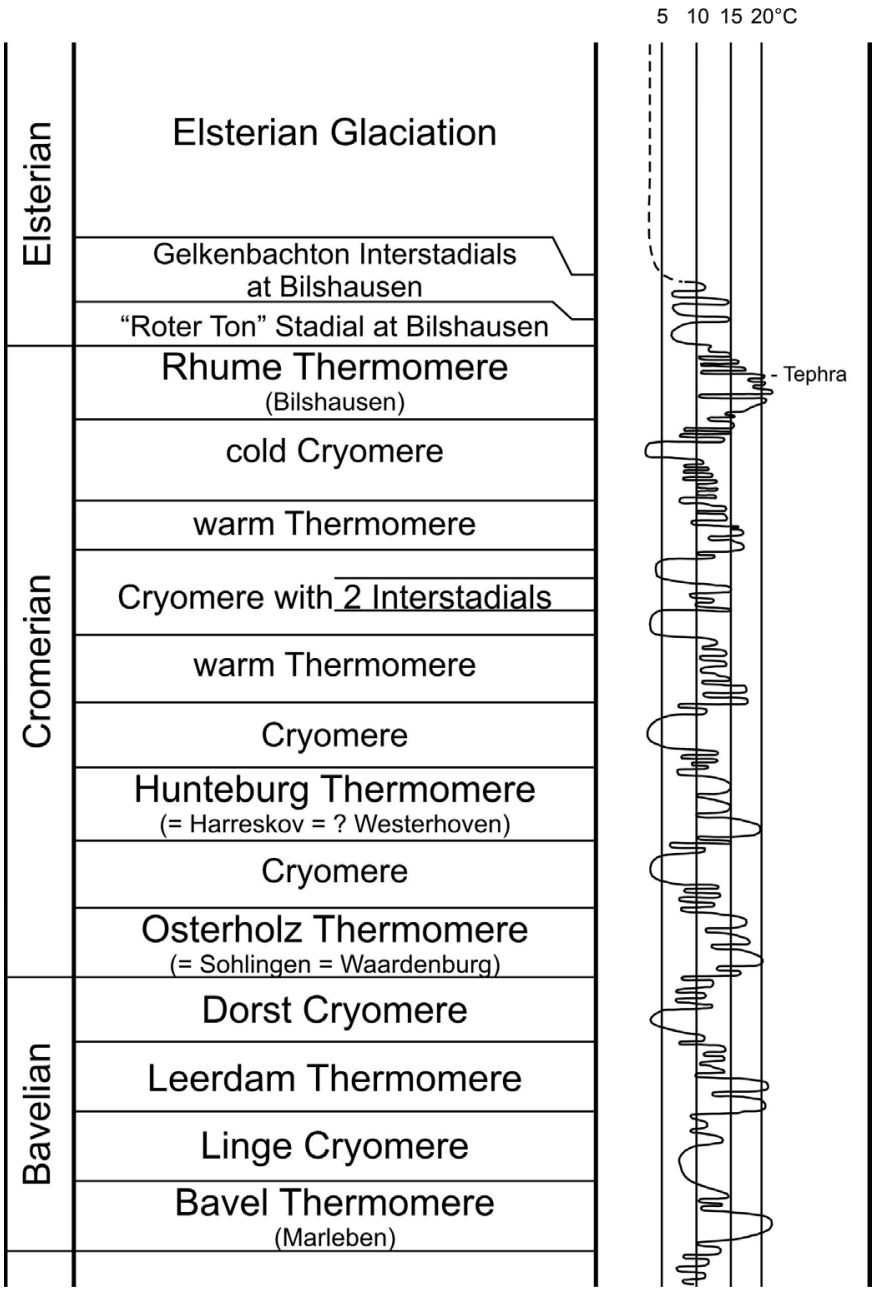

Abb. 3: Stratigraphie und rekonstruierte mittlere Julitemperatur zwischen Menap und Elster in Niedersachsen (nach MüLlER 1992).

Fig. 3: Schematic diagram of the stratigraphy and reconstructed mean July temperature between Menapian and Elsterian in Lower Saxony (after MüLLER 1992).

\section{Dorst-Kaltzeit}

\section{Definition, Erstbeschreibung}

Das „Dorst-Glazial“ wurde von ZAGwiJn \& DE JONG (1984) in den Niederlanden nach einem Dorf unweit Breda als Teil des Bavel-Komplexes beschrieben. Es handelt sich um pollenarme Sande mit Kräuterdominanz über dem Leerdam-Interglazial.

\section{Typuslokalität}

Typuslokalität ist der Aufschluss Bavel III mit dem zugehörigen Pollendiagramm in ZAGWIJN \& DE JONG (1984). Eine Mudde des Leerdam-Interglazials wird von humosen Sanden der Dorst-Kaltzeit überlagert, darüber folgen Ablagerungen der Weichsel-Kaltzeit. 


\section{Vergleichbare Profile, Verbreitung}

Ablagerungen der Dorst-Kaltzeit sind in Deutschland aus Gorleben als Sande zwischen den Pinneberg (Leerdam)- und Osterholz-Warmzeiten erbohrt worden (MÜLLER 1992).

\section{Datierung}

Mit numerischen Methoden der Altersbestimmung ermittelte absolute Daten liegen nicht vor. Eine Zuordnung zur MIS-Zeitskala ist bisher nicht möglich.

\section{Bemerkungen}

Durch die in Gorleben angetroffene kontinuierliche Folge vom Alt- zum Mittelpleistozän scheint die Lage der Dorst-Kaltzeit in dieser Grenzposition gesichert.

(BEHRE)

\section{Cromer-Komplex \\ (Syn.: Cromerium)}

\section{Definition, Erstbeschreibung}

Der Begriff stammt von der Ortschaft Cromer in Norfolk, East Anglia (GB). Als stratigraphische Einheit wurde er von REID $(1882,1890)$ eingeführt und verwendet. Er klassifizierte einen Teil der dort aufgeschlossenen präglazialen Sequenz als „Cromer Forest-bed Serie“ und gliederte diese in „Lower Freshwater Bed“, „Forest-bed“ (estuarine) und „Upper Freshwater Bed“. ReID (1882, 1890) erkannte bereits, dass die Ablagerungen des Forest-bed unter temperaten Klimabedingungen gebildet wurden. Lange Zeit erfolgten keine weiteren substanziellen Beiträge zur Stratigraphie des Cromer Forestbed, obwohl der Begriff „Cromerian“ weite Verbreitung in der Literatur zur europäischen Pleistozänstratigraphie als interglaziale Stufe unmittelbar vor der ältesten, weit verbreiteten nordischen Vergletscherung (Elster/Anglian) fand. Erst WeST \& WiLSON (1966) publizierten neue Ergebnisse zur Stratigraphie und Paläoökologie des Cromer Forest-bed, wobei sie zwei deutlich voneinander getrennte Warmzeiten unterscheiden. Eine ausführliche Dokumentation der stratigraphischen Gliederung der „Cromer Forest-bed Formation“ liegt in der Monographie von WeSt (1980) vor. Die jüngere Warmzeit bezeichnet WEST (1980) als „Cromerian“ (Cromer-Interglazial sensu stricto) und die ältere Warmzeit als „Pastonian“. Letztere gehört jedoch nach neueren Untersuchungen von GiBBARD et al. (1991) nicht in das ältere Mittelpleistozän, sondern in das Unterpleistozän.

In den Niederlanden wird das Cromerium mittlerweile als komplexe stratigraphische Einheit zwischen altpleistozänem Bavel-Komplex und dem Elster-Glazial aufgefasst (ZAGWIJN et al. 1971, ZaGwiJn 1985). Somit sind die stratigraphischen Konzepte zwischen den Regionen England und Niederlande eigentlich inkompatibel.

\section{Typuslokalität, Typusregion}

Das Typusprofil befindet sich in West Runton/Norfolk, GB, die Typusregion ist East Anglia (Norfolk, Suffolk) mit seinen Kliffprofilen (WEST 1980, 1996).

\section{Vergleichbare Profile, Verbreitung}

ZAGWIJN et al. (1971) sowie ZAGWIJN $(1985,1996)$ untergliedern den Cromer-Komplex der niederländischen Quartärstratigraphie in vier eigenständige Interglaziale: Interglazial I (Wardenburg, gehört noch in die invers magnetisierte Matuyama-Zone), Interglazial II (Westerhoven), Interglazial III (Rosmalen) und Interglazial IV (Noordbergum). Bislang ist allerdings die Korrelation zwischen dem Cromer-Interglazial s. str. in West Runton mit einem der niederländischen Interglaziale des Cromer-Komplexes nicht überzeugend gelungen. West (1996) korreliert das Cromerian in East Anglia mit dem Interglazial IV (Noordbergum). Allerdings wird dieser Korrelationsvorschlag nicht durch die Kleinsäugerstratigraphie gestützt, denn Noordbergum enthält Arvicola cantianus, in West Runton wurde aber Mimomys savini 
geborgen (Stuart 1996, vgl. auch von Koenigswald \& Heinrich, in diesem Band). Die Korrelation wird noch komplizierter durch den Fund von Arvicola cantianus aus nach WEST (1980) spät-cromerzeitlichen (s. str.) Ablagerungen in Ostend (Norfolk, East Anglia). Die Konsequenz wäre, dass entweder der Faunenwechsel von Mimomys savini und Arvicola cantianus während des Cromerium (s. str.) stattgefunden hat oder die verschiedenen Sequenzen aus East Anglia, die WeST (1980) dem Cromerium (s. str.) zuordnet, nicht nur zu einem Interglazial gehören. ZAGWIJN (1996) korreliert deswegen das niederländische Noordbergum mit Cromer/Ostend (beide Vorkommen mit Arvicola) und das niederländische Westerhoven mit Cromer/West-Runton (mit Mimomys).

Die stratigraphische Gliederung des älteren Mittelpleistozäns in NW Deutschland ist durch die benachbarten Niederlande beeinflusst. Interglazialvorkommen mit nahezu vollständig dokumentierter Vegetationsentwicklung aus Osterholz (GrÜGER 1968), Hunteburg (HAHNE et al. 1994a) und Bilshausen (MüLlER 1965, 1992) werden mittlerweile als dem Cromer-Komplex zugehörig betrachtet (MüLLER 1992). Wegen der Unvollständigkeit der Warmzeiten des Cromer-Komplexes in den Niederlanden ist eine Korrelation mit den in NW Deutschland bekannten Vorkommen mitunter problematisch. Die wohl vollständigste Folge des Cromer-Komplexes in NW Deutschland ist das Bohrprofil mit Sedimenten eines Subrosionsbeckens über dem Salzdom in Gorleben (MüLLER 1986, 1992). In stratigraphischer Superposition, allerdings mit fragmentarischer Überlieferung, wurden fünf Warmzeiten palynologisch dokumentiert: Osterholz-Warmzeit als ältestes Thermomer des Cromer-Komplexes, gefolgt von der Hunteburg-Warmzeit und zwei weiteren, allerdings von MüLLER unbenannten Warmzeiten sowie der Rhume (Bilshausen)-Warmzeit als jüngstes Interglazial vor der Elster-Kaltzeit. GRÜGER et al. (1994) beschreiben anhand einer Kernbohrung in Göttingen (Ottostraße) drei palynologisch nachweisbare Warmzeiten interglazialen Charakters in vertikaler Abfolge. Nach paläomagnetischen Daten gehören die Ablagerungen in die Brunhes-Zone. Durch Ausschluss von Holstein und Eem stellen GrüGER et al. (1994) die Folge in den Cromer-Komplex, wobei jedoch eine sichere Zuordnung zu den bekannten Cromer-Warmzeiten derzeit nicht möglich ist. In Voigtstedt (Thüringen) beschreibt ERD (1965a, 1970, 1973) zwei Warmzeiten, die er dem Cromer-Komplex zuordnet (ältere Artern-Warmzeit und jüngere Voigtstedt-Warmzeit, diese mit Mimomys savini, vgl. von KoEnigswald \& HeInRICH, in diesem Band). Allerdings sind auch die Befunde in Voigtstedt wegen der fragmentarischen Überlieferung von jeweils nur wenigen warmzeitlichen Pollenspektren bei schlechter Sporomorphenerhaltung nicht geeignet, die Gliederung und Korrelation innerhalb des Comer-Komplexes zu erhellen.

\section{Datierung}

Mit numerischen Methoden der Altersbestimmung ermittelte absolute Daten liegen für den Beginn des Cromer-Komplexes nicht vor. Das Interglazial I (Wardenburg) in den Niederlanden sowie das offenbar gleichaltrige Osterholz-Interglazial in NW Deutschland sind invers magnetisiert (Matuyama). ZAGWIJN (1996) vermutet für diese Warmzeit eine Korrelation mit der MIS 21.

Die jüngste Warmzeit des Cromer-Komplexes in NW Deutschland ist die Rhume-Warmzeit (bzw. Bilshausen-Warmzeit als Synonym), die von BitTMAnN \& Müller (1996) mit dem Kärlich-Interglazial (Mittelrhein-Gebiet) korreliert wird. ${ }^{40} \mathrm{Ar} /{ }^{39} \mathrm{Ar}$-Laserdatierungen und konventionelle ${ }^{40} \mathrm{Ar} /{ }^{39} \mathrm{Ar}-$ Stufenheizungsdatierungen des mit dem Kärlich-Interglazial verbundenen Brockentuffs zeigen nach VAN DEN BoOGARD et al. (1989) übereinstimmende Alter um 400 ka (MIS 11).

\section{Bemerkungen}

Die zahlreichen Versuche bzw. Vorschläge zur Gliederung und Korrelation des Cromer-Komplexes sind mittlerweile sehr unübersichtlich. Es besteht die Gefahr, dass diese komplexe stratigraphische Einheit als Sammelbecken für fragmentarische und nicht näher einzuordnende mittelpleistozäne Warmzeitfolgen fungiert. Eine Revision ist dringend nötig, wobei lange kontinentale Folgen wie Gorleben hierfür ein hohes Potenzial besitzen, da der Wechsel zwischen Kalt- und Warmzeiten in stratigraphischer Superposition überliefert ist. Leider ist bislang eine detaillierte Dokumentation und Interpretation der örtlichen Befunde von Gorleben nicht erfolgt. 


\section{Osterholz-Warmzeit}

\section{Definition, Erstbeschreibung}

Die „Osterholz-Warmzeit“" wurde erstmalig in einem Erdfall im Osterholz bei Elze entdeckt und von GRÜGER (1968) mit einem Pollendiagramm dokumentiert. Kennzeichnend sind u.a. hohe Werte von Eucommia. Die stratigraphische Einordnung erfolgte nach pollenanalytischen Gesichtspunkten zunächst allgemein in den Cromer-Komplex.

\section{Typuslokalität}

Typuslokalität ist das Waldstück Osterholz bei Elze südlich von Hannover. Salzauslaugung im liegenden Gipskeuper führte dort zu einer Subrosionssenke, in der sich Seekreideablagerungen eines interglazialen Sees fanden. Das fast vollständige Pollendiagramm von GRÜGER (1968) kennzeichnet die Osterholz-Warmzeit.

\section{Vergleichbare Profile, Verbreitung}

Ein gleich altes Vorkommen aus einem Erdfall im Elm südöstlich von Braunschweig wurde ebenfalls von GRÜGER (1968) pollenanalytisch untersucht. Wenige meist fragmentarisch erhaltene Interglaziale werden nach den pollenanalytischen Befunden überdies hier eingeordnet. Hierzu gehört vor allem das von ZAGWIJN et al. (1971) aus Waardenburg/Niederlande beschriebene Vorkommen, das zwar nur ein Bruchstück ist, jedoch Eucommia führt. Stratigraphisch genau an der erwarteten Stelle und ebenfalls mit Eucommia wurde das Osterholz-Interglazial von MüLLER (1992) über dem Salzstock von Gorleben nachgewiesen. Dieser Autor benutzt dort auch die Zweitbezeichnung „Sohlingen-Warmzeit“, denn aus einer Kiesgrube nordwestlich von Sohlingen sind ebenfalls zeitgleiche Ablagerungen überliefert (HOMANN \& LEPPER 1994).

\section{Datierung}

Die Waardenburg-Warmzeit, von der die Osterholz-Warmzeit ein Pendant ist, fällt nach ZAGWIJN et al. (1971) in die erste Cromer-Warmzeit. In den Niederlanden hat sie eine inverse Matuyama-Magnetisierung. ZAGWIJN (1996) korreliert sie mit MIS 21. In Sohlingen hat Fromm (1994) an entsprechenden Interglazialsedimenten ebenfalls eine überwiegend inverse Magnetisierung nachgewiesen.

\section{Bemerkungen}

Das Osterholz-Interglazial stellt die mit Abstand vollständigste erste Cromer-Warmzeit dar. Da es als erstes beschrieben wurde, sollte es allgemein namengebend sein.

(BEHRE)

\section{Mittelpleistozän \\ Hunteburg-Warmzeit}

\section{Definition, Erstbeschreibung}

Die Bezeichnung „Hunteburg-Warmzeit“" stammt vom gleichnamigen Ort nordöstlich von Osnabrück in Niedersachsen. Die Definition und Erstbeschreibung erfolgten in der Publikation von HaHNE et al. (1994a) und beziehen sich auf mittelpleistozäne Seeablagerungen aus einer Forschungsbohrung, die nach pollenanalytischen Untersuchungen eine vollständige Warmzeit (Hunteburg-Interglazial) erbracht haben. Lithostratigraphisch liegen die Interglazialsedimente unter Ablagerungen der SaaleKaltzeit (Mittelterrasse und Schmelzwassersande des Drenthe-Stadiums) und möglicherweise noch älteren Fließerden (Elster-Kaltzeit?). Die Hunteburg-Warmzeit wird von HAHNE et al. (1994a) in neun Pollenzonen untergliedert und in den Cromer-Komplex gestellt. 


\section{Typuslokalität}

Die Bohrung Hunteburg wurde 1985 in der dem Wiehengebirge unmittelbar nördlich vorgelagerten Niederung abgeteuft. Der Bohrpunkt liegt ca. 18 km nordöstlich von Osnabrück, im äußersten SW des Gebietes der Topographischen Karte 1:25 000, 3515 Hunteburg, und etwa $45 \mathrm{~m}$ über NN. Die Sedimente der Hunteburg-Warmzeit wurden in einer Tiefe von 56,0 bis 51, $59 \mathrm{~m}$ erbohrt (HAHNE et al. 1994a).

\section{Vergleichbare Profile, Verbreitung}

HAHNE et al. (1994) sehen gewisse Probleme bei der Korrelation der Hunteburg-Warmzeit mit einer der pollenstratigraphisch definierten Warmzeiten (I bis IV) des Cromer-Komplexes in den Niederlanden. Gute Korrelationsmöglichkeiten bestehen jedoch nach HAHNE et al. (1994a) bzw. HAHNE (1996) mit den jütländischen Interglazialvorkommen von Harreskov und Ølgod (ANDERSEN 1965). Überdies sieht HAHNE (1996) aus palynostratigraphischer Sicht Übereinstimmung mit dem Ferdinandov-Interglazial in Polen (JANZYK-KopiKOva 1975). ZAGWIJN (1996) korreliert jedoch die Hunteburg-Warmzeit mit dem niederländischen Westerhoven (Interglazial II) sowie mit dem Harreskov-Interglazial, dem unteren Teil der Ferdinandow-Warmzeit und mit dem Cromerian s. str. (mit Mimomys savini). MüLler (1992) verwendet in Kenntnis der zum damaligen Zeitpunkt noch unpublizierten Befunde von Hunteburg den Namen dieser Warmzeit für das dem Osterholz unmittelbar folgende Thermomer in der Folge von Gorleben (und als Synonym für Harreskov sowie mit Fragezeichen für Westerhoven).

\section{Datierung}

Mit numerischen Methoden der Altersbestimmung ermittelte absolute Daten liegen nicht vor. Paläomagnetische Untersuchungen von Fromm (1994) zeigen jedoch eine inverse Polarität aus dem Hunteburg-Interglazial, woraus zwei Datierungsmöglichkeiten in Erwägung gezogen werden, nämlich die Zeit vor der Brunhes-Zone vor 780 ka oder ca. 100.000 Jahre später im Lishi-Event innerhalb der Brunhes-Zone.

\section{Bemerkungen}

In den Niederlanden liegt die Brunhes-Matuyama-Grenze nach ZaGwisn et al. (1971) innerhalb des Cromer-Komplexes zwischen Interglazial I (Waardenburg) und Interglazial II (Westerhoven). Mit der Wardenburg- bzw. der zeitgleichen Osterholz-Warmzeit ist jedoch Hunteburg keinesfalls zu korrelieren (abweichende Sukzession und Fehlen von Eucommia in Hunteburg). Die zunächst von MüLLER (1992) und ZAGWIJN (1996) vermutete Korrelation zwischen Westerhoven und Hunteburg wird durch die inverse Magnetisierung in Hunteburg problematisch. Als einfachste Lösung böte sich nach Fromm (1994) eine Einstufung der Hunteburg-Warmzeit zwischen den Warmzeiten I und II der niederländischen Gliederung an (also noch innerhalb Matuyama). Die alternative Lösung wäre, dass in Hunteburg ein inverses Event innerhalb der Brunhes-Zone erfasst wurde (sog. Lishi-Event, vgl. Fromm 1994). Dann wäre die Korrelation mit Westerhoven nicht ausgeschlossen.

\section{Rhume-Warmzeit \\ (Syn.: Bilshausen-Warmzeit)}

\section{Definition, Erstbeschreibung}

Der Begriff „Rhume-Warmzeit“ wurde von LütTig \& MAARLEVELD (1962) nach einem Flüsschen im südlichen Niedersachsen eingeführt. Er bezieht sich auf interglaziale Ablagerungen (sog. Kohleton) unmittelbar vor Sedimenten der Elster-Kaltzeit (sog. Roter Ton), die in einer Tongrube in Bilshausen (nordöstlich von Göttingen) aufgeschlossen waren. LüTtIG \& REIN (1954) nahmen zunächst eine pollenstratigraphische Gleichstellung mit Cromer Forest-bed vor und bezeichneten die warmzeitlichen Ablagerungen als „Cromer- (Günz/Mindel-) Interglazial von Bilshausen“. Um voreilige 
Parallelisierungen zu vermeiden, schlagen später LütTIG \& MaARLeveld (1962) die Bezeichnung „Rhume-Warmzeit" vor. Detaillierte pollenanalytische Untersuchungen eines Bohrkerns mit jährlich geschichteten Sedimenten aus Bilshausen durch MüLLER (1965) verdeutlichen, dass durch LüTTIG \& REIN (1954) nur der jüngere Teil des Interglazials erfasst wurde. MüLLER (1965) definiert den Beginn der Rhume-Warmzeit mit dem Übergang zwischen „Waldfreier Zeit“ (Abschnitt a) und der „Frühen Wiederbewaldungszeit" (Abschnitt b), während das Ende der Warmzeit durch die Grenze zwischen „Fichten-Birken-Kiefern-Zeit“ (Abschnitt k) und der schon elsterzeitlichen „Tundrenzeit“" (Abschnitt 1) eindeutig erfasst wird.

\section{Typuslokalität}

Das Typusprofil der Rhume-Warmzeit befindet sich auf dem Gelände der ehemaligen Ziegeleigrube Jacobi in Bilshausen, Kr. Duderstadt, nordöstlich von Göttingen (LüTTIG 1965b). In der von MüLLER (1965) bearbeiteten Kernbohrung 1/62 wurde der „Kohleton“ zwischen 8,5 m und 21,3 m Sedimenttiefe erfasst. Reproduzierbare Ergebnisse liegen durch eine weitere Bohrung in Bilshausen vor (Bohrung 1/78, Kohleton zwischen $37 \mathrm{~m}$ und $48 \mathrm{~m}$, vgl. MüLLER 1992).

\section{Vergleichbare Profile, Verbreitung}

MüLLER (1986) erwähnt zeitgleiche Sedimente im Deckgebirge des Salzstockes Gorleben, nordöstliches Niedersachsen (Bohrung GoHy 940/944). Überdies sind aus einer Bohrung in Salzderhelden (BK 20), $25 \mathrm{~km}$ nördlich von Bilshausen, torfige Ablagerungen palynologisch bearbeitet worden, die in den jüngeren Abschnitt der Rhume-Warmzeit eingeordnet werden (MÜLLER 1992). BITTMANN \& MülLER (1996) korrelieren den jüngeren Teil der Rhume-Warmzeit in Bilshausen mit dem KärlichInterglazial im Mittelrhein-Gebiet. ZAGWIJN (1996) hält eine Korrelation zwischen Kärlich und Bilshausen einerseits sowie Noordbergum (Interglazial IV des Cromer-Komplexes in den Niederlanden) andererseits für wahrscheinlich.

\section{Datierung}

${ }^{40} \mathrm{Ar} /{ }^{39} \mathrm{Ar}$-Laserdatierungen und konventionelle ${ }^{40} \mathrm{Ar} /{ }^{39} \mathrm{Ar}$-Stufenheizungsdatierungen des mit dem Kärlich-Interglazial verbundenen Brockentuffs zeigen nach VAN DEN BOOGARD et al. (1989) übereinstimmende Alter um 400 ka (MIS 11). Nach Jahresschichtenzählungen dauerte die Rhume-Warmzeit etwa 27.000 Jahre (MüLLER 1992).

\section{Bemerkungen}

MülLER (1992) korrelierte die Rhume-Warmzeit von Bilshausen mit der sog. Voigtstedt-Warmzeit nach ERD (1965a) in Thüringen, deren Ablagerungen unter elsterglaziären Sedimenten liegen. Allerdings wurde von ERD (1965a) dort nur das Ende der Warmzeit palynologisch erfasst, und die wenigen warmzeitlichen Spektren bei schlechter Pollenerhaltung (Beschreibung von ERD 1973: 1090) sind kaum geeignet für die Definition eines eigenständigen Palyno-Stratotyps. Die Korrelation von MüLLER (1992) basierte lediglich auf dem Vorkommen von Tanne in Bilshausen und Voigtstedt. Im Liegenden der pollenanalytisch untersuchten Lehmzone befinden sich Sande und Schluffe der Voigtstedt-Warmzeit, aus denen der größte Teil der Voigtstedter Wirbeltierfauna stammt. Wegen des Vorkommens von Mimomys savini müssen die Ablagerungen der Voigtstedt-Warmzeit jedoch älter als die von Noordbergum (Cromer IV, mit Arvicola cantianus) sein, wodurch auch die Korrelation Bilshausen - Voigtstedt nicht zu halten ist (vgl. von Koenigswald \& HeinRICH, in diesem Band). Eine Neubearbeitung der Lokalität Voigtstedt wäre dringend geboten. 


\section{Elster-Kaltzeit \\ (Syn.: Elster-Eiszeit, Elster-Zeit, Elster-Glazial)}

\section{Definition, Erstbeschreibung}

Die Bezeichnung „Elster-Eiszeit“ für den vorher üblichen Begriff „Erste Eiszeit“ wurde zuerst von KeilHack (1910) in seinen Erläuterungen zur GK 25 Teltow verwendet (Schwab et al. 1994). Sie gilt für den Zeitraum der ältesten quartären Vergletscherung, die im gesamten nordmitteleuropäischen Vereisungsgebiet nachgewiesen werden konnte (EHLERs 1994). Die Elster-Eiszeit bzw. Elster-Kaltzeit beginnt mit der Abkühlung nach dem letzten Interglazial des Cromer-Komplexes und endet mit der Erwärmung am Beginn des Holstein-Interglazials.

Nach der lithostratigraphischen Definition durch die Subkommission für Europäische Quartärstratigraphie (SEQS) von 1977 folgt die „Elster-Formation“ über den Ablagerungen des Voigtstedt-Interglazials und ist begrenzt durch die überlagernden Bildungen des Holstein-Interglazials (MEYER 1981).

Die bisherige Korrelation des Voigtstedt-Interglazials mit dem jüngsten Interglazial des Cromer-Komplexes beruht nur auf der relativen Konkordanz der Schichtenfolge Voigtstedt/Elster an der Typuslokalität und auf palynologischen Befunden aus dem oberen Abschnitt der Warmzeit (ERD 1965a). Die Kleinsäugerfauna mit Mimomys savini spricht eher dafür, dass das Interglazial von Voigtstedt in einen älteren Abschnitt des Cromer-Komplexes einzuordnen ist (von Koenigswald \& HeInRICH 1999), was aufgrund der subrosiv beeinflussten Sedimentation und Lagerung plausibel wäre (EISSMANN 1994). Damit ist die in Voigtstedt definierte Untergrenze der Elster-Kaltzeit in Frage gestellt.

\section{Typuslokalität, Typusregion}

Eine Typuslokalität wurde von KeILHAск (1910) nicht benannt. Namengebend war die Weiße Elster, ein rechter Nebenfluss der Saale in Mitteldeutschland. Hier sind die Bildungen der „Ersten Eiszeit“ weit verbreitet und wurden durch SIEGERT \& WEISSERMEL (1911) erstmals detailliert beschrieben (Woldstedt 1950). Keilhack wählte die Bezeichnung offenbar in Kenntnis der Untersuchungen von Siegert \& WeIsSERmel (nach Ehlers 1994).

Auf Beschluss der SEQS von 1977 wurde das Profil von Voigtstedt als Lecto-Stratotyplokalität für das Elster-Glazial gewählt (MeYer 1981). Die Elster-Formation besteht an der Typuslokalität vom Liegenden zum Hangenden aus folgenden Abschnitten: subarktischer Teil der „Lehmzone“ (limnisch), Sande und Kiese der Helme („Obere Kiese“), glazilimnische warvige Tone, Grundmoräne, glazifluviatile Sande und Kiese (STEINMÜLLER 1977).

Die festgelegte Typuslokalität ist aus folgenden Gründen problematisch:Die stratigraphische Stellung der liegenden Ablagerungen bzw. des Voigtstedt-Interglazials ist unsicher (s. o.).

Das hangende Holstein-Interglazial ist aus einer Bohrung in das Profil projiziert worden.

Die Elster-Kaltzeit ist weit verbreitet durch zwei glaziäre Zyklen vertreten, von denen in Voigtstedt nur der ältere vorkommt. Das Profil befindet sich außerhalb der Verbreitung des jüngeren Elster-Inlandeises.

\section{Vergleichbare Profile, Verbreitung}

Elsterglaziäre Ablagerungen sind in Nord- und Mitteldeutschland weit verbreitet. Sie reichen bis zur Maximalausdehnung des Elster-Inlandeises, die in Sachsen-Anhalt, Thüringen und Sachsen in etwa durch die „Feuersteinlinie“ markiert wird. Sie verläuft am nördlichen Harzrand entlang nach Osten bis zum Bodetal und quert dann den Unterharz. Südlich des Harzes stieß das Eis in großen Loben nach Westen vor und überfuhr das Thüringer Becken bis Bad Langensalza - Erfurt - Weimar. Der weitere Verlauf der Maximalausdehnung ist über Jena, Weida nach Zwickau verfolgbar und von dort am Fuße des Erzgebirges entlang über Chemnitz - Roßwein nach Freital und weiter in das Elbsandsteingebirge und das Lausitzer Bergland. Vom Nordharzrand nach Westen sind elsterzeitliche Sedimente bis Seesen - Alfeld - Rinteln und im Emsland nachgewiesen. Die Grenze der Elster-Vergletscherung ist in Niedersachsen und Nordrhein-Westfalen nicht eindeutig fixierbar. 
Vom Elbe-Weser-Dreieck über weite Teile Nord- und Mitteldeutschlands bis in die Lausitz sind zwei glaziäre Zyklen der Elster-Kaltzeit überliefert, ohne dass diese durch Warmzeit-Sedimente getrennt sind. EISSMANN (1994) geht von zwei großen Eisvorstößen aus, zwischen denen die fluviatile Aktivität auflebte und das Eis wahrscheinlich mehrere $100 \mathrm{~km}$ zurückgeschmolzen ist (Miltitzer Intervall) und spricht ihnen (in EISSMANN 1997) unter Vorbehalt den Rang „,relativ autonomer Stadien“ zu. Die überregionale Korrelation der Zyklen ist jedoch nicht belegt. Es ist also noch unsicher, ob die Zyklen zwei durch eine deutliche Abschmelzphase getrennte Inlandeisvorstöße repräsentieren oder ob sie durch geringer dimensionierte, aufeinanderfolgende Eisrandverschiebungen entstanden sind.

\section{Datierung}

Die Untergrenze der Elsterkaltzeit entspricht dem Ende des jüngsten Cromer-Interglazials (wohl Rhume/Bilshausen = Kärlich), das nach absoluten Datierungen mit MIS 11 korreliert (vAN DEN BooGARD et al. 1989). Die Obergrenze der Elster-Kaltzeit entspricht der Untergrenze des Holstein-Interglazials, das nach absoluten Datierungen mit MIS 9 korreliert (GEYH \& MülLER 2005). Somit würde sich eine Einstufung der Elster-Kaltzeit in MIS 10 ergeben (etwa zwischen 400 ka und 320 ka v.h.).

\section{Bemerkungen}

Der von einigen Autoren verwendete Begriff „Elster-Komplex“ ist unzutreffend, da die Elster-Kaltzeit durch keine Warmzeit geteilt ist. Die Voigtstedt-Warmzeit und die vorausgehende Helme-Kaltzeit gehören nicht zur Elster-Kaltzeit (MEYER 1981). Die von K. ERD als intraelsterzeitlich angesehenen Interglazialsedimente von Ummendorf (Oberes Allertal) lagern über der zweiten Elster-Grundmoräne und sind daher jünger als die Elster-Kaltzeit (STRAHL 1999).

(WANSA)

\section{Zwickau-Phase (Syn.: Zwickauer Phase)}

\section{Definition, Erstbeschreibung}

Die Bezeichnung „Zwickauer Phase“ wurde zuerst von Eissmann (1969, 1970) verwendet. Die Zwickau-Phase ist der Zeitraum des ersten und am weitesten nach Süden reichenden Inlandeisvorstoßes der Elster-Kaltzeit in Mitteldeutschland (EIssmanN 1975). Er beginnt mit der Abkühlung nach dem letzten Interglazial des Cromer-Komplexes und endet mit dem Rückschmelzen des Inlandeises nach der Maximalausdehnung. Die Ablagerungen der Zwickau-Phase umfassen frühelsterzeitliche Flussschotter (Frühelsterterrasse, siehe Punkt 5) und Schmelzwasserbildungen sowie die erste (untere) Elster-Grundmoräne. Die Untergrenze wird von den Ablagerungen der jüngsten Warmzeit des Cromer-Komplexes gebildet (Rhume), die Obergrenze durch die Schmelzwasserbildungen des Miltitz-Intervalls.

\section{Typuslokalität, Typusregion}

Eine Typuslokalität ist noch nicht benannt worden. Als Typusregion gilt das Gebiet zwischen Saale und Elbe, in dem sich die elsterglaziale Sedimentsukzession der Zwickau- und der Markranstädt-Phase zuordnen lassen (EISSMANN 1969, 1975).

\section{Vergleichbare Profile, Verbreitung}

Bildungen der Zwickau-Phase sind in Mitteldeutschland weit verbreitet und reichen bis an den Rand der Mittelgebirge von Thüringen und Sachsen („Feuersteinlinie“). In Thüringen wird die Maximalausdehnung synonym auch als Erfurt-Phase (UNGER 1995) bezeichnet. Der Kannawurfer Halt und der Greußener Halt sind Zwischenhalte des zur Maximalausdehnung vorrückenden Eises im Thüringer Becken (UNGER 1974). Der Nachweis äquivalenter Bildungen in anderen Gebieten ist unsicher, da die überregionale Korrelation der elsterglazialen Zyklen nicht belegt ist (vgl. „Elster-Kaltzeit“). 


\section{Datierung}

Mit numerischen Methoden der Altersbestimmung ermittelte absolute Daten liegen nicht vor.

\section{Bemerkungen}

Teile der als Frühelsterterrassen bezeichneten Ablagerungen wurden mehrphasig akkumuliert und können auch cromerzeitliche Anteile enthalten (GROSSE \& FISCHER 1989). Andere Teile sind in etwa zeitgleich zum Eisvorstoß entstanden und verzahnen sich mit den glaziären Sedimenten (UNGER 1974). Eine eindeutige zeitliche Zuweisung der Ablagerungen ist i.d.R. nicht möglich. Als Bildungen der Zwickau-Phase sollten deshalb im mitteldeutschen Vereisungsgebiet, vergleichbar der Gliederung des Saale-Komplexes (vgl. LitT \& TuRnER 1993), nur glaziäre Sedimente angesehen werden.

Der glaziäre Zyklus des ersten Elster-Eisvorstoßes in Mitteldeutschland soll künftig als „ZwickauGlaziär-Formation" bezeichnet werden.

(WANSA)

\section{Miltitz-Intervall \\ (Syn.: Miltitzer Intervall)}

\section{Definition, Erstbeschreibung}

Die Bezeichnung „Miltitzer Intervall“ wurde zuerst von Eissmann (1975) verwendet. Das Miltitz-Intervall umfasst den Zeitraum zwischen der Zwickau- und der Markranstädt-Phase der Elster-Kaltzeit in Mitteldeutschland. Lithostratigraphisch ist das Miltitz-Intervall an den „Miltitzer Horizont“ bzw. das „Miltitzer Zwischensediment“ gebunden (EISSMAnN 1975), das sich aus Schmelzwasserablagerungen und sog. „Rückzugsschottern“ bzw „Mischschottern“ aufbaut, d. h. fluviatilen Ablagerungen mit erhöhter nordischer Geröll-Komponente. Die Untergrenze wird durch die Grundmoräne der Zwickau-Phase gebildet, die Obergrenze durch den Vorstoßbänderton oder die Grundmoräne der Markranstädt-Phase.

\section{Typuslokalität, Typusregion}

Eine Typusregion wurde bisher nicht benannt. Als Typusregion gilt das Gebiet zwischen Saale und Elbe, in dem sich die elsterglaziale Sedimentsukzession der Zwickau- und der Markranstädt-Phase zuordnen lassen (EISSMANN 1975).

\section{Vergleichbare Profile, Verbreitung}

Bildungen des Miltitz-Intervalls sind in Mitteldeutschland weit verbreitet und bis fast an den Rand des zweiten Elster-Inlandeises nachweisbar. Zwei durch Schmelzwasserbildungen des Miltitz-Intervalls getrennte Elster-Grundmoränen sind zwischen Unstrut und Neiße vielfach belegt. Unsicher ist bisher, ob sich die beiden elsterglazialen Zyklen Mitteldeutschlands mit denen anderer Gebiete korrelieren lassen (siehe „Elster-Kaltzeit“).

\section{Datierung}

Mit numerischen Methoden der Altersbestimmung ermittelte absolute Daten liegen nicht vor.

\section{Bemerkungen}

Die Ablagerungen des Miltitz-Intervalls sind generell kaltklimatisch entstanden, Belege für wärmeres Klima sind nicht bekannt. Zu vermeintlichen intraelsterzeitlichen Interglazialsedimenten siehe „Elster-Kaltzeit", Punkt 5. 


\section{Markranstädt-Phase \\ (Syn.: Markranstädter Phase)}

\section{Definition, Erstbeschreibung}

Die Bezeichnung „Markranstädter Phase“ wurde zuerst von Eissmann (1969, 1970) verwendet. Die Markranstädt-Phase ist der Zeitraum des zweiten Inlandeisvorstoßes der Elster-Kaltzeit in Mitteldeutschland (EISSMANN 1975). Er beginnt mit dem Wiedervorstoß des Inlandeises nach dem MiltitzIntervall und endet mit dem erneuten Rückschmelzen und dem Übergang zum späten Elsterglazial. Die Ablagerungen der Markranstädt-Phase umfassen die zweite (obere) Elster-Grundmoräne und den liegenden Vorstoßbänderton. Die Untergrenze wird von den Schmelzwasserablagerungen des Miltitz-Intervalls gebildet, die Obergrenze durch die Schmelzwasserbildungen des „Spätelsterglazials“ (EISSMANN 1975).

\section{Typuslokalität, Typusregion}

Eine Typuslokalität ist bisher nicht benannt worden. Als Typusregion gilt das Gebiet zwischen Saale und Elbe, in dem sich die elsterglaziale Sedimentsukzession der Zwickau und der Markranstädt-Phase zuordnen lassen (EISSMANN 1969, 1975).

\section{Vergleichbare Profile, Verbreitung}

Bildungen der Markranstädt-Phase sind in Mitteldeutschland weit verbreitet. Sie sind bis an den Rand des zweiten Elster-Inlandeises nachweisbar, der am nördlichen Harzrand von der Randlage des ersten Eisvorstoßes (Zwickau-Phase) abspaltet und über Sangerhausen in Richtung Naumburg verläuft. Zwischen Saale und Elbe bleibt der zweite Vorstoß nur wenige Kilometer bis Zehnerkilometer hinter der Maximalausdehnung des ersten zurück (EISSMAnN 1994). In der Oberlausitz ist örtlich unsicher, welcher der beiden Vorstöße am weitesten nach Süden reichte. Zwei durch Schmelzwasserbildungen getrennte Elster-Grundmoränen sind zwischen Unstrut und Neiße vielfach nachgewiesen. Unsicher ist bisher, ob sich die beiden elsterglazialen Zyklen Mitteldeutschlands mit denen anderer Gebiete korrelieren lassen (siehe „Elster-Kaltzeit"“).

\section{Datierung}

Mit numerischen Methoden der Altersbestimmung ermittelte absolute Daten liegen nicht vor.

\section{Bemerkungen}

Der glaziäre Zyklus des zweiten Elster-Eisvorstoßes in Mitteldeutschland soll künftig als „Markranstädt-Glaziär-Formation“ bezeichnet werden. Im Hangenden der zweiten Elster-Grundmoräne tritt örtlich noch eine weitere elster-kaltzeitliche Moränenbank auf, so dass EISSMANN (1997) den zweiten Vereisungszyklus (Markranstädt-Phase) in den älteren (Markranstädter) Eisvorstoß und den jüngeren (Dahlener) Eisvorstoß gliedert.

(WANSA)

\section{Offleben I-Interstadial}

\section{Definition, Erstbeschreibung}

Die Bezeichnung „Offleben I-Interstadial“ wurde zuerst von URBAN et al. (1988) verwendet. Das Offleben I-Interstadial ist das erste Interstadial der späten Elster-Kaltzeit im Tagebau Schöningen. Palynologische Untersuchungen an humosem Schluff belegen eine Bewaldung mit Kiefer, Fichte und Birke, in vernässten Standorten auch mit Erle (UrBAN et al. 1988).

Die Untergrenze wird durch klastische Ablagerungen aus der späten Elster-Kaltzeit gebildet, die Obergrenze durch grobklastische Bildungen, die die Sedimente der Interstadiale Offleben I und II trennen. 


\section{Typuslokalität, Typusregion}

Das Offleben I-Interstadial ist bisher nur aus dem Tagebau Schöningen südlich von Helmstedt bekannt. Da sich das Interstadial in den Sedimenten nur unvollständig abbildet, ist die Festlegung als Typuslokalität jedoch problematisch.

Zwischen der Elster-Grundmoräne und limnischen Bildungen der Holstein-Warmzeit ist eine vielgliedrige Sedimentfolge ausgebildet. Sie beginnt im Liegenden mit Schmelzwasserablagerungen und Schwemmlöss. Darüber folgen die Bildungen des Offleben I-Interstadials: ca. $5 \mathrm{~m}$ mächtiger humoser Beckenschluff, der durch Einschaltungen von tonigem Schluff („Bröckelton“) und Torf gegliedert ist. Er wird von bis $2 \mathrm{~m}$ mächtigen Sanden und Kiesen überlagert, die von URBAN et al. (1988) unter Vorbehalt als niveofluviatile Bildungen eines kurzen Stadials interpretiert wurden. Im Hangenden schließen sich an: limnische humose Ablagerungen des Offleben II-Interstadials, gröberes klastisches Material („Feinsandserie“) eines Stadials, Beckenablagerungen des Esbeck-Interstadials, Fließerde einer Kaltphase und pollenanalytisch belegte Seeablagerungen der Holstein-Warmzeit.

Das Offleben I-Interstadial ist nach dem pollenanalytischen Befund durch relativ kühle und trockene interstadiale Klimaverhältnisse charakterisiert. Urban et al. (1988) halten fünf lokale Pollenzonen aus: Pinus-Betula-Picea-Zone (Zone OF 1), Pinus-Picea-Betula-Zone (Zone OF 2), Pinus-BetulaPoaceae-Zone (Zone OF 3), Alnus-Pinus-Zone (Zone OF 4), Pinus-Poaceae-Zone (Zone OF 5).

\section{Vergleichbare Profile, Verbreitung}

Vergleichbare Profile in anderen Gebieten sind nicht bekannt.

\section{Datierung}

Mit numerischen Methoden der Altersbestimmung ermittelte absolute Daten liegen nicht vor.

\section{Bemerkungen}

Die Pollensukzession lässt keine Klimaentwicklung erkennen, Anfangs- und Endphase des Interstadials sind nicht belegt. Die Interstadiale Offleben I und II sind pollenanalytisch nicht unterscheidbar. Die Trennung der interstadialen Ablagerungen beruht nur auf sedimentologischem Befund und ist möglicherweise nicht klimatisch verursacht.

(WANSA)

\section{Offleben II-Interstadial}

\section{Definition, Erstbeschreibung}

Die Bezeichnung „Offleben II-Interstadial“ wurde zuerst von URBAn et al. (1988) verwendet. Das Offleben II-Interstadial ist das zweite Interstadial der späten Elster-Kaltzeit im Tagebau Schöningen. Es ist lediglich durch zwei Pollenspektren aus humosem Schluff belegt, die eine dem Offleben I-Interstadial sehr ähnliche Bewaldung mit Kiefer, Fichte und Birke anzeigen (UrBAN et al. 1988).

Die Untergrenze wird durch grobklastische Ablagerungen gebildet, der die Sedimente der Interstadiale Offleben I und II trennt. Die Obergrenze ist durch klastische Bildungen des nachfolgenden Stadials gegeben (,Feinsandserie“).

\section{Typuslokalität, Typusregion}

Das Offleben II-Interstadial ist bisher nur aus dem Tagebau Schöningen südlich von Helmstedt bekannt. Da sich die Definition lediglich auf zwei Pollenspektren gründet, ist die Festlegung als Typuslokalität jedoch problematisch.

Zwischen der Elster-Grundmoräne und limnischen Bildungen der Holstein-Warmzeit ist eine vielgliedrige Sedimentfolge ausgebildet. Sie beginnt im Liegenden mit Schmelzwasserablagerungen und Schwemmlöss. Darüber folgen humose limnische Ablagerungen des Offleben I-Interstadials. Sie werden von bis 2 m mächtigen Sanden und Kiesen überlagert, die von URBAN et al. (1988) unter Vor- 
behalt als niveofluviatile Bildungen eines kurzen Stadials interpretiert wurden. Im Hangenden lagern bis $3 \mathrm{~m}$ starke, teilweise humose Schluffe, aus denen die pollenanalytischen Befunde des Offleben II-Interstadials stammen. Die Schluffe enthalten zwei ca. $20 \mathrm{~cm}$ mächtige Torflagen. Darüber schließen sich an: gröberes klastisches Material („Feinsandserie“) eines Stadials, Beckenablagerungen des Esbeck-Interstadials, Fließerde einer Kaltphase und pollenanalytisch belegte Seeablagerungen der Holstein-Warmzeit.

\section{Vergleichbare Profile, Verbreitung}

Vergleichbare Profile in anderen Gebieten sind nicht bekannt.

\section{Datierung}

Mit numerischen Methoden der Altersbestimmung ermittelte absolute Daten liegen nicht vor.

\section{Bemerkungen}

Das Interstadial Offleben II ist lediglich durch zwei Pollenspektren belegt. Die Interstadiale Offleben I und II sind pollenanalytisch nicht unterscheidbar. Die Trennung der interstadialen Ablagerungen beruht nur auf sedimentologischem Befund und ist möglicherweise nicht klimatisch verursacht.

(WANSA)

\section{Esbeck-Interstadial}

\section{Definition, Erstbeschreibung}

Die Bezeichnung „Esbeck-Interstadial“ wurde zuerst von URBAN et al. (1988) verwendet. Das Esbeck-Interstadial ist das dritte Interstadial der späten Elster-Kaltzeit im Tagebau Schöningen. Palynologische Untersuchungen an humosem Schluff belegen eine Bewaldung mit Kiefer und Birke (URBAN et al. 1988).

Die Untergrenze wird durch klastische Bildungen („Feinsandserie“) des vorhergehenden Stadials gebildet, die Obergrenze durch eine Fließerde der nachfolgenden Kaltphase.

\section{Typuslokalität, Typusregion}

Das Esbeck-Interstadial ist aus dem Tagebau Schöningen südlich von Helmstedt beschrieben worden. Da sich die Klimaentwicklung in den Sedimenten nur unvollständig rekonstruieren ließ, ist die Festlegung als Typuslokalität problematisch. Profile in der Nachbarschaft sind zwar detaillierter palynologisch untersucht worden, doch ist die Korrelation mit dem Ort der Erstbeschreibung nicht gesichert (Pkt. 3). Im Tagebau Schöningen ist zwischen der Elster-Grundmoräne und limnischen Bildungen der Holstein-Warmzeit eine vielgliedrige Sedimentfolge ausgebildet. Sie beginnt im Liegenden mit Schmelzwasserablagerungen und Schwemmlöss. Darüber folgen humose limnische Ablagerungen der Interstadiale Offleben I und II, die durch Sande und Kiese getrennt werden. Im Hangenden schließen sich gröbere klastische Bildungen („Feinsandserie“) eines Stadials an. Sie bilden das Liegende der bis $4 \mathrm{~m}$ mächtigen Schluffe, in deren basalem Teil das Esbeck-Interstadial pollenanalytisch nachgewiesen wurde. Die Schluffe enthalten vereinzelt Torf in Lagen oder Linsen. Darüber lagern eine Fließerde der nachfolgenden Kaltzeit und pollenanalytisch belegte Seesedimente der Holstein-Warmzeit.

Urban et al. (1988) halten zwei lokale Pollenzonen des Esbeck-Interstadials aus: Pinus-Betula-Zone (Zone E 1) und Pinus-Betula-Poaceae-Zone (Zone E 2). Die Initialphase des Interstadials ist nicht überliefert. Dagegen lässt sich die Klimaverschlechterung am Ende des Interstadials gut durch die Pollensukzession belegen.

\section{Vergleichbare Profile, Verbreitung}

Das im benachbarten Baufeld Esbeck des Tagebaus Schöningen aufgeschlossene Interstadial-Vorkommen wurde nach eingehenden palynologischen Untersuchungen dem Esbeck-Interstadial zugeordnet 
(URBAN et al. 1991). Dies ist insofern unsicher, als die pollenanalytische Charakterisierung des EsbeckStadials am Ort der Erstbeschreibung für Korrelationen zu ungenau ist und im Baufeld Esbeck keine Sedimente der älteren spätelsterzeitlichen Interstadiale Offleben I und II angetroffen wurden.

Das Profil der späten Elster-Kaltzeit beginnt im Baufeld Esbeck über der Elster-Grundmoräne mit mächtigen glazilimnischen und glazifluviatilen Bildungen. Darüber lagern $3 \mathrm{~m}$ mächtige humose Schluffe mit eingeschalteten kleinen Torflagern. Dieses Sedimentpaket wird von einer Rinnenstruktur abgeschnitten, die stark lithologisch wechselnde Bildungen der späten Elster-Kaltzeit und der Holstein-Warmzeit enthält (URBAN et al. 1991).

In den humosen Schluffen ist eine nahezu vollständige Sukzession eines Kiefern-Birken-(Fichten)-Interstadials überliefert, die in fünf lokale Pollenzonen gegliedert wird (URBAN et al. 1991): Poaceae-Cyperaceae-Artemisia-Zone (Zone ESB 1), Betula-Artemisia-NBP-Zone (Zone ESB 2), Poaceae-NBP-Betula-Zone (Zone ESB 3), Pinus-Betula-Picea-Zone (Zone ESB 4), Pinus-Cyperaceae-NBP-Zone (Zone ESB 5).

Vergleichbare Profile in anderen Gebieten sind nicht bekannt.

\section{Datierung}

Mit numerischen Methoden der Altersbestimmung ermittelte absolute Daten liegen nicht vor.

\section{Bemerkungen}

Das im Baufeld Esbeck beschriebene Esbeck-Interstadial ist das einzige Interstadial der späten Elster-Kaltzeit, das durch eine Pollensukzession von der Anfangs- bis zur Endphase hinreichend belegt ist. Wegen der unsicheren Korrelation mit dem Spätelster-Profil aus dem Tagebau Schöningen ist die genaue stratigraphische Position des Interstadials innerhalb der späten Elster-Kaltzeit fraglich.

(WANSA)

\section{Holstein-Warmzeit \\ (Syn.: Holstein-Interglazial)}

\section{Definition, Erstbeschreibung}

Die Bezeichnung stammt von GeIKIE (1894), der interglaziale marine Ablagerungen als „Holstein beds" bezeichnete. PENCK (1922) hielt sie fälschlicherweise für eine Transgression zwischen Eem und Holozän. Grahle (1936) korrigierte diese Auffassung und verwendete den Begriff für das sog. Marine Interglazial I (nach GotTsche 1898). Durch die Bearbeitung des Profils Hamburg-Hummelsbüttel (mit Lauenburger Ton im Liegenden) durch HaLliK (1960) wurde erstmals marines Holstein sensu GraHLE palynologisch definiert und mit limnisch-terrestrischen Interglazialvorkommen korreliert. Die Vegetationsentwicklung der Holstein-Warmzeit ist von verschiedenen Bearbeitern beschrieben und regional unterschiedlich palynostratigraphisch definiert worden (ERD 1970, MüLLER 1974a). Nach einem Beschluß der INQUA-Subkommission für Europäische Quartärstratigraphie - SEQS (JERZ \& LINKE 1987) wird die Untergrenze des Holstein-Interglazials durch den Übergang von subarktischen (noch spätelsterzeitlichen) zu borealen Verhältnissen festgelegt, während die Obergrenze durch den Übergang von borealen zu subarktischen Klimazeugen (Beginn der Fuhne-Kaltzeit) definiert wird.

\section{Typuslokalität, Typusregion}

Nach einem Beschluß der SEQS gilt das Unterelbe-Gebiet als Typregion (JERZ \& LinkE 1987). Im westlichen Stadtgebiet von Hamburg (Kernbohrung Hamburg-Dockenhuden) wurde in einer elsterzeitlichen Rinne über spätelsterzeitlichem Lauenburger Ton konkordant limnisches Holstein nachgewiesen, das von marinem sowie limnisch-fluviatilem Holstein überlagert wird (JERZ \& Linke 1987, Linke 1993). Die Interglazialablagerungen werden diskordant von saalezeitlichen, glaziären Sedimenten (glazifluviale Sande und Grundmoräne) überdeckt. Von der SEQS wurden als Typusprofile für die Untergrenze des Holstein-Interglazials vorgeschlagen: marines Milieu in 
Eggerstedter Holz in Schleswig-Holstein, limnisches Milieu in Hamburg-Dockenhuden (vgl. auch Linke \& Hallik 1993) und in Bossel westlich Hamburg (Müller \& Höfle 1994). Das Ende des Holstein-Interglazials (Beginn des Saale-Komplexes) ist in der Typusregion nicht erfasst worden. Es ist in den limnischen Profilen in Munster-Breloh (MüLLER 1974a) und Pritzwalk (ERD 1970) gut ausgebildet und dokumentiert.

\section{Vergleichbare Profile, Verbreitung}

Im Gebiet der nordischen Vereisung sind zahlreiche Vorkommen des Holstein-Interglazials über elsterglazialen Bildungen (häufig über elsterglazialen Rinnenfüllungen) bekannt. Wichtige Profile mit fast vollständiger Sequenz sind: Gröbern-Schmerz (EISSMANN et al. 1995) und Rossendorf (ERD et al. 1987). In zahlreichen Holstein-Vorkommen wurde Pterocarya und Azolla filiculoides nachgewiesen. Zur Ausdehnung des Holstein-Meeres vgl. Ehlers (1988), STreif (1990), RüHBERG et al. (1995).

\section{Datierung}

Mit Hilfe von ${ }^{230} \mathrm{Th} / \mathrm{U}-\mathrm{Daten}$ ist eine verlässliche Synchronisierung mit MIS 9 erfolgt, entsprechend der Zeitspanne um 320-310 ka v. h. (GEYH \& MüLLER 2005). Aufgrund von Jahresschichtenzählungen in Munster-Breloh kommt MüLLER (1974a) zu einer Gesamtdauer des Holstein-Interglazials von 15.000 Jahren.

\section{Bemerkungen}

Der Begriff „Holstein-Komplex“ im Sinne von CЕPEK (1968) ist wegen der eindeutigen Abgrenzung der Holstein-Warmzeit s. str. unzweckmäßig und sollte nicht weiter verwendet werden (vgl. LiTT \& TURNER 1993, LitT et al. 2005).

\section{Saale-Komplex \\ (Syn.: Saale-Zeit)}

\section{Definition, Erstbeschreibung}

Die Bezeichnung „Saale-Eiszeit““ wurde von Stoller (1910, Erläuterungen 1911) auf der GK 25 Ebstorf (2918) für den vorher üblichen Begriff „,Vorletzte Eiszeit“ verwendet; ein Andruck dieser Karte (Ex. 4 Bibliothek LBEG) trägt bereits die Jahreszahl 1909. Desgleichen verwendet KeILHACK (1910) diese Bezeichnung in den Erläuterungen zur GK 25 Spandau und Teltow. Eine Neudefinition des Saale-Komplexes erfolgte durch Beschlüsse der Subkommission für Europäische Quartärstratigraphie in den Jahren 1986 und 1992 (JERZ \& LinKe 1987, LitT \& TuRnER 1993). Danach umfasst der Saalekomplex den Zeitraum vom Übergang zwischen Holstein-Warmzeit und Fuhne-Kaltzeit (Grenze zwischen borealer und subarktischer Phase) bis zum Beginn der Eem-Warmzeit (Birken-Zeit, Zone I nach Selle 1962 sowie Menke \& Tynni 1984).

Nach diesen Festlegungen erweist sich die Saale-Zeit als komplexe Einheit mit mehrfachem Wechsel von Kälte- und Wärmeschwankungen, letztere mit Interglazialcharakter (URBAN 1997), jedoch nicht durch glaziäre Sedimente getrennt und eindeutig vor der ersten Eisbedeckung im Drenthe-Stadium. Warmzeitliche Ablagerungen zwischen den einzelnen Eisvorstößen sind nicht nachweisbar.

\section{Typuslokalität, Typusregion}

Eine Typlokalität wurde seinerzeit nicht genannt, die betreffenden Beschreibungen beruhen auf Bohrungen. Bislang erfolgte auch keine Neufestlegung an einzelnen Profilen. Nach der Namengebung gilt das Saalegebiet in Mitteldeutschland als Typusregion.

\section{Vergleichbare Profile, Verbreitung}

Die maximale Verbreitung des Eises des ältesten Saale-Vorstoßes ist etwa markiert durch die Orte 
Düsseldorf - Paderborn - Hameln - Goslar - Eisleben - Zeitz - Meißen - Görlitz. Die Reichweite und Benennung der einzelnen Stadien wird unterschiedlich gehandhabt. Im extraglaziären Bereich sind fluviatile und periglaziäre Sedimente flächenhaft verbreitet.

\section{Datierung}

Mit numerischen Methoden der Altersbestimmung ermittelte absolute Daten liegen nicht vor. Die Untergrenze fällt mit dem Ende des Holsteins (MIS 9) zusammen, also etwa mit $300 \mathrm{ka}$, die Obergrenze mit dem Beginn des Eem bei 130 ka (MIS 5e). Eine Korrelation des Saale-Komplexes mit MIS 8, 7 und 6 ist daher wahrscheinlich.

\section{Bemerkungen}

Die Korrelation der verschiedenen Abschnitte des Saale-Komplexes ist mit vielen Unsicherheiten behaftet.

(MEYER)

\section{Fuhne-Kaltzeit \\ (Syn.: Fuhne-Kälteschwankung)}

\section{Definition, Erstbeschreibung}

Die Bezeichnung (nach einem Flüsschen in Sachsen-Anhalt) wurde von KNoth (1964) als „FuhneKälteschwankung“" eingeführt und bezieht sich auf eine Abkühlung nach dem Holstein-Interglazial, die durch kaltklimatische Akkumulation der Schotter des sog. Edderitzer Saale-Mulde-Laufes mit syngenetischen Verbrodelungen und Eiskeilen gekennzeichnet ist und von einer intensiven Verwitterung mit Bodenbildung abgeschlossen wird (sog. 2. Mittelterrasse, vor der Saale-Vereisung). Zeitgleiche pollenführende Ablagerungen zeigen, dass es zur Entwaldung und zur Herausbildung einer subarktischen Vegetation kam (ERD 1970, 1973). Auch sedimentologisch ist der Übergang zu kaltklimatischen Bedingungen durch klastische Ablagerungen mit teilweise periglaziären Erscheinungen mehrfach belegt (CEPEK 1967). Die Untergrenze wird durch das Ende des Holstein-Interglazials definiert, während die Obergrenze mit dem Beginn einer weiteren Warmzeit (Dömnitz/Wacken) vor der eigentlichen Saale-Glaziation beschrieben wird.

\section{Typuslokalität}

Die Typuslokalität Edderitz ín Sachsen-Anhalt belegt nach KNOTH (1964) eine Mehrphasigkeit der Aufschotterung zwischen Holstein und Saale-Glaziation, die durch eine starke Verwitterung (Edderitzer Boden) unterbrochen wurde.

In der Bohrung Pritzwalk (Brandenburg) wurde erstmals sowohl die Untergrenze als auch die Obergrenze sedimentologisch als auch palynologisch erfasst (CEPEK 1965, 1967, ERD 1970, 1973).

\section{Vergleichbare Profile, Verbreitung}

Neben Edderitz (Sachsen-Anhalt) und Pritzwalk (Brandenburg) wurde die Fuhne-Kaltzeit in Wacken (Schleswig-Holstein) durch feinsandige Sedimente beschrieben, die im oberen Bereich Tropfenböden aufweisen (sog. Mehlbek-Kaltzeit nach DüCKER 1969). Im Tagebau Schöningen wurde die FuhneKaltzeit im Hangenden der Holstein-Sedimente erfasst (URBAN et al. 1988).

\section{Datierung}

Nach U/Th-Daten der liegenden Holstein-Warmzeit in Bossel (GEYH \& MüLler 2005) und der hangenden Dömnitz-Warmzeit in Schöningen (UrBAN 1995) ist eine Korrelation der Fuhne-Kaltzeit mit MIS 8 wahrscheinlich. 


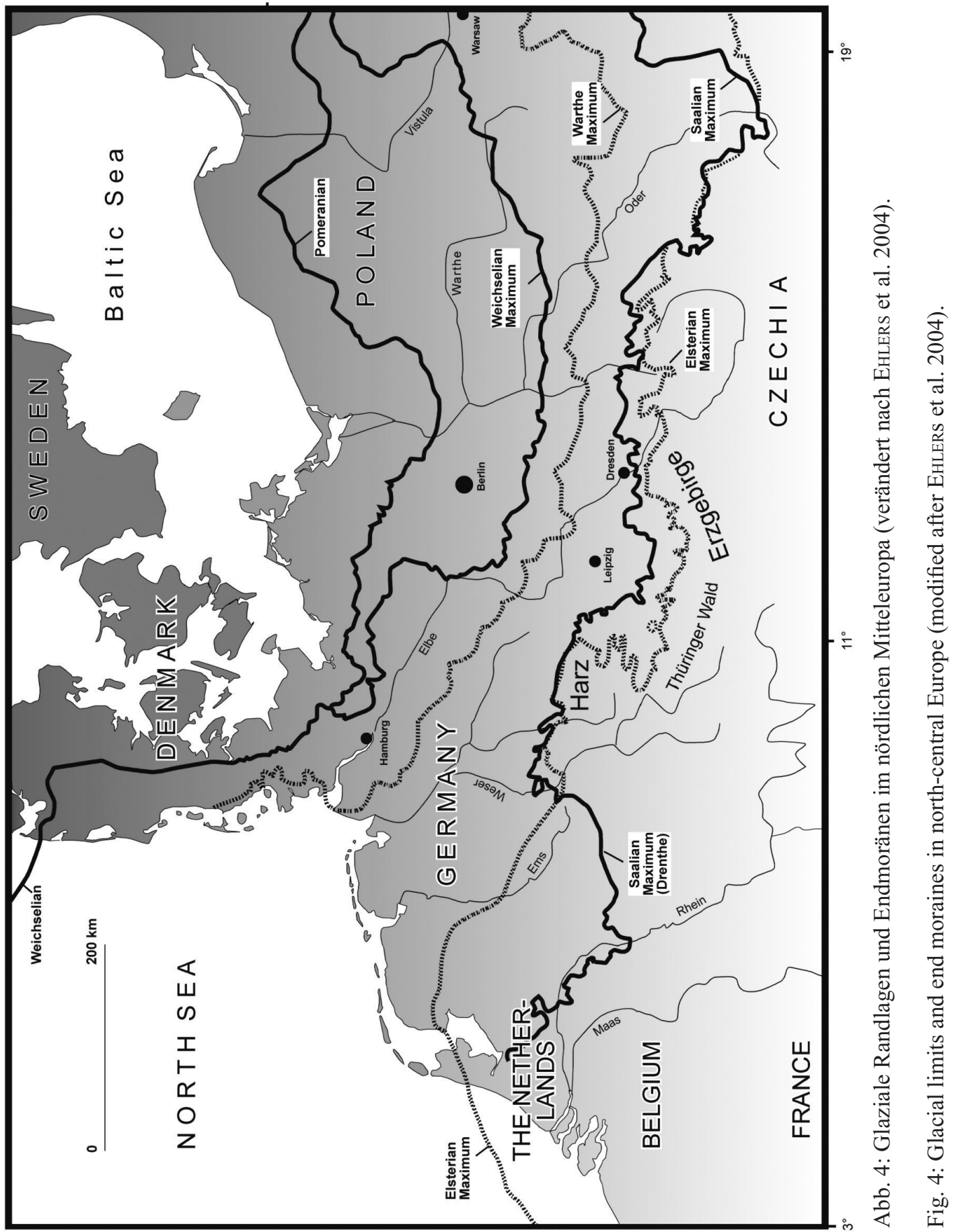




\section{Bemerkungen}

ERD et al. (1987) untergliedern die Fuhne-Kaltzeit über dem Holstein-Interglazial in Rossendorf in Fuhne A und Fuhne B, beide getrennt durch ein Interstadial (A/B). URBAN et al. (1991) beschreiben in Schöningen drei Interstadiale über Holstein (Missaue Interstadial I und II sowie Interstadial SU A).

\section{Dömnitz-Warmzeit \\ (Syn.: Wacken-Warmzeit)}

\section{Definition, Erstbeschreibung}

Die Bezeichnung „Dömnitz-Warmzeit“ (nach einem Flüßchen in der Brandenburger Region Prignitz) wurde von CEPEK (1965) und ERD (1965b) aufgrund von Bohrungen in Pritzwalk/Prignitz als neue stratigraphische Einheit zwischen Holstein-Warmzeit und unmittelbar nachfolgender Fuhne-Kaltzeit einerseits und dem ersten saalezeitlichen Eisvorstoß (Saale 1) andererseits eingeführt. Die Untergrenze der Dömnitz-Warmzeit wird von ERD $(1970,1973)$ palynologisch mit dem Übergang arktischer bis subarktischer Pollenspektren am Ende der Fuhne-Kaltzeit (Zone 1) und der borealen Zone 2 definiert. Die Dömnitz-Warmzeit ist in der Bohrung von Pritzwalk/Prignitz unvollständig dokumentiert. Nur der untere Teil der warmzeitlichen Vegetationsentwicklung konnte pollenanalytisch erfasst werden, der aber eindeutig Interglazialcharakter aufweist (mit Eichenmischwald, Hasel, Hainbuche). Bemerkenswert ist das Auftreten des Wasserfarns Azolla filiculoides.

\section{Typuslokalität}

Die Typuslokalität ist Pritzwalk/Prignitz in Brandenburg (Bohrung Pritzwalk 1E/61, CEPEK 1965, 1967, ERD 1965b, 1970, 1973). Die Abgrenzung zwischen Holstein-Interglazial und Dömnitz-Warmzeit ist im Typusprofil Pritzwalk durch 23 m kaltzeitliche Feinsande der Fuhne-Kaltzeit gesichert. Überdies ist die Grenze Holstein/Fuhne und Fuhne/Dömnitz durch pollenführende Schichten dokumentiert.

\section{Vergleichbare Profile, Verbreitung}

Wie in Pritzwalk (Brandenburg) wurden in Wacken (Schleswig-Holstein) warmzeitliche Ablagerungen (sog. Wacken-Warmzeit nach Menke 1968a) über holsteinzeitlichen Sedimenten beschrieben, die durch kaltzeitliche Sande getrennt waren. Aufgrund pollenanalytischer Kriterien ist eine Korrelation zwischen Dömnitz- und Wacken-Warmzeit sehr wahrscheinlich. Im Tagebau Schöningen (Niedersachsen) beschreiben URBAN et al. (1991) warmzeitliche Sedimente zwischen Elster- und DrentheMoräne als „Schöningen-Interglazial“, die palynologisch von der Holstein-Warmzeit unterschieden, jedoch mit der Dömnitz- bzw. Wacken-Warmzeit korreliert werden.

\section{Datierung}

U/Th-Datierungen von Ablagerungen der Schöningen-Warmzeit im Tagebau Schöningen liegen zwischen 180 und 227 ka v.h. (URBAN 1995). Eine Korrelation der Dömnitz-Warmzeit mit MIS 7 wäre somit wahrscheinlich, sofern die Korrelation mit Pritzwalk korrekt ist.

\section{Bemerkungen}

Das Pollendiagramm der „Schöningen-Warmzeit” (URBAN et al. 1991) kann allerdings nicht so ohne weiteres mit Wacken und Dömnitz verglichen werden, da in Schöningen gerade die Frühphase des Interglazials fehlt. Es handelt sich im gegebenen Falle auch um Pollensprektren aus fluviatil geprägten Sedimenten mit Torfen und klastischen Bildungen. Hierbei sind Hiaten nicht auszuschließen. Eine eindeutige palynologische Charakterisierung der „Schöningen-Warmzeit“" ist anhand der pollenanalytischen Befunde von URBAN et al. (1991, Fig. 6, Profil P1) problematisch, wenn die geringe Summe der ausgezählten Pollen und Sporen berücksichtigt wird. In den meisten warmzeitlichen Spektren wird nicht einmal die Gesamtsumme von 200 Sporomorphen erreicht. Dies ist für eine statistische 
Auswertung unzulänglich und ermöglicht keine reproduzierbaren Ergebnisse. Dennoch bleibt die Korrelation der Schöningen-Warmzeit mit Wacken und Dömnitz wahrscheinlich.

URBAN (1995, 2007) beschreibt im Tagebau Schöningen neben Holstein- und Dömnitz- (bzw. Schöningen) Interglazial eine weitere Warmzeit zwischen Elster- und Saale-Grundmoräne, die sie als „Reinsdorf-Interglazial“ bezeichnet und zwischen die beiden vorgenannten Warmzeiten stellt. Hier ist jedoch die stratigraphische Position nicht gesichert, sondern konstruiert. Die Einführung eines neuen Stratotyps „Reinsdorf-Interglazial“ ist überdies nach den Prinzipien der Stratigraphie (SALVADOR 1994) unzulässig, da im Tagebau Schöningen nicht die Untergrenze (boundary stratotype) dieser Warmzeit definiert werden kann. Nachdem die neuen Pollendiagramme von URBAN (2007) aber die gesamte Abies-Phase abdecken und dazu am Ende des Interglazials auch Fagus, Pterocarya und cf. Celtis auftreten, muss das „Reinsdorf“ sehr wahrscheinlich in das Holstein eingeordnet werden.

(LitT \& BEHRE)

\section{Delitzsch-Phase \\ (Syn.: Delitzscher Phase)}

\section{Definition, Erstbeschreibung}

Die Bezeichnung „Delitzsch-Phase“ wurde, einem Vorschlag von Eissmann (mdl. Mitt.) folgend, von LitT \& TuRner (1993) in die Literatur eingeführt. Die Delitzsch-Phase umfasst den Zeitraum zwischen der Wacken/Dömnitz-Warmzeit und der Zeitz-Phase. Sie stellt somit den tiefsten Abschnitt des oberen Teils des Saale-Komplexes dar. Die Delitzsch-Phase ist durch fluviatile Ablagerungen des Hauptterrassen-Komplexes im Saale-Elbe-Gebiet belegt. Die Liegendgrenze wird von fluviatilen bis limnischen Ablagerungen der Dömnitz-Warmzeit gebildet, die Hangendgrenze durch den kontinuierlichen Übergang der fluviatilen zur glazilimnischen Sedimentation der Zeitz-Phase.

\section{Typuslokalität, Typusregion}

Eine Typuslokalität ist noch nicht benannt worden. Als Typusregion gilt das Saale-Elbe-Gebiet, in dem der Hauptterrassen-Komplex 30 - 40 \% der Gesamtfläche einnimmt und einen wichtigen lithostratigraphischen Leithorizont bildet.

\section{Vergleichbare Profile, Verbreitung}

Bildungen der Delitzsch-Phase sind in den mitteldeutschen Flusstälern weit verbreitet. Darüber hinaus ist davon auszugehen, dass ein großer Teil der frühsaalezeitlichen Flussablagerungen im nördlichen Mitteleuropa während der Delitzsch-Phase akkumuliert wurde. Eissmann (mdl. Mitt.) hat den Raum Lochau - Schkeuditz mit dem Tal der Weißen Elster zwischen Halle und Leipzig zur Beschreibung des Lithostratotyps der Saalesequenz vorgeschlagen (LitT \& TuRnER 1993).

\section{Datierung}

Aus dem oberen Teil des Hauptterrassen-Komplexes der Mulde im ehemaligen Tagebau DelitzschSW liegt ein korrigiertes TL-Alter von $150 \pm 21$ ka vor (KRBETSChEK \& Stolz 1994).

\section{Bemerkungen}

Die Bezeichnung „Delitzsch-Phase“ wird in chronostratigraphischem Sinne verwendet und entspricht der Hauptakkumulationsphase der Hauptterrasse der mitteldeutschen Flüsse (entspricht der Mittelterrasse in Niedersachsen). Sie darf nicht zum Drenthe-Stadium gerechnet werden, sondern geht diesem voraus. 


\section{Drenthe-Stadium \\ (Syn.: Drenthe-Stadial, Drenthe-Zeit)}

\section{Definition, Erstbeschreibung}

Das Drenthe-Stadium umfasst die glaziäre Abfolge zwischen dem Ende des Bantega-Interstadials bzw. der Dömnitz-Warmzeit und dem Warthe-Stadium. VAn der Vlerk \& Florschütz (1950) gebrauchten den Begriff „Drenthien“ für den Zeitraum zwischen dem „Needian“ (= Holstein) und Eem. Später erfolgte eine Einschränkung und Abänderung in „Drenthe-Formation“ (ZAGWIJN 1961). Woldstedt (1954a) hat mit dem Begriff „Drenthe-Abschnitt“ den älteren Teil der Saale-Vereisung bezeichnet.

\section{Typuslokalität, Typusregion}

Eine Typuslokalität wurde seinerzeit nicht benannt. Typusregion ist das Grundmoränenplateau der Provinz Drenthe in den östlichen Niederlanden.

\section{Vergleichbare Profile, Verbreitung}

Die maximale Verbreitung der glaziären Sedimente des Drenthe-Stadiums ist in Deutschland identisch mit der des maximalen Saale-Vorstoßes. Die Untergliederung und Benennung der einzelnen Abschnitte des Drenthe-Stadiums wird unterschiedlich gehandhabt, z.B. wird das „Jüngere Drenthe-Stadium“ in Niedersachsen (Meyer 1965) in Hamburg „Niendorfer Stadium“ (GruBE 1967), in Schleswig Holstein (StEPHAN, zuletzt 1998) „Kuden-Vorstoß“ genannt und dort bereits zum WartheStadium gerechnet. Das Drenthe-Stadium wird in Brandenburg im Allgemeinen mit dem „Älteren Saale-Stadium“ (LIPPSTREU et al. 1995) korreliert, das nach geschiebeanalytischen Befunden wahrscheinlich dem „Haupt-Drenthe“ Niedersachsens entspricht (EHLERS et al. 2004). Im mitteldeutschen Randpleistozän der Saale-Vereisung wird das Ältere Saale-Stadium in die Zeitz-Phase und LeipzigPhase gegliedert.

\section{Datierung}

Mit numerischen Methoden der Altersbestimmung ermittelte absolute Daten liegen nicht vor. Eine Korrelation mit MIS 6 ist wahrscheinlich.

\section{Bemerkungen}

Eine Korrelation des Drenthe-Stadiums bzw. des Älteren Saale-Stadiums mit der „Saale-Kaltzeit im engeren Sinne“ („Saale I-Glazial“) sensu CЕРеK (1967) ist nur bedingt möglich. CEPEKs Gliederung beruhte hauptsächlich auf der Geschiebefazies der Grundmoränen, deren stratigraphische Relevanz stark überschätzt wurde (LipPSTREU et al. 1995). Das Ältere Saale-Stadium ist im Wesentlichen an den Unteren Grundmoränenkomplex Brandenburgs gebunden, der eine weitaus variablere Geschiebezusammensetzung aufweist als CEPEKS SI-Grundmoräne.

Eine Korrelation der verschiedenen Abschnitte des Drenthe-Stadiums ist mit vielen Unsicherheiten behaftet.

(Meyer \& WANSA)

\section{Zeitz-Phase (Syn.: Zeitzer Phase)}

\section{Definition, Erstbeschreibung}

Die Bezeichnung „Zeitzer Phase““ wurde zuerst von Eissmann (1975) verwendet. Die Zeitz-Phase ist der Zeitraum des ersten und am weitesten nach Süden reichenden Inlandeisvorstoßes des Saale-Komplexes in Mitteldeutschland (EISSMAnN 1975). Er beginnt mit der Entwicklung des Eisstausees vor dem vorstoßenden Eis und endet mit dem Rückschmelzen nach der Maximalausdehnung. Die Ablagerungen 
der Zeitz-Phase umfassen den Böhlen-Lochauer Bänderton, die 1. Saale-Grundmoräne und Ablagerungen der Eisrandlagen (z. B. Zeitzer Randlage, Grimmaer Randlage). Die Untergrenze wird von der Hauptterrasse (Delitzsch-Phase) gebildet, die im Hangenden kontinuierlich in feinkörnige Stauseesedimente (Beckenschluff, „Bänderton“) übergeht. Im Hangenden grenzen die Ablagerungen der ZeitzPhase an Schmelzwasserbildungen des Pomßen-Intervalls bzw. Bruckdorf-Horizontes (siehe Pkt. 5).

\section{Typuslokalität, Typusregion}

Eine Typuslokalität ist noch nicht benannt worden. Als Typusregion gilt die Leipziger Tieflandsbucht, in dem sich die saaleglazialen Sedimentsukzessionen der Zeitz- und der Leipzig-Phase zuordnen lassen (EIssmann 1975). EIssmann (mdl. Mitt.) hat den Raum Lochau - Schkeuditz mit dem Tal der Weißen Elster zwischen Halle und Leipzig zur Beschreibung des Lithostratotyps der Saalesequenz vorgeschlagen (LiTT \& TURNER 1993).

\section{Vergleichbare Profile, Verbreitung}

Bildungen der Zeitz-Phase sind in Mitteldeutschland weit verbreitet und reichen bis an den Außenrand der Saale-Eisbedeckung. Der Eisvorstoß war Süd-orientiert. Der Maximalstand verlief am Nord- und Ostrand des Harzes entlang und weiter über Eisleben, Querfurt, Naumburg, Zeitz, Grimma, Döbeln, Kamenz nach Görlitz. Vermutlich entspricht die Zeitz-Phase einem älteren Abschnitt des Hauptdrenthe-Vorstoßes in Niedersachsen.

\section{Datierung}

Mit numerischen Methoden der Altersbestimmung ermittelte absolute Daten liegen nicht vor.

\section{Bemerkungen}

Der Begriff „Zeitz-Phase“ kennzeichnet einen Abschnitt im oberen Teil des Saale-Komplexes und wird in chronostratigraphischem Sinne verwendet (LITT \& TURNER 1993).

Da der Eisrückzug im nachfolgenden Pomßen-Intervall wahrscheinlich nur 50 - $70 \mathrm{~km}$ betrug (EIsSMANN 1995), werden die glazifluviatilen und glazilimnischen Bildungen im Hangenden der 1. Saale-Grundmoräne meist der Zeitz-Phase als Nachschütt- bzw. der Leipzig-Phase als Vorschüttbildungen zugerechnet (Bruckdorfer Horizont nach MANHENKE \& Grosse 1970). Der glaziäre Zyklus des ersten Saale-Eisvorstoßes in Mitteldeutschland soll künftig als ,Zeitz-Glaziär-Formation“ bezeichnet werden.

(WANSA)

\section{Pomßen-Intervall \\ (Syn.: Pomßener Intervall)}

\section{Definition, Erstbeschreibung}

Die Bezeichnung „Pomßener Intervall“ wurde zuerst von EissmanN (1975) verwendet. Das PomßenIntervall umfasst die Abschmelzphase zwischen den Eisvorstößen der Zeitz- und Leipzig-Phase im Oberen Teil des Saale-Komplexes in Mitteldeutschland. Lithostratigraphisch ist das Pomßen-Intervall im Wesentlichen an Schmelzwassersedimente sowie glazifluviatile/fluviatile Mischschotter des Bruckdorfer Horizontes (ManhenKe \& Grosse 1970) gebunden. Die Mischschotter belegen eine kurze Wiederbelebung der südlichen Flüsse (Bruckdorfer Basalschotter, Pomßener Mischschotter, Eissmann 1975). Die Untergrenze der Ablagerungen des Pomßen-Intervalls wird von der Grundmoräne der Zeitz-Phase bzw. den überlagernden Eisstauseesedimenten gebildet (Unterer Bruckdorfer Bänderton nach JUNGE et al. 1999), die Obergrenze vom Bruckdorfer Bänderton i. e. S. bzw. Oberen Bruckdorfer Bänderton nach Junge et al. (1999) an der Basis der ersten Grundmoräne der LeipzigPhase. 


\section{Typuslokalität, Typusregion}

Eine Typuslokalität ist noch nicht benannt worden. Als Typusregion gilt die Leipziger Tieflandsbucht (EISSMANN 1975). Eissmann (mdl. Mitt.) hat den Raum Lochau - Schkeuditz mit dem Tal der Weißen Elster zwischen Halle und Leipzig zur Beschreibung des Lithostratotyps der Saalesequenz vorgeschlagen (LiTT \& TURNER 1993).

\section{Vergleichbare Profile, Verbreitung}

Bildungen des Pomßen-Intervalls sind in Mitteldeutschland westlich der Elbe weit verbreitet. Sie reichen von der Linie Zörbig - Bitterfeld - Belgern im Norden, wo sich die Grundmoränengabel der Zeitz- und Leipzig-Phase schließt (EIssmann 1994, 1995), bis nahe an den Maximalstand der Zeitzer Phase (EISSMAnN 1975).

\section{Datierung}

Aus dem Bruckdorfer Horizont im Tagebau Delitzsch-SW liegt ein korrigiertes TL-Alter von $141 \pm$ 16 ka vor (KRBETSCHeK \& Stolz 1994).

\section{Bemerkungen}

Der Begriff „Pomßen-Intervall“ wird in chronostratigraphischem Sinne verwendet, kennzeichnet aber nur eine kurze Abschmelzphase des Inlandeises. Der Eisrückzug betrug wahrscheinlich 50 - $70 \mathrm{~km}$ (EISSMANN 1995). Die Ablagerungen des Intervalls sind generell kaltklimatisch entstanden, Belege für wärmeres Klima sind nicht bekannt. Die Schluffe, Sande und Kiese stellen überwiegend Vor- bzw. Nachschüttbildungen dar und werden deshalb meist der vorhergehenden oder nachfolgenden Vereisungsphase zugerechnet. Zudem werden die Eisvorstöße der Leipzig-Phase (bzw. -Subphase) seit den 1990er Jahren als Eisrandoszillationen interpretiert (EISSMANN 1994), so dass der Begriff Pomßen-Intervall nur noch eingeschränkte Bedeutung besitzt. Seine Berechtigung gründet sich insbesondere auf das Vorkommen der glazifluviatil/fluviatilen Pomßener Mischschotter.

(WANSA)

\section{Leipzig-Phase \\ (Syn: Leipziger Phase, Leipzig-Subphase)}

\section{Definition, Erstbeschreibung}

Die Bezeichnung „Leipziger Phase“ wurde zuerst von Eissmann $(1969,1970)$ verwendet. Die Leipzig-Phase ist der Zeitraum des zweiten und dritten Inlandeisvorstoßes des Saale-Komplexes in Mitteldeutschland (EISSMANN 1975). Er beginnt mit der Entwicklung des Stausees vor dem vorstoßenden zweiten Inlandeis (Bruckdorfer Vorstoß) und endet mit dem Rückschmelzen nach dem dritten Vorstoß (Breitenfelder Vorstoß). Die Ablagerungen der Leipzig-Phase umfassen bei vollständiger Ausbildung zwei glaziäre Sedimentationszyklen mit Vorschüttbildungen, Grundmoräne und Nachschüttbildungen sowie Ablagerungen der Eisrandlagen. Wesentliche lithostratigraphische Schichtglieder vom Liegenden zum Hangenden sind der Obere Bruckdorfer Bänderton, die 2. Saale-Grundmoräne (heute: 2. Saale-Grundmoräne, untere Bank; EISSMANN \& MüLlER 1979), Schmelzwassersedimente des Breitenfeld-Horizontes (Manhenke \& Grosse 1970) mit dem Breitenfelder Bänderton, die 3. Saale-Grundmoräne (heute: 2. Saale-Grundmoräne, obere Bank; Eissmann \& Müller 1979). Die Untergrenze wird von den Schmelzwasserablagerungen des Bruckdorf-Horizontes (Pomßen-Intervall) gebildet. Im Hangenden lagern in der Regel diskordant weichselzeitliche Sedimente, örtlich limnische EemBildungen. Im chronostratigraphischen Sinne folgt nach der Leipzig-Phase das Seyda-Intervall, das durch mächtige Schmelzwassersedimente im mittleren Elbe-Gebiet belegt ist.

\section{Typuslokalität, Typusregion}

Eine Typuslokalität ist noch nicht benannt worden. Als Typusregion gilt die Leipziger Tieflandsbucht, 
in der die beiden Sedimentationszyklen voll entwickelt sind (Eissmann 1975). Eissmann (mdl. Mitt.) hat den Raum Lochau - Schkeuditz mit dem Tal der Weißen Elster zwischen Halle und Leipzig zur Beschreibung des Lithostratotyps der Saalesequenz vorgeschlagen (LiTT \& TURNER 1993).

\section{Vergleichbare Profile, Verbreitung}

Bildungen der Leipzig-Phase sind in Mitteldeutschland westlich der Elbe weit verbreitet. Sie reichen von der Linie Petersberg - Bitterfeld - Belgern im Norden, wo sich die Grundmoränengabel der Zeitz- und Leipzig-Phase schließt (EIssmann 1994, 1995), bis über Halle und Leipzig hinaus, in Randbereichen der Leipziger Tieflandsbucht örtlich bis nahe an den Maximalstand der Zeitz-Phase. Der jüngere glaziäre Zyklus mit der 2. Saale-Grundmoräne, obere Bank tritt lückenhaft im Rückland der Petersberger, Breitenfelder und Tauchaer Endmoräne auf, etwa bis zur Linie Köthen - Eilenburg, d. h. teilweise noch nördlich der erwähnten Grundmoränengabel. Die Eisvorstöße waren Südwestorientiert. Nördlich der Grundmoränengabel sowie östlich der Elbe ist nur eine Saale-Grundmoräne des Drenthe-Stadiums verbreitet. Die Leipzig-Phase ist wohl mit einem jüngeren Abschnitt des Hauptdrenthe-Vorstoßes in Niedersachsen zu korrelieren. Eine Korrelation mit dem Jüngeren Drenthe-Eisvorstoß ist unwahrscheinlich, da dieser mit der kreidereichen Fazies der Warthe-Grundmoräne in Brandenburg in Verbindung stehen dürfte (LiPpSTReu et al. 1995, EhLERS et al. 2004).

\section{Datierung}

Mit numerischen Methoden der Altersbestimmung ermittelte absolute Daten liegen nicht vor.

\section{Bemerkungen}

Der Begriff „Leipzig-Phase“ kennzeichnet einen Abschnitt im oberen Teil des Saale-Komplexes und wird in chronostratigraphischem Sinne verwendet (LiTT \& TURNER 1993). Seit Mitte der 1990er Jahre wird die Leipzig-Phase zunehmend als Subphase angesehen, da sich herausgestellt hat, dass die jüngeren Saale-Eisvorstöße in den Halle-Leipziger Raum eher als Eisrandoszillationen zu interpretieren sind (EIsSmann 1994). Die glaziären Zyklen des zweiten und dritten Saale-Eisvorstoßes in Mitteldeutschland sollen künftig als „Leipzig-Glaziär-Formation“ bezeichnet werden.

(WANSA)

\section{Seyda-Intervall \\ (Syn.: Seydaer Intervall)}

\section{Definition, Erstbeschreibung}

Die Bezeichnung „Seydaer Intervall“ wurde zuerst von MüLler (1988) verwendet. Das Seyda-Intervall umfasst die Abschmelzphase zwischen der ersten und zweiten Saale-Vergletscherung des mittleren Elbegebiets. MüLLER (1988) interpretiert die 1. Saale-Grundmoräne als Bildung der Zeitz- und Leipzig-Phase (Drenthe-Stadium), räumt aber auch die Möglichkeit ein, dass die 1. Moräne zur ZeitzPhase und die 2. Moräne zur Leipzig-Phase gehören könnte. In diesem Fall würden sich Seyda-Intervall und Pomßen-Intervall entsprechen. EISSMANN (1994) stützt die Auffasung von MüLLER (1988) und stellt das Seyda-Intervall zwischen die Leipzig-Phase und die Fläming-Phase bzw. zwischen das Drenthe-Stadium und das Warthe-Stadium. Lithostratigraphisch ist das Seyda-Intervall an die SeydaFolge gebunden (MüLLER 1988), die aus mächtigen glazifluviatilen Ablagerungen mit glazilimnischen Anteilen besteht. Ihre Untergrenze wird durch die 1. Saale-Grundmoräne des mittleren Elbe-Gebiets gebildet, die Obergrenze durch die 2. Saale-Grundmoräne.

\section{Typuslokalität, Typusregion}

Eine Typuslokalität wurde bisher nicht benannt. Als Typusregion gilt das mittlere Elbe-Gebiet zwischen Riesa und Dessau (MülLER 1988). 


\section{Vergleichbare Profile, Verbreitung}

Sofern das Seyda-Intervall tatsächlich den Zeitraum zwischen dem Drenthe- und dem Warthe-Stadium repräsentiert, sind äquivalente Schmelzwasserbildungen im nördlichen Mitteleuropa weit verbreitet (siehe Punkt 5).

\section{Datierung}

Mit numerischen Methoden der Altersbestimmung ermittelte absolute Daten von Sedimenten des Seyda-Intervalls liegen nicht vor.

\section{Bemerkungen}

Der Begriff „Seyda-Intervall“ wird in chronostratigraphischem Sinne verwendet. Er kennzeichnet wahrscheinlich die Abschmelzphase zwischen dem Drenthe-Stadium und dem Warthe-Stadium, in der sich der aktive Eisrand vielleicht bis in den Ostseeraum zurückverlagerte. Sofern dies eindeutig bewiesen würde, könnte die Bezeichnung „Seyda-Intervall“ überregionale Bedeutung erlangen. Die Sedimente des Intervalls sind generell kaltklimatisch entstanden. Sie stellen Vor- bzw. Nachschüttbildungen dar und werden deshalb oft der vorhergehenden oder nachfolgenden Vereisungsphase zugerechnet. Belege für wärmeres Klima sind nicht bekannt.

(WANSA)

\section{Warthe-Stadium \\ (Syn.: Warthe-Stadial, Warthe-Zeit)}

\section{Definition, Erstbeschreibung}

Das Warthe-Stadium umfasst die glaziäre Abfolge zwischen dem Drenthe-Stadium und der EemWarmzeit. WoldSTEDT (1927) führte den Begriff zunächst als „Warthe-Vereisung“ für die FlämingZone ein, abgeändert 1928 in „Warthe-Vorstoß“ und 1929 in „Warthe-Stadium“.

\section{Typuslokalität, Typusregion}

Eine Typuslokalität wurde seinerzeit nicht benannt. Typusregion ist das Endmoränengebiet im oberen Warthe-Raum bei Lodz.

\section{Vergleichbare Profile, Verbreitung}

Die maximale Ausdehnung des Warthe-Stadiums ist nach WoldSTEDT (1927) morphologisch durch den Verlauf der Endmoränen vom Warthe-Lobus über die Niederlausitz, den Fläming, den Südrand der Altmark über die Lüneburger Heide ins mittlere Schleswig-Holstein gegeben. Lithostratigraphisch sind die zugehörigen Glaziärsedimente durch ostbaltische Geschiebegemeinschaften gekennzeichnet (Hesemann 1934, Lüttig 1958, Meyer 1983).

Das Warthe-Stadium wird in Brandenburg im Allgemeinen mit dem „Jüngeren Saale-Stadium“ (LipPSTREu et al. 1995) korreliert, das auch als „Fläming-Phase“ (EISSMANN 1994) bezeichnet wird. Der ältere Abschnitt dieses Stadiums entspricht nach geschiebeanalytischen Befunden wahrscheinlich der Jüngeren Drenthe in Niedersachsen (EHLERS et al. 2004).

\section{Datierung}

Mit numerischen Methoden der Altersbestimmung ermittelte absolute Daten liegen nicht vor. Nach grober Schätzung des Drenthe-Alters wird für das Warthe-Stadium ein Alter zwischen 150-130 ka angenommen, bis zum Beginn des Eems. Die Korrelation sowohl von Drenthe als auch von Warthe mit MIS 6 ist wahrscheinlich.

\section{Bemerkungen}

Die Reichweite der Warthegletscher wird unterschiedlich bewertet. 
Eine Korrelation des Warthe-Stadiums bzw. des Jüngeren Saale-Stadiums mit der „Fläming-Kaltzeit“ („Fläming-Glazial“, „Fläming-Kryomer“, „SII-Glazial“) und der „Lausitzer Kaltzeit“ („Lausitzer Glazial“, „Lausitz-Kaltzeit“, „SIII-Glazial“") sensu CEPEK (1967) ist problematisch. CEPEKs Gliederung beruhte hauptsächlich auf der Geschiebefazies der Grundmoränen, deren stratigraphische Relevanz stark überschätzt wurde (LipPSTREu et al. 1995). Das Jüngere Saale-Stadium Brandenburgs ist im Wesentlichen an den Oberen Grundmoränenkomplex gebunden, der teilweise ähnliche Geschiebezusammensetzungen aufweist wie der Untere Grundmoränenkomplex. Danach kann die SII-Grundmoräne CEPEKs beiden Grundmoränenkomplexen angehören. Zudem hat die sog. SIII-Grundmoräne oft weichselzeitliches Alter, da im Liegenden Eem-Sedimente nachgewiesen wurden (RÜHBERG et al. 1995, MüLLER 2004).

(Meyer \& WANSA)

\section{Jungpleistozän}

\section{Eem-Warmzeit \\ (Syn.: Eem-Interglazial)}

\section{Definition, Erstbeschreibung}

Die Bezeichnung „Eem-Warmzeit“ stammt von HARTING (1874), der interglaziale Sedimente nach einem Flüsschen in der Umgebung von Amersfoort (Niederlande) benannte. Zunächst verwendete man den Terminus nur für marine Ablagerungen der letzten Warmzeit in Dänemark, Norddeutschland und den Niederlanden (MADSEN et al. 1908). Später wurde er auch auf zeitgleiche terrestrische Ablagerungen ausgedehnt (JESSEN \& Milthers 1928), wobei bereits die Pollenanalyse für die biostratigraphische Einstufung bzw. Korrelation eine entscheidende Rolle spielte. Gegenwärtig basiert die Palynostratigraphie der Eem-Warmzeit in Deutschland auf verschiedenen Gliederungsvorschlägen je nach regionalen Besonderheiten (in NW-Deutschland zunächst Pollenzonen von SELLE 1962 und Behre 1962, später Menke \& Tynni 1984; in NO-Deutschland Erd 1973, in Mitteldeutschland LitT 1994). Die Untergrenze wird allgemein mit dem Übergang zwischen spätsaalezeitlicher subarktischer zu borealer Vegetation (Beginn Betula-Pollenzone) und die Obergrenze mit dem Übergang zwischen borealer zu subarktischer (schon weichselzeitlicher) Vegetation gekennzeichnet.

\section{Typuslokalität, Typusregion}

Die Umgebung von Amersfoort gilt als Typusregion der Eem-Warmzeit. Aus dem Amersfoort-Becken liegen pollenanalytische Untersuchungen von ZAGWIJN (1961) vor, die allerdings nicht den Beginn der Warmzeit erfassen (zur Diskussion über die Stratotyp-Lokalität in Amersfoort siehe Cleveringa et al. 2000). Als neuer Parastratotyp wurde die Bohrung in Amsterdam-Terminal vorgeschlagen, da dort die Untergrenze des Eem dokumentiert ist (VAN LEEUwEN et al. 2000).

\section{Vergleichbare Profile, Verbreitung}

Im Gebiet der nordischen Vereisung ist die Eem-Warmzeit das am besten erfasste Interglazial, dessen Sedimente unmittelbar über den örtlich jeweils jüngsten saalezeitlichen glaziären Bildungen liegen (sowohl über Drenthe wie in der Typusregion als auch über Warthe). Sie werden von keinen weiteren glaziären Bildungen als denen aus der Weichselkaltzeit überdeckt. Sowohl in Deutschland als auch im angrenzenden nördlichen Mitteleuropa ergibt sich eine erstaunliche Übereinstimmung in den Grundzügen der allgemeinen Waldentwicklung. Profile mit vollständiger Eem-Folge wurden in Rederstall, Schleswig-Holstein (Menke \& Tynni 1984), Bispingen, Niedersachsen (MüLLER 1974b), Quakenbrück, Niedersachsen (HAHNE et al. 1994b), Gröbern, Sachsen-Anhalt (LiTT 1994), und Kittlitz, Brandenburg (ERD 1973) beschrieben. Zur Ausdehnung des Eem-Meeres vgl. Höfle et al. (1985).

\section{Datierung}

Gegenwärtig besteht Übereinstimmung hinsichtlich einer Verknüpfung der Eem-Warmzeit mit dem marinen Isotopenstadium 5e. Der Beginn der Warmzeit liegt somit bei $126 \mathrm{ka}$, das Ende vor $115 \mathrm{ka}$ 
vor heute. Aufgrund von Jahresschichtenzählungen nimmt MüLlER (1974b) eine Gesamtdauer des Eem-Interglazials von 11.000 Jahren an.

\section{Bemerkungen}

Die Diskussion um die Möglichkeit, dass Pollensequenzen vom Eem-Typ in unterschiedlicher stratigraphischer Position auftreten könnten (z.B. Funrmann 1989), ist irreführend. Aufgrund der Beziehungen zwischen Lithostratigraphie und Biostratigraphie in der Typusregion und im gesamten Gebiet der nordischen Vereisung existiert nur ein Interglazial zwischen Drenthe und Frühweichsel, das Eem. Dies betrifft auch die Einstufung des Interglazials von Neumark-Nord (entgegen der Interpretation von SEIFERT 1990 sowie MANIA 1990). Die Korrelation der lokalen Pollenzonen von Neumark-Nord mit Pollenzonen typischer Eem-Folgen ist unproblematisch (vgl. LiтT 1994). Wie in der Typusregion der Eem-Warmzeit in den Niederlanden befinden sich auch in Neumark-Nord die interglazialen Sedimente unmittelbar über der Drenthe-Moräne, und sie werden von keinen weiteren saalezeitlichen glaziären Sedimenten überdeckt. Der Begriff „Treene-Warmzeit“ als Stratotyp zwischen Drenthe und Warthe im Sinne von PICARD (1959) ist auch hinfällig geworden. Erneute Untersuchungen am Typusprofil der sog. Treene-Warmzeit bei Husum zeigen, dass sie ein Pseudonym der Eem-Warmzeit ist (Menke 1985). ERD (1970) führte die sog. Uecker-Warmzeit als neuen interglazialen Stratotyp ein und korrelierte sie mit der sog. Treene-Warmzeit. Die Ablagerungen liegen jedoch nicht zwischen saalezeilichen Grundmoränen, sondern zwischen glazigenen Sedimenten der Elster- und Weichsel-Kaltzeit. Nachuntersuchungen von Hermsdorf \& StraHL (2006) verdeutlichen, dass es sich um eine lagerungsgestörte Folge handelt. Auch die Vegetationsabfolge ist dadurch verfälscht. Offenbar handelt es sich um gestörte eemzeitliche Sedimente. Somit ist die Ausweisung des Röpersdorfer Profils als „Locus typicus“ eines neuen Warmzeittyps ebenfalls abzulehnen.

\section{Weichsel-Kaltzeit \\ (Syn.: Weichsel-Eiszeit, Weichsel-Zeit, Weichsel-Komplex, Weichsel-Glazial)}

\section{Definition, Erstbeschreibung}

Die Bezeichnung „Weichsel-Eiszeit“ geht wahrscheinlich auf einen Vorschlag von KeILHACK zurück (s. Woldstedt 1928). Seit 1909 wird sie bei den Kartierern der Preußischen Geologischen Landesanstalt verwendet und erscheint in Publikationen des Staatlichen Geologischen Dienstes (HARBORT, Monke \& Stoller 1909, Legende zum Blatt Ebstorf, Lieferung 156, der Geologischen Karte von Preußen und benachbarten Ländern), desgleichen in der dazu gehörenden Erläuterung aus dem Jahre 1911 (Erläut. z. geol. Kt. Blatt Ebstorf usw., S. 17 und 27). Von KeILHack (1910) wird sie bei der lithostratigraphischen Gliederung von vier Bohrungen im SW von Berlin gemeinsam mit den Bezeichnungen Saale- und Elster-Eiszeit verwendet.

\section{Typuslokalität, Typusregion}

Der Name wurde offenbar bezogen auf das untere Weichseltal, wo Ablagerungen der Weichsel-Eiszeit über marinen Ablagerungen des ,letzten Interglazials“ liegen.

Eine Neudefinition erfolgte durch WoLDSTEDT (1929) unter Begrenzung auf das glazialmorphologisch definierte Jungmoränengebiet.

Typusregion: Unteres Weichseltal (INQUA-SEQS 1979; MeYER 1981). Ein Typusprofil wurde nicht benannt.

\section{Vergleichbare Profile, Verbreitung}

Im Gebiet der nordeuropäischen Vereisungen und im begleitenden periglaziären Gürtel gehören alle Ablagerungen zwischen der Eem-Warmzeit und dem Holozän zur Weichsel-Kaltzeit. Glaziäre Ablagerungen bedecken weite Teile Skandinaviens und umgreifen in einem breiten Gürtel die heutige Ostsee (Jungmoränengebiet). 
Für den westlichen Teil des Verbreitungsgebietes wurde vom Geologischen Landesamt SchleswigHolstein das Lübecker Becken als Paratypus-Region vorgeschlagen, wo eine vielschichtige Sequenz weichselzeitlicher Ablagerungen zwischen marinen Schichten des Eems und des Holozäns liegen. Weitere vergleichbare Vorkommen finden sich südlich von Wismar und Rostock (RÜHBERG et al. 1995).

\section{Datierung}

Die Weichsel-Kaltzeit umfaßt MIS 5d bis MIS 2 und entspricht damit dem Zeitraum von ca. 115.000 bis ca. 11.600 Jahren v.h. (DANSGAARD et al. 1993, LitT et al. 2001, RASMUSSEN et al. 2006).

\section{Bemerkungen}

Nach längerer Diskussion, wohin das Fläming-Stadium zu stellen sei - zur Saale- oder zur Weichseleiszeit, oder etwa eine eigene Eiszeit sein könnte - entschied sich WoLDSTEDT (1928) (Internationaler Geologenkongress in Kopenhagen), die Grenze des weichselzeitlichen Gebietes an den Rand des Landschaftsteiles mit den offenen Seen zu legen. Hiermit wählte er eine Grenzziehung, die bereits viel früher Klockmann (1884) und Geikie (1894: pl.X) vornahmen, die das Fläming-Stadium damit zur vorletzte n V e r e is ung stellten.

Im neueren Schrifttum wird zunehmend der Begriff „Weichsel-Kaltzeit“ benutzt, um damit zu verdeutlichen, dass die eigentliche Eiszeit mit Gletscherablagerungen im Großteil des Gebietes mit weichselzeitlichen Sedimenten nur einen relativ kurzen Zeitraum der gesamten Kaltzeit einnimmt. Außerdem sind einige wärmere Abschnitte (Interstadiale) in der Weichsel-Zeit eingeschaltet. Von einigen Wissenschaftlern wird diese Zeit deshalb „Weichsel-Komplex“ genannt. Dem Weichsel-Glazial entspricht das Würm-Glazial des alpinen Bereiches.

(STEPHAN)

\section{Herning-Stadial (WF I)}

\section{Definition, Erstbeschreibung}

Das Herning-Stadial stellt die erste Kaltphase nach dem Eem und damit den Beginn des Weichselglazials dar. In Mitteleuropa war das Herning weitgehend unbewaldet. Nach oben schließt sich das Brörup an. Erstmals als „Herning-Stadial“ benannt wurde es von ANDERSEN (1980) nach der bereits von JeSSEN \& Milthers (1928) untersuchten Lokalität Herning in Mittel-Jütland/Dänemark. Beschrieben wurde es als noch unbenanntes Kryomer von ANDERSEN (1961).

\section{Typuslokalität}

Typuslokalität ist Brörup Hotel Bog, als Typusprofil hat die dortige Bohrung BP 1 (STA) mit dem zugehörigen Pollendiagramm zu gelten (ANDERSEN 1961).

\section{Vergleichbare Profile, Verbreitung}

An mehreren Lokalitäten liegen zwischen Eem und Brörup limnische pollenführende Sedimente vor, so u.a. in Rederstall (Menke \& Tynni 1984), Oerel (Behre \& Lade 1986) und Groß Todtshorn (CASPERs \& FREUND 1997) sowie in Mitteldeutschland in Gröbern (LiTT 1994). Das gleiche gilt für Süddeutschland, wo das in Grande Pile (Ostfrankreich) als Melisey I benannte Stadial dem Herning entspricht.

\section{Datierung}

Das Herning-Stadial entspricht dem MIS 5d.

\section{Bemerkungen}

Das von ANDERSEN $(1961,1980)$ innerhalb des Herning abgegrenzte baumlose Rodebaek-Interstadial ließ sich in Deutschland bisher nicht nachweisen. 


\section{Amersfoort-Interstadial}

\section{Definition, Erstbeschreibung}

Das „Amersfoort-Interstadial“ wurde erstmals von ANDERSEN et al. (1960) benannt und von ZAGWIJN (1961) beschrieben. Es stellt den Beginn des ersten großen Unterweichsel-Interstadials mit Birkenund Kiefernwäldern dar und wurde von den damaligen Autoren als getrennt vom folgenden Brörup gesehen. In mehreren Unterweichselprofilen liegt zwischen dem Amersfoort und dem Brörup s.str. eine Abkühlungsphase, die jedoch noch bewaldet war, in anderen fehlt diese. Die inzwischen zahlreichen Untersuchungen ließen das Amersfoort als die Frühphase des Brörup erkennen, die nur in Profilen mit deutlichem Klimarückschlag noch nomenklatorisch als Amersfoort vom Brörup im engeren Sinne abgetrennt wird. Damit ist das Amersfoort kein eigenständiges Interstadial mehr.

\section{Typuslokalität}

Typuslokalität für das Amersfoort ist Amersfoort Tunnel Pit in den Niederlanden, Typusprofil die Bohrung 3, in der es als Torf ausgebildet ist (ZAGWIJN 1961).

\section{Vergleichbare Profile, Verbreitung}

In Brörup-Profilen Westeuropas, die eine klimatische Dreiteilung aufweisen, wird die untere Wärmephase vielfach noch als Amersfoort bezeichnet.

\section{Datierung}

Das Amersfoort-Interstadial fällt in den Beginn des marinen Isotopenstadiums MIS 5c.

\section{Bemerkungen}

Die früher vorgenommene Korrelation des Amersfoort mit einem unbewaldeten Rodebaek-Interstadial in Dänemark ist entfallen.

(BEHRE)

\section{Brörup-Interstadial (WF II)}

\section{Definition, Erstbeschreibung}

Das Brörup-Interstadial stellt das erste große Unterweichsel-Interstadial dar. Die Erstbeschreibung erfolgte durch ANDERSEN (1957, 1961). Der Begriff „Brörup-Interstadial“ erscheint erstmals bei ANDERSEn et al. (1960). Nach den Pollenanalysen ist das Brörup in Dänemark und Norddeutschland (vgl. Punkt 3) durch boreale Mischwälder gekennzeichnet, in denen zunächst für längere Zeit Baumbirken, danach für etwa ebenso lange Zeit Waldkiefern vorherrschen. Wichtig sind auch erhebliche Anteile an Fichte und Lärche sowie geringere von Erle. Wärmeliebende Bäume fehlen.

\section{Typuslokalität}

Die Typuslokalität ist das Brörup Hotel Bog in Mitteljütland/Dänemark, wo sie bereits von JESSEN \& Milthers (1928: Taf. XIII) entdeckt worden ist. Typusprofil ist BP 1 (STA) (ANDERSEN 1957, 1961).

\section{Vergleichbare Profile, Verbreitung}

In Nordwestdeutschland ist das Brörup an zahlreichen Stellen angetroffen worden, in optimaler Form als bis zu über $1 \mathrm{~m}$ mächtiger Torf (vgl. die Karte bei CASPERS \& FREUND 1997). Besonders vollständig ist es in Odderade (Averdieck 1967, 1998), Osterwanna (BeHre 1974) und Rederstall (MeNKE \& TYNNI 1984) sowie in Mitteldeutschland in Gröbern (LiTT 1994) und in der Niederlaustz in Kittlitz (ERD 1973). Darüber hinaus ist es in Süddeutschland sowie in anderen europäischen Ländern verbreitet. In Frankreich entspricht es dem St.Germain I, in dem die wärmeliebenden Arten bereits eine große Rolle spielen. 


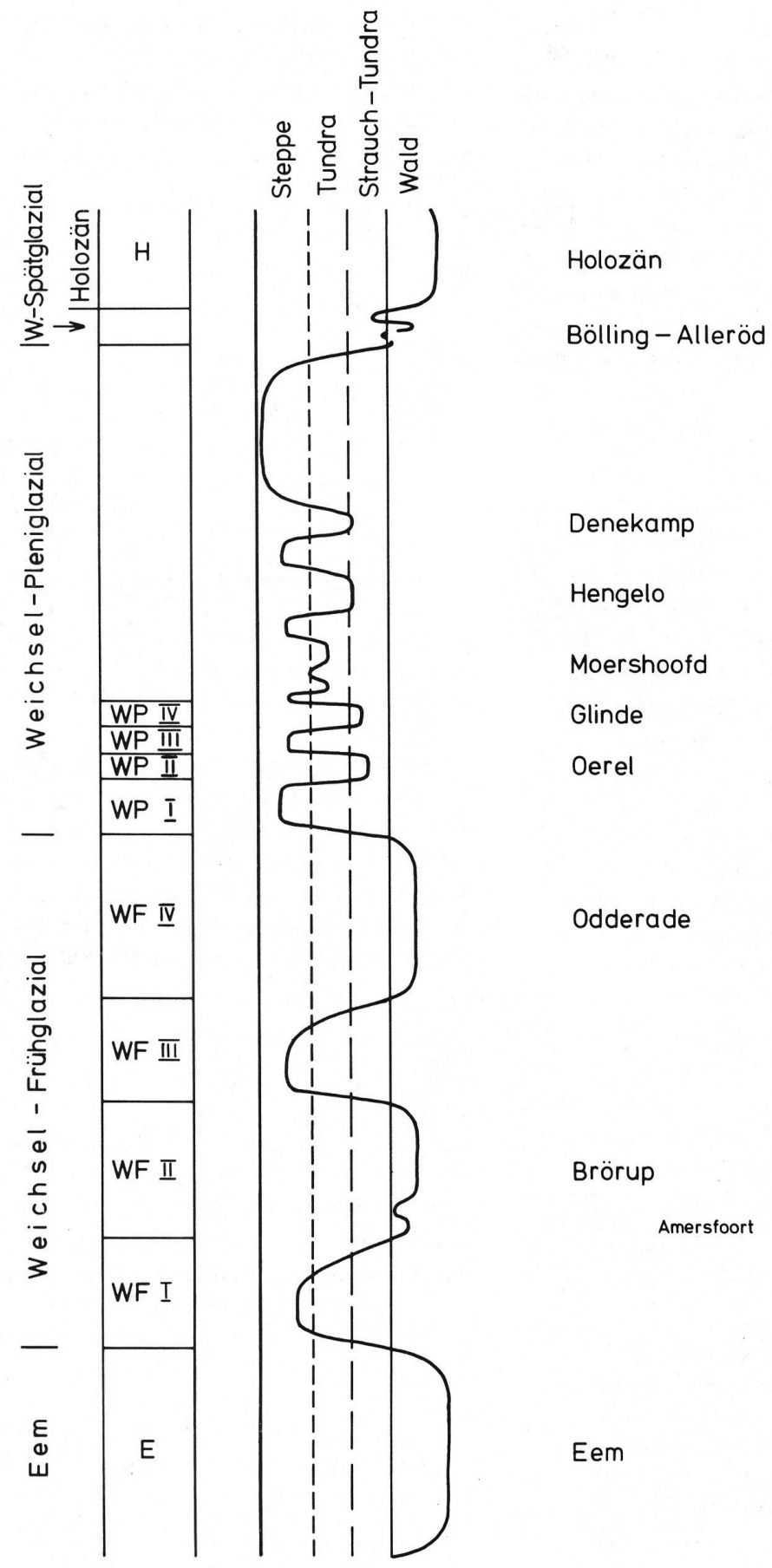

Abb. 5: Schematische Darstellung des Vegetationscharakters im norddeutschen Tiefland während des Jungpleistozäns und Holozäns (aus BEHRE \& LADE 1986).

Fig. 5: Schematic diagram of the stratigraphy and vegetation development in northern Germany during the Young Pleistocene and Holocene (after BeHRE \& LADE 1986). 


\section{Datierung}

Das Brörup-Interstadial repräsentiert im terrestrischen Bereich das marine Isotopenstadium MIS 5c. Jahresschichtenzählungen aus einem Teilbereich der Kieselgur in Rederstall lassen auf eine Gesamtdauer des Brörup zwischen 5.800 und 10.500 Jahren schließen (GRÜGER 1991). Wegen Unvollständigkeit der Profile ist eine genauere Bestimmung der Dauer unmöglich.

\section{Bemerkungen}

Die bereits Interglazial-ähnliche Ausbildung des St. Germain I in SO-Frankreich (Grande Pile) hat längere Zeit zu Diskussionen im Hinblick auf eine Gleichzeitigkeit geführt. Die Korrelierung von Brörup und St. Germain I kann inzwischen jedoch als gesichert gelten.

(BEHRE)

\section{Rederstall-Stadial (WF III)}

\section{Definition, Erstbeschreibung}

Das Rederstall-Stadial wurde erstmals von Menke (in Stremme \& Menke 1980) als das zwischen den Interstadialen Brörup und Odderade liegende Stadial definiert, näher beschrieben wurde es dann von Menke \& Tynni (1984). Es handelt sich überwiegend um Sandlagen, die meist erheblich mächtiger sind als die der vorangegangenen und nachfolgenden Stadiale und in diesem Zeitbereich offenbar vegetationsfrei waren. Der jüngere Teil des Stadials wird mehrfach von pollenführenden Mudden eingenommen, die Analysen weisen dort auf eine Grastundra mit späterem Übergang zur Strauchtundra hin.

\section{Typuslokalität}

Typuslokalität ist das Profil Rederstall I in Rederstall, Kreis Dithmarschen (MenKe \& Tynni 1984). Dort liegt das Stadial in sandiger Form zwischen den als Kieselgur ausgebildeten Interstadialen Brörup und Odderade.

\section{Vergleichbare Profile, Verbreitung}

Das Rederstall ist in Norddeutschland und darüber hinaus überall nachweisbar, wo Odderade in Superposition über Brörup liegt. Besonders genannt seien Odderade (AvERDIECK 1967, 1998), Oerel (BeHRE \& LADE 1986), Groß Todtshorn (CASPERs \& FREUnd 1997) und in Mitteldeutschland Gröbern (LitT 1994).

\section{Datierung}

Mit numerischen Methoden der Altersbestimmung ermittelte absolute Daten liegen nicht vor. Nach Pollenanalysen ist von einer Zuordnung zu MIS 5b auszugehen.

\section{Bemerkungen}

Durch die regelmäßige definitionsgerechte Position zwischen den Interstadialen Brörup und Odderade ist die Existenz dieses Stadials gesichert.

\section{Odderade-Interstadial (WF IV)}

\section{Definition, Erstbeschreibung}

Das Odderade-Interstadial ist das zweite große Unterweichsel-Interstadial. Es wurde von AvERDIECK (1963) erstmals benannt und von AvERDIECK (1967) beschrieben. Es ist meist als Torf ausgebildet, der zwischen stadialen Sandschichten eingebettet ist. Die Pollendiagramme zeigen für Norddeutschland einen borealen Wald, der mit einer kurzen Baumbirkenphase einsetzt und anschließend von der Kie- 
fer beherrscht wird. Lärche und Fichte sowie sehr wenig Erle sind ebenfalls vertreten. Im Gegensatz zum Brörup breiten diese sich erst in der Kiefernphase aus. Mit dem Odderade-Interstadial endet das Unterweichsel.

\section{Typuslokalität, Typusregion}

Die Typuslokalität liegt bei dem Dorf Odderade im Kreis Dithmarschen, als Typusprofil ist die Bohrung Odderade 5 mit dem Pollendiagramm von AvERDIECK (1967) (Neubearbeitung AvERDIECK 1998) zu nennen. An der Profilstelle liegt das Odderade als Torf mit einer Mächtigkeit von 0,95 m in Superposition über Eem und Brörup, von letzterem durch eine über $1 \mathrm{~m}$ mächtige Sandschicht getrennt. Das Odderade-Interstadial von der gleichen Stelle wurde von DÜCKER (1967) als Nordhastedt-Interstadial bezeichnet. In gleicher Position und ähnlicher Ausbildung sowie mit fast gleichen Pollendiagrammen wurde das Odderade inzwischen an verschiedenen Orten Nordwestdeutschlands nachgewiesen; genannt seien Rederstall (MenKe \& Tynni 1984), Oerel (Behre \& LADE 1986) und Groß Todtshorn (CASPERS 1997).

\section{Vergleichbare Profile, Verbreitung}

Neben den verschiedenen Vorkommen in Nordwestdeutschland wurde das Odderade in guter Ausbildung in Mitteldeutschland in Gröbern (LiTT 1994) und in der Niederlausitz in Kittlitz (ERD 1973) nachgewiesen. Ebenso wurde es in Süddeutschland, der Schweiz und Ostfrankreich mehrfach gefunden, dort aber mit z.T. viel wärmeliebenden Gehölzen. Als Bezeichnung wird dort z.T. ebenfalls Odderade oder auch nach französischem Vorbild St. Germain II benutzt (vgl. u.a. WeLTEN 1981, WoilLard 1975).

\section{Datierung}

Aus den Profilen von Oerel in Nordwestdeutschland gibt es vom Ende des Odderade-Interstadials zwei konventionelle ${ }^{14} \mathrm{C}$-Daten um $60.000{ }^{14} \mathrm{C}$-Jahre v.h. (Behre \& van Der Plicht 1992), die als Minimalwerte anzusehen sind. Nach der MIS-Zeitskala endete das Odderade-Interstadial um 74.000 Jahre v.h. entsprechend MIS 5a.

\section{Bemerkungen}

Während im eigentlichen Mitteleuropa das Odderade den Charakter eines bewaldeten Interstadials hat, kommt es bereits in Ostfrankreich (Grande Pile) einem von wärmeliebenden Bäumen geprägten Interglazial nahe, was lange Zeit zu Verwirrungen geführt hat.

(BeHRE)

\section{Schalkholz-Stadial (WP I)}

\section{Definition, Erstbeschreibung}

Das Schalkholz-Stadial ist als die zwischen dem Odderade- und dem Oerel-Interstadial liegende Kaltphase definiert, die als meist pollenfreie Sandschicht auftritt und zumindest in Norddeutschland eine vegetationslose Phase repräsentiert. Erstmals beschrieben wurde sie durch MenKe (in Stremme \& MenKe 1980). Mit dem Schalkholz-Stadial beginnt das Mittelweichsel.

\section{Typuslokalität, Typusregion}

Die Typuslokalität ist Schalkholz, Kreis Dithmarschen. Dort liegt die entsprechende Schicht auf einem Boden des Odderade-Interstadials und unter einem Boden, der von Menke (in Stremme \& Menke 1980) als Keller-Interstadial beschrieben und dem Oerel-Interstadial gleichgesetzt wurde. Da wegen mangelnder absoluter Datierung diese Gleichsetzung nicht völlig zwingend ist, muss eine Paratypuslokalität mit sicherem Oerel über Odderade und dazwischen liegenden stadialen Sanden benannt werden; als solche wurde Oerel gewählt, das auch Typuslokalität für das Oerel-Interstadial ist (BEHRE \& LADE 1986, Behre 1989). 


\section{Vergleichbare Profile, Verbreitung}

Das Schalkholz-Stadial ist in Nordwestdeutschland an allen Fundorten von Oerel über Odderade nachweisbar (CASPERS \& FREUnd 1997). Darüber hinaus bildet es in der Regel die Basis der über dem Odderade liegenden pleistozänen Sedimente.

\section{Datierung}

Nach den konventionellen ${ }^{14} \mathrm{C}$-Daten des Oerel-Interstadials endete das Schalkholz-Stadial vor $57.700{ }^{14}$ C-Jahre v.h. (Behre \& van Der Plicht 1992), entsprechend MIS 4.

\section{Bemerkungen}

Durch die regelmäßige definitionsgerechte Position zwischen den Interstadialen Odderade und Oerel ist die Existenz dieses Stadials gesichert.

(BEHRE)

\section{Oerel-Interstadial (WP II)}

\section{Definition, Erstbeschreibung}

Das Oerel-Interstadial wurde von BEHRE \& LADE (1986) als solches benannt und eingehend beschrieben. Der zugehörige Torf wurde vorher bereits von Selle \& SchneEkLoth (1965) entdeckt und als „oberes Interstadial von Oerel“ bezeichnet. Es handelt sich an der Typuslokalität um einen in sandige Sedimente eingeschalteten reinen Nieder- bis Hochmoortorf von $80 \mathrm{~cm}$ Mächtigkeit. Das Pollendiagramm weist auf eine baumfreie Strauchtundra.

\section{Typuslokalität}

Typuslokalität ist die Senke von Oerel bei Bremervörde im Kreis Rotenburg/Wümme. Dort wurde ein drenthezeitliches Toteisloch aufgefüllt; über dem Eem liegen hier vier weichselzeitliche Interstadiale in Superposition, von denen das Oerel das dritte ist. Typusprofil ist OE 61 mit den Pollendiagrammen von BEHRE \& LADE (1986).

\section{Vergleichbare Profile, Verbreitung}

Dem Oerel vergleichbare Interstadiale wurden in gleicher Position in Norddeutschland inzwischen mehrfach gefunden. Dabei entwickelte sich im $50 \mathrm{~km}$ entfernten Groß Todtshorn die Stratigraphie in gleicher Weise bis zum Hochmoortorf (CASPERS 1997). Auf Grund der vergleichbaren geologischen Position ist das Oerel wahrscheinlich mit dem von MenKe (1976) aus Schleswig-Holstein als „Keller-Interstadial“" beschriebenen Boden zeitgleich. In Süddeutschland entsprechen dem Oerel wahrscheinlich die Vorkommen des Dürnten-Interstadials (nach WeLten 1982), z.B. in Samerberg (GRÜGER 1979). Dort ist dieses Interstadial jedoch bereits bewaldet (vgl. hierzu Welten 1981, Behre 1989).

\section{Datierung}

Vom Typusprofil in Oerel liegen sechs dicht beieinander liegende konventionelle Radiokarbondaten vor, nach denen dieses Interstadial in den Zeitraum zwischen 53.500 und $57.700{ }^{14} \mathrm{C}$-Jahren v.h. fällt (Behre \& van Der Plicht 1992). Es ist das erste Interstadial (WP II) im Mittelweichsel und fällt an den Beginn des MIS 3.

\section{Bemerkungen}

Da das Oerel-Interstadial wie auch das Dürnten fast immer in Superposition über dem Odderade-Interstadial gefunden wurde, lässt sich ein dazwischen liegendes weiteres Interstadial weitgehend ausschließen. 


\section{Ebersdorf-Stadial (WP III)}

\section{Definition, Erstbeschreibung}

Das Ebersdorf-Stadial ist durch die zwischen den Interstadialen Oerel und Glinde liegende Sandschicht gekennzeichnet, die keine autochthonen Pollen führt. Es wurde von BeHRE \& LADE (1986) beschrieben und nach einem Dorf in der Gemeinde Oerel benannt.

\section{Typuslokalität}

Typuslokalität ist Oerel bei Bremervörde im Kreis Rotenburg/Wümme. Dort beträgt die Mächtigkeit der Ebersdorf-Schicht bis zu 1,5 m (BeHRE \& LADE 1986).

\section{Vergleichbare Profile, Verbreitung}

Der untere Teil der hangenden Sande über weiteren in Nordwestdeutschland bekannten Oerel-Vorkommen (CASPERS \& FREUND 1997) dürfte in das Ebersdorf-Stadial gehören.

\section{Datierung}

Nach konventionellen ${ }^{14} \mathrm{C}$-Daten der liegenden und hangenden Interstadiale (Oerel bzw. Glinde) an der Typuslokalität Oerel fällt das Ebersdorf-Stadial in den Zeitraum zwischen 53.500 und $51.500{ }^{14} \mathrm{C}$ Jahren v.h. (BEHRE \& VAN DER Plicht 1992), entsprechend MIS 3.

\section{Bemerkungen}

Durch die klare Position zwischen den Interstadialen Oerel und Glinde ist das Ebersdorf-Stadial eindeutig festgelegt.

(BeHRE)

\section{Glinde-Interstadial (WP IV)}

\section{Definition, Erstbeschreibung}

Das Glinde-Interstadial ist das jüngste in der langen Oberpleistozän-Sequenz von Oerel und wurde von dort durch BeHRe \& LADE (1986) beschrieben. Der Name kommt von einer Ortschaft in der Gemeinde Oerel. Es wird dort durch einen reinen Niedermoortorf mit wenig rein organischer Mudde im Hangenden in einer Gesamtmächtigkeit von $26 \mathrm{~cm}$ repräsentiert. Das Pollendiagramm zeigt eine baumlose Strauchtundra.

\section{Typuslokalität}

Typuslokalität des Glinde ist der bisher einzige sichere Fundplatz in der Senke von Oerel bei Bremervörde im Kreis Rotenburg/Wümme. Dort liegt es in der Füllung eines drenthezeitlichen Toteislochs als letztes von vier Interstadialen in Superposition über dem Eem und wird im Liegenden und Hangenden durch Sande begrenzt. Typusprofil ist das Profil OE 61 mit dem zugehörigen Pollendiagramm in BEHRE \& LADE (1986).

\section{Vergleichbare Profile, Verbreitung}

Bislang sind in Deutschland Interstadiale im Zeitbereich des Glinde nicht bekannt geworden. Wegen des gleichen Radiokarbonalters könnte das im ostfranzösischen Grande Pile beschriebene Pile-Interstadial (Woillard 1975, Woillard \& MooK 1982) dem Glinde entsprechen.

\section{Datierung}

Vom Typusprofil in Oerel gibt es fünf dicht beieinander liegende konventionelle ${ }^{14} \mathrm{C}$-Daten, nach denen das Glinde-Interstadial in die Zeit vor 48.700 und $51.550{ }^{14} \mathrm{C}$-Jahre v.h. fällt (BEHRE \& VAN Der Plicht 1992). Es ist das zweite Mittelweichsel-Interstadial (vgl. Behre 1989) und entspricht dem Abschnitt WP IV des marinen Isotopenstadiums 3. 


\section{Bemerkungen}

Durch die Bildung von reinem Torf und die klare Abgrenzung zu liegenden und hangenden Sanden ist das Glinde als eigenständiges Interstadial gekennzeichnet.

(BEHRE)

\section{Moershoofd-Interstadial}

\section{Definition, Erstbeschreibung}

Der Begriff „Moershoofd-Interstadial“ wurde erstmals von ZAGWIJN \& PAEPE (1968) für einen torfigen Lehmhorizont benutzt und dabei grob beschrieben. Danach ist es eine „Klimaverbesserung, die sich zwar pollenanalytisch nicht eindeutig hat nachweisen lassen...". Der Name bezieht sich dabei auf die bereits von ZAGwiJn (1961) untersuchte Lokalität bei Moershoofd. Die Pollenanalysen von dort weisen auf baumlose Tundrenvegetation mit sehr hohen Werten von Cyperaceen.

\section{Typuslokalität, Typusregion}

Obwohl die Erstbeschreibung als Interstadial mit dem Profil De Liendert bei Amersfoort/Niederlande verknüpft ist, muss als Typuslokalität Moershoofd im äußersten Süden der Niederlande an der Grenze nach Belgien gelten, von der auch das erste Pollendiagramm stammt (vgl. ZAGWIJN 1961).

\section{Vergleichbare Profile, Verbreitung}

Gute Profile fehlen; humose Lagen, vor allem aus mehreren Plätzen der Niederlande, die nach den ${ }^{14} \mathrm{C}$-Daten in den Zeitbereich passen, werden oft als „Moershoofd“ angegeben, z.B. aus Duckenburg bei Nijmwegen, wo ein Pollendiagramm aus einem Torf von sehr hohen Cyperaceen-Werten geprägt ist (Teunissen \& Teunissen-VAn OORschot 1974).

\section{Datierung}

In der Erstbeschreibung wird der Sedimentationszeitraum mit $>50.000$ bis $43.000{ }^{14} \mathrm{C}$-Jahre v.h. angegeben (Lokalität De Liendert; ZAGwIJN \& PAEPE 1968). Aus Moershoofd selber liegen konventionelle ${ }^{14} \mathrm{C}$-Daten von $43.500 \pm 1.000$ und $46.250 \pm 1.500{ }^{14} \mathrm{C}$-Jahren v.h. vor (ZAGWIJN 1961, Daten korrigiert nach VAN DER HAMmEN et al. 1967). Wegen des hohen Alters ist von Minimalwerten auszugehen. Sicher ist die Zuordnung zu MIS 3.

\section{Bemerkungen}

Wegen der unscharfen Begrenzungen und einer wahrscheinlichen Unterbrechung in der Mitte wird in der jüngeren Literatur meist nur noch von einem Moershoofd-Interstadial-Komplex gesprochen. Da in dieser Periode eine deutliche Erwärmung pollenanalytisch kaum fassbar ist und die hier untergebrachten humosen Schichten auch zeitlich divergieren, sind die Vorkommen als lokal an edaphisch zeitweise günstigen Stellen entstanden aufzufassen (VAndenberghe 1985, VANDEnBerghe \& van Huissteden 1989). Der Begriff „Moershoofd-Interstadial“ bzw. -komplex sollte deshalb fallen gelassen werden.

(BEHRE)

\section{Hengelo-Interstadial}

\section{Definition, Erstbeschreibung}

Die Benennung des „Hengelo-Interstadials“ mit zunächst grober Beschreibung erfolgte durch VAN DER HAMmen et al. (1967). Danach ist es charakterisiert durch eine Lage von humoser Schluffmudde in einer Lehmschicht des oberen Mittelweichsel. Eine genauere Beschreibung mit Pollendiagrammen erfolgte später durch ZAGWIJN (1974c). In den Pollendiagrammen herrschen Cyperaceen weit vor, ein deutlicher Gipfel von (Zwerg-)Birke weist auf eine vorübergehende Strauchphase in der baumlosen Tundra. 


\section{Typuslokalität}

Die Typuslokalität liegt im Becken von Hengelo in den östlichen Niederlanden und damit dicht bei, aber außerhalb Deutschlands.

\section{Vergleichbare Profile, Verbreitung}

In den Niederlanden gibt es mehrere Vorkommen, die dem Hengelo zugeordnet werden. Ebenso wie bei den gelegentlichen dorthin gestellten Fundstellen in den benachbarten Ländern erfolgt die Einordnung in dieses Interstadial allerdings nur anhand von Radiokarbondaten, da die meist von den Cyperaceen dominierten Pollendaten nicht spezifisch sind und eine Superposition der Vorkommen mit anderen Interstadialen in der Regel nicht gegeben ist.

\section{Datierung}

Von der Typuslokalität liegt für den Beginn des Hengelo-Interstadials (van DER HAMmEN et al. 1967) ein konventionelles ${ }^{14} \mathrm{C}$-Alter von $38.700 \pm 400$ Jahren v.h. vor ( GrN 2504). Nach weiteren ${ }^{14} \mathrm{C}$-Daten verschiedener Autoren wurde das Hengelo-Interstadial auf die Zeit zwischen 39.000 und $36.000{ }^{14} \mathrm{C}-$ Jahren v.h. eingeengt. Eine klare Abgrenzung nach unten und oben im MIS 3 ist aber nicht gegeben.

\section{Bemerkungen}

In den Niederlanden gibt es eine größere Zahl von Mittelweichsel-Vorkommen, deren Radiokarbondaten weit streuen, wobei zwischen 36.000 und 39.000 Jahren v.h. ein Maximum auftritt (RAN 1990). Reine Torfe sind dabei sehr selten, Superposition ebenfalls. U.a. VANDENBERGHE \& VAN Huissteden (1985) nehmen deshalb an, dass die humosen Lagen dieser Vorkommen nur der Ausdruck zeitweiliger besserer und lokal begrenzter edaphischer Bedingungen waren und keine eigentlichen Interstadiale darstellen.

(BEHRE)

\section{Denekamp-Interstadial}

\section{Definition, Erstbeschreibung}

Das Denekamp-Interstadial wurde erstmals von vAN DER HAMMEN et al. (1967) benannt und zunächst grob beschrieben. An der Typuslokalität besteht es aus Schluffmudde innerhalb der oberen Lehmschicht, in der Umgebung ist es auch als Torf ausgebildet. Kurze Pollendiagramme aus diesem Gebiet zeigen sehr hohe Cyperaceen-Werte, doch auch Betula (nana) ist vorhanden (vAN DER HAMMEN 1971). In dieser Zeit herrschte eine Tundra- bis Strauchtundravegetation.

\section{Typuslokalität, Typusregion}

Typusregion ist das Dinkeltal bei Denekamp in den östlichen Niederlanden dicht an der deutschen Grenze.

\section{Vergleichbare Profile, Verbreitung}

In den Niederlanden sind mehr oder weniger organogene Ablagerungen aus dieser Zeit mehrfach nachgewiesen worden. Da sie pollenanalytisch nicht eindeutig charakterisiert werden können, erfolgte die Zuordnung nach den jeweiligen Radiokarbondaten. Organische Lagen mit passenden ${ }^{14} \mathrm{C}$-Daten wurden auch in den Nachbarländern in dieses Interstadial gestellt.

\section{Datierung}

Die ersten Radiokarbondaten aus der Typusregion lagen bei $30.100 \pm 300$ und $29.300 \pm 300{ }^{14} \mathrm{C}$-Jahre v.h. (van DeR Hammen 1971). Nach weiteren Daten verschiedener Autoren wird das Denekamp jetzt zwischen 32.000 und $28.000{ }^{14} \mathrm{C}-J a h r e n$ v.h. angenommen ohne klare Abgrenzung nach unten und oben. Nach den marinen Isotopenstadien fällt dieser Zeitraum in MIS 3. 


\section{Bemerkungen}

Da die ${ }^{14} \mathrm{C}$-Daten organischer Lagen des oberen Mittelweichsel in den Niederlanden über einen groBen Zeitbereich streuen (vgl. RAN 1990) und nur schwache Häufungen etwa wie beim Denekamp zeigen, ist die Existenz des Denekamp-Interstadials wie auch der Interstadiale Hengelo und Moershoofd umstritten, zumal sie alle fast nie in einem Profil und nur selten als reine Torfe vorkommen. Nach VANDENBERghe (1985) und VANDENBERghe \& VAn Huissteden (1989) handelt es sich um lokale Bildungen an edaphisch, zeitweise günstigen Stellen, die keine allgemeine Klimaverbesserung anzeigen.

(BEHRE)

\section{Brandenburg-Phase \\ (Syn.: Brandenburgische Phase, Brandenburger Stadium)}

\section{Definition, Erstbeschreibung}

Ursprünglich morphostratigraphischer Begriff (Endmoränenlage), von WoLDSTEDT (1926: 175) „Brandenburgische Phase“ genannt. 1928 zum Zweck der Angleichung an die im alpinen Raum übliche Terminologie umbenannt zu „Brandenburger Stadium“(WoldstedT 1928: 231).

\section{Typuslokalität, Typusregion}

WoLDSTEDT (1926: 175) gibt als Typusregion das Land Brandenburg an, wo die Endmoräne besonders gut ausgeprägt sei und dort ,nahe südlich der Stadt Brandenburg“verläuft.

\section{Verbreitung}

Nach Woldstedt (1926: 177, Karte; 1958: 119, Abb. 37) wäre die Endmoränenlage nach Osten hin über Polen und Litauen bis nach Nordrussland verfolgbar. Nach neueren polnischen Arbeiten liegen aber östlich von Konin bis nach Weißrussland entsprechende Ablagerungen unter denen der FrankfurtPhase, die dort den weichselzeitlichen Außenrand bildet (Marks 2002, Poznan-Phase). Nach Westen hin soll nach WoldstedT (1926) die Endmoräne (und die dazu gehörende Grundmoräne) ebenfalls noch östlich der Elbe nach Norden abbiegen und unter den Ablagerungen der Frankfurt-Phase liegen. Dies kommt geschiebestatistischen Ableitungen von LÜTTIG (2005) nahe, der die westliche Grenze der Grundmoräne im Raum Perleberg zieht. Sie soll sich von dort unter den Ablagerungen der FrankfurtPhase in Richtung Rerik hinziehen.

Eine gegenüber der Darstellung in der geologischen Karte 1:500.000 von Mecklenburg-Vorpommern entsprechend deutlich größere Ausdehnung des weichselzeitlich vergletscherten Gebietes bis in den Raum Perleberg-Pritzwalk wird bereits bei MüLLER et al. (1993) diskutiert.

LiEDTKE (1981: Abb. 10) zieht die Randlage von Brandenburg über Mecklenburg und Schleswig-Holstein bis Jütland durch. Im Norden Schleswig-Holsteins wird nach WoLDSTEDT (1928) die äußerste Verbreitungsgrenze weichselzeitlicher Ablagerungen stellenweise aber von deutlich jüngeren Vorstößen erreicht. In Dänemark soll nach WoLDSTEDT (1926) wieder das Eis der Brandenburg-Phase (zusammen mit dem der Frankfurt-Phase) die weichselzeitliche Außengrenze bilden.

In Westmecklenburg (Geol. Karte 1: 500.000 von Mecklenburg-Vorpommern 2000) werden aus der Sanderoberfläche südlich der Frankfurt-Randlage (W1F) herausragende kleine Kuppen heute zur Brandenburg-Phase (W1B) gerechnet. Der Anschluss an die weichselzeitliche Moräne in Südostholstein ist bisher jedoch nicht abgesichert.

\section{Datierung}

Cepek (1965), Liedtke (1981: Abb. 7) und Kozarski (1995) nehmen ein Alter um 20.000 Jahren v.h. an. MARKs (2002) leitet aus ${ }^{14} \mathrm{C}$-Daten von letzten organischen Sedimenten unter den weichselglaziären Ablagerungen ein konventionelles ${ }^{14} \mathrm{C}$-Alter von $<21.000{ }^{14} \mathrm{C}$-Jahren ab. Das entspricht einem kalibrierten ${ }^{14} \mathrm{C}$-Alter von $<24.000$ Jahren v. h. (STUIVER et al. 1998). 


\section{Bemerkungen}

СЕРек (1965) charakterisiert die Geschiebegemeinschaft der Brandenburg- (und Frankfurt-) Phase und bezeichnet sie als W1. Nach LÜTTIG (2005) sind die Geschiebegemeinschaften beider Phasen aber verschieden und gut trennbar.

Die Verbindung zwischen der W1B-Randlage südöstlich von Schwerin und dem äußersten bekannten Vorkommen weichselzeitlicher Ablagerungen in Schleswig-Holstein wäre über die Linie Büchen - Schwanheide denkbar (StePHAn 1997). Die in dieser Außenlage bekannt gewordenen Grundmoränen scheinen aber eine Zusammensetzung zu haben, die sehr saalezeitlichen Geschiebemergeln ähnelt (W0-Grundmoräne nach U. MülLER 1996, 2004, vgl. RüHBERG et al. 1995, Ww bei RÜHBERG 1999).

(StephAN)

\section{Frankfurt-Phase \\ (Syn.: Frankfurter Stadium, Frankfurter Vorstoß, Posensche Phase)}

\section{Definition, Erstbeschreibung}

Ursprünglich morphostratigraphische Definition.

Der Begriff erscheint erstmals bei WoldSTEDT (1928: 232) und ersetzt den von WoLDSTEDT noch 1926 verwendeten Terminus „Posensche Phase“, um diese Vorstoßphase mit der älteren Brandenburger Phase und der jüngeren Pommerschen Phase in eine ,alphabetische Reihenfolge“ zu bringen. Zum Zwecke der Angleichung an die im alpinen Raum übliche Terminologie wurde von WoLDSTEDT (1928: 231) die Bezeichnung „Stadium“ gewählt.

\section{Typuslokalität, Typusregion}

WoLDSTEDT (1926: 178) beschreibt die Endmoräne „hart nördlich der Stadt Posen“ als Typus. Im Zusammenhang mit der Umbenennung definiert er die Endmoräne, die bei Frankfurt die Oder kreuzt, als namengebend (WoLDSTEDT 1929: 166).

\section{Verbreitung}

Nach Woldstedt $(1926,1958)$, ebenso Woldstedt \& Duphorn (1974) ist die Frankfurt-Phase von Jütland (Hauptstagnationslinie nach Ussing 1913) über Schleswig-Holstein und Mecklenburg (vgl. LüTTIG 2005) bis nach Pommern (Poznan-Phase) verfolgbar, wo sie sich streckenweise nicht mehr eindeutig von der Brandenburg-Randlage trennen lässt, bzw. sich mit jener vereinigt. Nach MARKS (2002), der jüngere polnische Arbeiten auswertet, bildet sie östlich von Konin bis mindestens nordöstlich von Grodno die maximale weichselzeitliche Außengrenze.

\section{Datierung}

KoZARSKI (1995) extrapoliert aus ${ }^{14} \mathrm{C}$-Daten, die aus Sedimenten im Liegenden der glaziären Ablagerungen gewonnen wurden, für die Randlage ein konventionelles ${ }^{14} \mathrm{C}$-Alter von ca. $18.800{ }^{14} \mathrm{C}$-Jahren v.h. Es entspricht dem kalibrierten ${ }^{14} \mathrm{C}-$ Alter (StUIVER et al. 1998) von 22.300 Jahren v.h. Nach MARKS (2005) wurde an organischem Material unter Ablagerungen des poznanzeitlichen Außenrandes nördlich Konin ein konventionelles ${ }^{14} \mathrm{C}$-Alter von $20.050{ }^{14} \mathrm{C}$-Jahren v.h. ermittelt. Das entspricht einem kalibrierten ${ }^{14} \mathrm{C}$-Alter von ca. 23.800 v.h. LÜTTIG (2005) gibt das konventionelle ${ }^{14} \mathrm{C}$-Alter einer unter frankfurtzeitlichen Sedimenten liegenden Mudde vom Segrahner Berg mit $28.000{ }^{14} \mathrm{C}-J$ ahren v.h. an. Ihr kalibriertes ${ }^{14} \mathrm{C}$-Alter ist nach StUIVER et al. (1998) ca. 32.000 v.h.

\section{Bemerkungen}

Das von KozARSKI (1995) für die Randlage angegebene ${ }^{14} \mathrm{C}$-Alter ist eine Abschätzung.

Zwischen Frankfurt- und Brandenburg-Phase liegt nach WoLDSTEDT (1929 und später) kein längerer Zeitabschnitt. СЕРЕK (1965) bestreitet die Existenz einer eigenen Grundmoräne. Entsprechend wäre 
die Frankfurt-Phase eigentlich als Staffel aus der Rückschmelzphase der Brandenburg-Phase anzusprechen (vgl. MARKs 2002, Poznan-Phase).

LÜtTIG (1999) meint jedoch, die Frankfurt-Phase geschiebekundlich von der Brandenburg-Phase und der Pommern-Phase abgrenzen zu können.

Die A-Moränen von GRIPP $(1949,1964)$ gehören wahrscheinlich weitgehend der Frankfurt-Phase an. Für die Endmoräne der Frankfurt-Phase ist im älteren Schrifttum häufig die Bezeichnung ,äußere baltische Endmoräne" zu finden.

(STEPHAN)

\section{Pommern-Phase \\ (Syn.: Pommersches Stadium, Pommerscher Vorstoß)}

\section{Definition, Erstbeschreibung}

Ursprünglich morphostratigraphische Definition.

Der Begriff wurde als „Pommersche Phase“ von WoldstedT (1925, erschienen 1926) eingeführt. Er bezeichnete damit die „letzte große zusammenhängende (Endmoränenbildungs-)Phase Norddeutschlands“. Die Umbenennung in „Pommersches Stadium“ erfolgte durch WoLDSTEDT (1928) zum Zweck der Angleichung an die im alpinen Raum übliche Benennung.

\section{Typuslokalität, Typusregion}

Woldstedt (1926: 179) gibt Pommern als Typusregion an. (,Sie zeigt in Pommern ihre schönste Entwicklung"). Eine Typuslokalität wurde nicht benannt.

\section{Verbreitung}

Als ausgeprägte Endmoränenbildung (und Grundmoränenablagerung) südlich der Ostsee soll die Pommern-Phase nach Woldstedt (1958: 119, Abb. 37) nach Nordosten bis in das Gebiet östlich Archangelsk verfolgbar sein. Die Fortsetzung nach Schleswig-Holstein und Dänemark ist umstritten. Der von WoldSTEDT (1958) und anderen Autoren in älteren Publikationen (u.a. GRIPP 1964) dargestellten Auffassung, dass sich die Pommersche Endmoräne um die Fördenenden in Schleswig-Holstein herum nach Norden an die „ostjütische Randlage“ Dänemarks anschließt, stehen geschiebekundliche Untersuchungen entgegen, nach denen diese Randlage in Dänemark einem späteren Gletschervorstoß (,jungbaltische Phase“") zuzurechnen wäre (ANDERSEn 1945, SMED 1997).

Schulz (1968) rechnet eine im westlichen Mecklenburg im Vorland der WoldstedTschen Pommerschen Endmoräne („Hauptendmoräne“) liegende Staffel zur Pommern-Phase. Ihre Grenze wird in der Geologischen Karte 1:500.000 von Mecklenburg-Vorpommern (2000) mit W2 ${ }_{\max }$ bezeichnet.

\section{Datierung}

Von der Haupteisrandlage der Pommern-Phase liegt nach LiEdTKe (1996) vom Gebiet der Oder ein konventionelles ${ }^{14} \mathrm{C}$-Alter von $15.200{ }^{14} \mathrm{C}$-Jahren v.h. vor. KozARSKI $(1995$ : 24, 41) extrapoliert aus ${ }^{14} \mathrm{C}$-Daten, die aus Sedimenten im Liegenden der weichselglaziären Ablagerungen gewonnen wurden, für die Pommern-Randlage ein konventionelles ${ }^{14} \mathrm{C}$-Alter von ca. $16.200{ }^{14} \mathrm{C}$-Jahren v.h. MARKS (2002) gibt dem kleineren ${ }^{14} \mathrm{C}$-Alter ein höheres Gewicht. Ihm entspricht ein kalibriertes Alter (STUIVER et al. 1998) von 17.600 Jahren v.h.

\section{Bemerkungen}

Die Pommern-Phase wird neben der Brandenburg-Phase häufig auch klimastratigraphisch gesehen. Zwischen der Frankfurt-Phase und der Pommern-Phase soll ein starkes Niedertauen und weites Zurückschmelzen der Eismassen erfolgt sein. Interstadiale Bildungen zwischen beiden Phasen wurden aber bisher nicht nachgewiesen. Aus diesem Grund wird anstelle der von WoldSTEDT (1928) eingeführten Bezeichnung „Stadium“ hier wieder der ursprüngliche Begriff „Phase“ eingesetzt. 
Nach LiedTKe (1996: 336-337) ist ein Zurückschmelzen der Eismassen im Gebiet des Oderbruches allenfalls in der Größenordnung von 20 bis $30 \mathrm{~km}$ glaubhaft. Vor dem pommerschen Eisrand hätten noch große Toteismassen der Frankfurt-Phase gelegen. Beide Phasen könnten insofern nur durch einen relativ kurzen Zeitraum getrennt gewesen sein (ebenso KLIEWE \& JAHNKE 1972: 32-33). CЕPEK $(1965,1972)$ gibt für die Grundmoräne der Pommern-Phase eine eigenständige Geschiebegemeinschaft (W2) an. MüLler (zit. in RÜHBERG et al. 1995: 109) unterscheidet mit Hilfe der Kleingeschiebeanalyse zwei pommersche Grundmoränen (W2u, W2o), die zu den Endmoränenlagen W2 $2_{\max }$ bzw. W2 (Hauptendmoräne) gehören.

Die M-Moränen und z.T. die I-Moränen von GRIPP (1964) gehören wahrscheinlich zur Pommern-Phase.

(Stephan)

\section{Mecklenburg-Phase \\ (Syn.: Mecklenburger Stadium, Mecklenburger Vorstoß, Rosenthaler „Staffel“)}

\section{Definition, Erstbeschreibung}

GEIKIE (1895) definierte innerhalb seiner Pleistozängliederung ein „Mecklenburgian“, das die Grundund Endmoränen des letzten baltischen Eisstromes umfassen sollte. Diese „Mecklenburger Stufe“ (KeILHACK 1896) hätte das ,südliche Ende der nordeuropäischen Glazialablagerungen an der Endmoräne des baltischen Höhenrückens" erreicht. Dieser Beschreibung nach handelt es sich um das Gebiet des heutigen Weichsel-Glazials bis zur Endmoräne der Frankfurt-Phase. HeErdT (1965) erkannte, dass ein post-pommernzeitlicher Gletschervorstoß im Norden Mecklenburgs eine eigenständige Grundmoräne hinterlassen hatte und korrelierte sie mit der Rosenthaler Staffel.

Neudefinition durch EIERMANN (1984) als „Mecklenburger Stadium“.

\section{Typuslokalität, Typusregion}

Typusregion ist das nördliche Land Mecklenburg. Eine Typuslokalität wurde nicht benannt.

\section{Verbreitung}

Nach Heerdt (1965), Eiermann (1984), Rühberg (1987, 1999) und RüHBerg et al. (1995) ist die Grundmoräne der Mecklenburg-Phase im nördlichen Land Mecklenburg verbreitet. Endmoränen begrenzen den Vorstoß nur stellenweise („Rosenthaler Staffel“; Schulz 1965, 1967). Die Grenze verläuft im westlichen Mecklenburg als „W3-Randlage“ dicht nördlich der „Pommerschen Hauptendmoräne" und setzt sich erst in Vorpommern mit deutlichem Abstand von ihr ab (Geologische Karte von Mecklenburg-Vorpommern 1:500.000; Oberfläche). Nach Schleswig-Holstein und Dänemark findet sie in der innersten Randlage der Lübecker Bucht (WoLDSTEDT 1925), der „Sehberg-Randlage“ (Stephan 1980) und der „Ostjütischen Randlage“ (Andersen 1945, Berthelsen 1973 und andere später) als äußerer Staffel des „Jungbaltischen Vorstoßes“ (vgl. CеPEK 1967: 398, StePHAN 2001) ihre Fortsetzung. Nach Osten hin bindet sie nach LIEDTKE (1981) an die Stettiner Staffel an und soll - mit größeren Unterbrechungen - bis nach Masuren verfolgbar sein (= östlicher Teil der Randlage F nach RichTER 1937, LieDTKE 1981).

\section{Datierung}

Nach kalibrierten ${ }^{14} \mathrm{C}$-Daten, die LAGerLund \& Houmark-Nielsen (1993) publiziert haben, hat die aktive jungbaltische Vergletscherung auf Seeland deutlich vor 14.000 Jahren v.h. geendet. Das entspricht der aus den Grönlandeiskernen abzuleitenden ersten ausgeprägten spätweichselzeitlichen Erwärmung ab ca. 14.650 Jahren v.h. (DANSGAard et al. 1993, Stuiver et al. 1995). Die Mecklenburg-Phase müsste in die davor liegende Abkühlungsphase zwischen ca. 17.000 und 15.000 Jahre v.h. fallen. GLSL- und TL-Daten von Kame-Sedimenten aus der Abschmelzphase des bereits stagnierenden jungbaltischen Eises bei Brodten (Lübecker Bucht) ergaben einen Mittelwert von 15.000 Jahren v.h. (Preusser 1999). 


\section{Bemerkungen}

Im Verlauf der Mecklenburg-Phase gelangten Eismassen aus dem Gebiet der östlichen Ostsee nach Westen und transportierten typische „baltische“ Geschiebegemeinschaften (vgl. STEPHAN 2001), die sonst im Odergebiet und weiter östlich verbreitet sind, fahnenartig bis nach Djursland.

RÜHBERG (1999) charakterisiert die Kleingeschiebegemeinschaft der Grundmoräne (W3) in Mecklenburg.

Die I-Moränen von GRIPP (1964) gehören überwiegend zum Sehberg-Vorstoß und damit zur Mecklenburg-Phase.

LiedtKe \& MARCineK (2002) rechnen in Dänemark nur die Ablagerungen des Beltsee-Vorstoßes zur Mecklenburg-Phase und damit die Jungmoräne Ostjütlands zur Pommern-Phase. Schulz (2003) rechnet die jüngsten glaziären Ablagerungen Nordmecklenburgs und der dänischen Inseln mit stellenweise baltischer Geschiebegemeinschaft zur Pommernphase.

(STEPHAN)

\section{Meiendorf-Interstadial}

\section{Definition, Erstbeschreibung}

Menke (1968b) bezeichnete die erste Erwärmungsphase nach dem Hoch- bzw. Pleniglazial als „Meiendorf-Intervall“" (benannt nach dem Stadtteil Hamburg-Meiendorf). Später präzisierte er die Gliederung des Spätglazials in Schleswig-Holstein und nannte dieses Thermomer „Meiendorf-Interstadial“ (MENKE, in Bock et al. 1985). Der Beginn dieses Interstadials ist in dieser Region gekennzeichnet durch den Anstieg von Betula (wohl B. nana), Salix, Hippophaë, Juniperus und Artemisia. Der Heliophytenanteil ist hoch. Die obere Grenze wird durch einen NBP-Anstieg nach dem Hippophä̈-Maximum festgelegt. Das Meiendorf-Interstadial im Sinne von MENKE entspricht inhaltlich und stratigraphisch der sog. Hippophaë-Betula nana-Pollenzone vor dem „Bölling-Alleröd-Komplex“ nach UsINGER (1985).

\section{Typuslokalität, Typusregion}

Das Typusprofil ist Glüsing 72 in Schleswig-Holstein (Menke 1968b, Neugliederung in Bock et al. 1985). Die Typusregion ist der periglaziäre Raum Schleswig-Holsteins.

\section{Vergleichbare Profile,Verbreitung}

In Schleswig-Holstein ist das Meiendorf-Interstadial mit den o.g. Kriterien sensu MenKe gut verbreitet: Esinger Moor (UsINGER 1985), Heiligenhafen, Eichholzniederung (UsINGER 1985), Liether Kalkgrube (Bokelmann et al. 1983). Außerhalb Schleswig-Holsteins wurde das Meiendorf-Interstadial im Hämelsee (Merkt \& Müller 1999) und im Holzmaar sowie Meerfelder Maar in der Eifel sicher nachgewiesen (LitT \& STEBich 1999).

\section{Datierung}

Konventionelle Radiokarbondaten liegen aus Schleswig-Holstein sowohl vom Hippophaë-Maximum als auch von den innerhalb des Interstadials nachgewiesenen Fundschichten der Hamburger Stufe vor (zwischen 12.570 und $11.990{ }^{14}$ C-Jahren v.h.; vgl. FisCher \& TAUBER 1986, BoKelmann et al. 1983). Nach Jahresschichtenzählungen begann das Interstadial im Meerfelder Maar um 14.450 Warvenjahre v.h. und endete um 13.800 Jahre v.h. (Brauer et al. 1999, LitT \& Stebich 1999).

\section{Bemerkungen}

Verwechslungen zwischen Meiendorf-Interstadial und Bölling-Interstadial sind offenbar in zahlreichen Bearbeitungen erfolgt. 


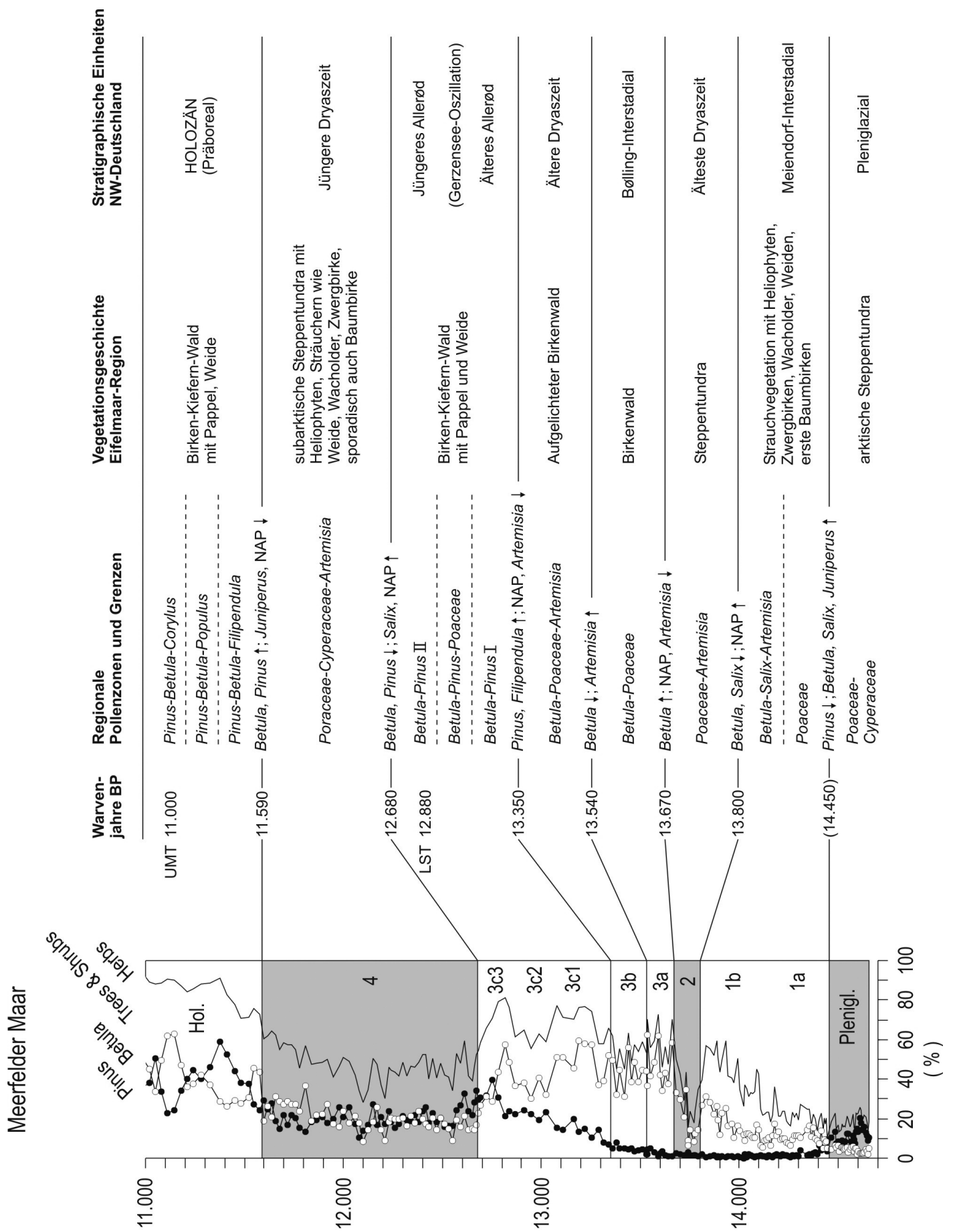

Abb. 6: Bio- und Chronostratigraphie des Weichsel-Spätglazials in Nordwestdeutschland (Eifel) (nach LiTT et al. 2003).

Fig. 6: Bio- and chronostratigraphy of the Weichselian Lateglacial in north-western Germany (from LiTT et al. 2003). 


\section{Älteste Dryaszeit \\ (Syn.: Ältere Tundrazeit, Dryas 1)}

\section{Definition, Erstbeschreibung}

Der Begriff „Älteste Dryaszeit““ wurde von Iversen (1942) für die kühle Phase mit NBP-Maximum unmittelbar vor dem ersten spätglazialen BP-Maximum des Bölling-Interstadials (mit Baumbirke) im Profil Bøllingsø geprägt (Pollenzone Ia sensu Iversen). Als Synonym verwendete er später Begriffe wie „Daniglacial tundra period“ (Iversen 1954) bzw. „earliest tundra period“ (IVERSEN 1973). Die Älteste Dryaszeit sensu IvERSEN ist im Typusprofil Bøllingsø allerdings ohne Untergrenze definiert worden. MenKe (1968b) sowie MenKe (in Bock et al. 1985) bezeichnet das NBP-Maximum nach dem Hippophaё-Maximum am Ende des Meiendorf-Interstadials und vor dem Bölling-Interstadial als Ältere Tundrazeit (entspricht der Helianthemum-Betula nana Zone nach UsINGER 1985).

\section{Typuslokalität}

Das Typusprofil wurde von IvERSEN $(1942,1954)$ in Bøllingsø/Jütland beschrieben. Parastratotyp für die Ältere Tundrazeit sensu MENKE ist Glüsing in Schleswig-Holstein (MENKE 1968b, Bock et al. 1985).

\section{Vergleichbare Profile, Verbreitung}

In zahlreichen Profilen Norddeutschlands ist die Älteste Dryaszeit als kühle Phase vor dem BöllingInterstadial palynologisch beschrieben worden (Ältere Tundrazeit oder Dryas 1 als Synonym), so in Glüsing (Menke 1968b), Wildes Moor (Bock et al. 1985), Esinger Moor (Usinger 1981), Hämelsee (Merkt \& Müller 1999) sowie Holzmaar und Meerfelder Maar (Litt \& Stebich 1999).

\section{Datierung}

Nach Jahresschichtenzählungen im Meerfelder Maar beginnt das Stadial um 13.800 Warvenjahren v.h. und endet um 13.670 Warvenjahren v.h. (Brauer et al. 1999, LitT \& STEBich 1999).

\section{Bemerkungen}

Offenbar kam es im Laufe der Zeit in Norddeutschland zu Verwechslungen zwischen Ältester und Älterer Dryaszeit.

\section{Bölling-Interstadial}

\section{Definition, Erstbeschreibung}

Der Begriff „Bölling-Oszillation“ bzw „Bölling period“ wurde von Iversen $(1942,1954)$ aufgrund der palynologischen Bearbeitung eines Profils in Bøllingsø geprägt. Das Bölling-Interstadial wird dort an seiner Untergrenze durch einen markanten Anstieg der Birkenpollen (im wesentlichen Baumbirken) nach dem Rückgang von Hippophaë charakterisiert (Pollenzone Ib sensu IVERSEN).

\section{Typuslokalität}

Das Typusprofil ist Bøllingsø, Dänemark (IVERSEN 1942), das durch IvERSEN (1954) nachbearbeitet wurde (vgl. auch IVERSEN 1973).

\section{Vergleichbare Profile, Verbreitung}

Im benachbarten Schleswig-Holstein lassen sich die biostratigraphischen Kriterien der Typuslokalität zwanglos übertragen. Vergleichbare Profile sind vor allem Glüsing (Menke 1968b, Neuinterpretation in Bock et al. 1985), Rabensbergmoor (Usinger 1975) und Wildes Moor (Bock et al. 1985). In Nordwestdeutschland wurde diese Wärmeschwankung eindeutig im Hämelsee (MERKT \& MüLlER 1999) sowie im Holzmaar und im Meerfelder Maar (Liтt \& Sтевісн 1999) nachgewiesen. 


\section{Datierung}

Nach Warvenzählungen im Meerfelder Maar dauerte das Bölling-Interstadial von 13.670 bis 13.540 Warvenjahren vor heute.

\section{Bemerkungen}

Offenbar kam es im Laufe der Zeit in Norddeutschland zu Verwechslungen zwischen Bölling-Interstadial und Meiendorf-Interstadial. Usinger (1985) setzt entgegen früherer Auffassungen (z. B. Usinger 1975) das Bölling-Interstadial Jütlands sensu IVERSEN mit dem unteren Abschnitt des Alleröd-Interstadials in Profilen auf den Dänischen Inseln (z. B. Profil Ruds Vedsby auf Seeland, vgl. KROG 1954) und in eigenen Profilen aus Schleswig-Holstein gleich („Alleröd a“ sensu Usinger 1985).

\section{Ältere Dryaszeit \\ (Syn.: Mittlere Tundrazeit, Dryas 2)}

\section{Definition, Erstbeschreibung}

Der Begriff „Ältere Dryaszeit“ wurde von IvERSEN (1942) für die Abkühlungsphase mit NBP-Maximum und Betula-Rückgang zwischen den BP-Maxima des Bölling- und Alleröd-Interstadials im Profil Bøllingsø geprägt (Pollenzone Ic sensu Iversen).

\section{Typuslokalität}

Das Typusprofil wurde von Iversen $(1942,1954)$ in Bøllingsø/Jütland beschrieben.

\section{Vergleichbare Profile, Verbreitung}

Die Ältere Dryaszeit sensu IVERSEN ist in zahlreichen Profilen Norddeutschlands palynologisch beschrieben worden (Mittlere Tundrazeit oder Dryas 2 als Synonym), so in Glüsing (MenKe 1968b), Wildes Moor (Bock et al. 1985), Hämelsee (Merkt \& Müller 1999) und Meerfelder Maar (LitT \& STEBICH 1999).

\section{Datierung}

Nach Jahresschichtenzählungen im Meerfelder Maar beginnt das Stadial um 13.540 Warvenjahren v.h. und endet um 13.350 Warvenjahren v.h. (Brauer et al. 1999, LitT \& STEBich 1999).

\section{Bemerkungen}

Durch die Umdeutung des Bölling-Alleröd-Komplexes durch Usinger (1981) wurde die „Mittlere Tundrenzeit bzw. Dryas 2“ in Rabensbergmoor (Usinger 1975) in „Alleröd b“ umbenannt.

\section{Alleröd-Interstadial}

\section{Definition, Erstbeschreibung}

Der Begriff wurde von Hartz \& Milthers (1901) für spätglaziale interstadiale Sedimente (aufgrund von pflanzlichen Großresten) nach der namengebenden Siedlung Allerød in Seeland (Dänemark) eingeführt. Die entsprechenden Ablagerungen wurden später von JESSEN (1935) palynologisch bearbeitet. Iversen $(1942,1954)$ definiert im Profil Bøllingsø (Jütland) die über dem Bölling-Interstadial nach einer Kälteschwankung (Ältere Dryaszeit) erneut fassbare Birkenausbreitung als „Alleröd-Oszillation“ bzw. „Alleröd period“" (Pollenzone II sensu IvERSEN). 


\section{Typuslokalität}

Das nicht mehr existente Typusprofil ist Allerød, die Typusregion Seeland in Dänemark (HARTz \& Milthers 1901, Jessen 1935). Wegen der gut definierten Pollenzonierung des Spätglazials durch Iversen $(1942,1954)$ ist das Profil Bøllingsø Parastratotyp auf Jütland.

\section{Vergleichbare Profile, Verbreitung}

Im benachbarten Schleswig-Holstein lassen sich die biostratigraphischen Kriterien von IvERSEN zwanglos übertragen. Vergleichbare Profile sind vor allem Glüsing (Menke 1968b, Neuinterpretation in Bock et al. 1985) und Wildes Moor (Bock et al. 1985). In Nordwestdeutschland wurde diese Wärmeschwankung eindeutig mit gut definierter Untergrenze im Hämelsee (MERKT \& MüLLER 1999) sowie im Holzmaar und im Meerfelder Maar (LitT \& StEBich 1999) nachgewiesen.

\section{Datierung}

Nach Warvenzählungen im Meerfelder Maar dauerte das Alleröd-Interstadial von 13.350 bis 12.680 Warvenjahren vor heute (LitT \& SteBich 1999, LitT et al. 2001). Die prominente und in Mitteleuropa weit verbreitete Laacher See-Tephra innerhalb des Alleröd konnte durch Warvenzählungen im Meerfelder Maar auf ein Alter von 12.880 Jahren bestimmt werden (BRAUER et al. 1999, LITT et al. 2001).

\section{Bemerkungen}

Problematisch ist die Abweichung bei der Definition der Untergrenze des Alleröd in der Literatur. Usinger (1985) setzt das Bölling-Interstadial Jütlands sensu IvERSEN mit dem unteren Abschnitt des Alleröd-Interstadials in Profilen auf den Dänischen Inseln (z. B. Profil Ruds Vedsby auf Seeland, vgl. KrOG 1954) und in eigenen Profilen aus Schleswig-Holstein gleich. MenKe (in BocK et al. 1985) folgt den Kriterien von Iversen (so auch Merkt \& Müller 1999, Litt \& Stebich 1999).

\section{Jüngere Dryaszeit \\ (Syn.: Jüngere Tundrazeit, Dryas 3)}

\section{Definition, Erstbeschreibung}

Der Begriff wurde von JESSEN (1935) geprägt. Er beinhaltet eine Abkühlungsphase nach dem Alleröd-Interstadial mit entsprechender stadialer Vegetation (höhere NBP-Werte mit Heliophyten) und charakteristischer Sedimentationsdynamik (stärkerer klastischer Einfluß).

\section{Typuslokalität}

Ein Typusprofil im engeren Sinne liegt nicht vor. Eindeutige biostratigraphische Kriterien wurden von IVERSEN $(1942,1954)$ in Bøllingsø/Jütland beschrieben (Pollenzone III).

\section{Vergleichbare Profile, Verbreitung}

Die Jüngere Dryaszeit ist in zahlreichen Profilen sehr gut palynologisch und sedimentologisch belegt, wobei über Inhalt, Definition und Korrelation praktisch keine kontroverse Diskussion besteht.

\section{Datierung}

Zahlreiche konventionelle ${ }^{14} \mathrm{C}$-Daten aus Europa liegen zwischen 10.800 und 10.000 Jahren v.h. Nach Jahresschichtenzählungen im Meerfelder Maar beginnt das Stadial um 12.680 Warvenjahren v.h. und endet um 11.590 Warvenjahren v.h. (Brauer et al. 1999, LitT \& STEBich 1999). Mittlerweile wurde auch die Grenze zwischen der Jüngeren Dryaszeit und dem Präboreal dendrochronologisch auf 11.570 Jahre v.h. bestimmt (FrIEDRICH et al. 1999). 


\section{Bemerkungen}

Die durch Warvenzählungen erfaßte Dauer der Jüngeren Dryaszeit im Meerfelder Maar von ca. 1.100 Jahren korrespondiert mit anderen Warvenzählungen im nördlichen Mitteleuropa (vgl. LiтT et al. 2001). Die obere Grenze entspricht zugleich dem Übergang zwischen Pleistozän und Holozän (Termination 1).

\section{Holozän \\ (Syn.: Flandrium)}

\section{Definition, Erstbeschreibung}

Der Begriff „Holozän“ (aus dem Griechischen: das völlig Neue) wurde durch den französischen Zoologen Gervais (1867-1869) eingeführt. Auf dem 3. Geologischen Kongress in London 1885 wurde die von LyelL geprägte Bezeichnung „Recent“ in „Holocene“ umbenannt.

Das Holozän wird chronostratigraphisch als eigenständige Serie/Epoche innerhalb des Quartärs aufgefasst (GiBBARD \& VAN KOLFSCHOTEN 2004).

Der Begriff „Flandrium“ (geprägt durch marine Transgressionssedimente an der belgischen Küste, vgl. HeINZELIN \& TAVERnier 1957) wurde als Synonym für das Holozän genutzt. Er wurde vor allem von Autoren verwendet, die dafür plädierten, dass der Zeitraum der letzten $10.000{ }^{14} \mathrm{C}$-Jahre den selben Status wie diejenigen der vorhergehenden Interglaziale hätte und deshalb in das Pleistozän mit einbezogen werden sollte (z. B. WeSt 1977). Allerdings hat sich diese Meinung wegen der Besonderheiten des Holozäns (z.B. anthropogener Einfluss) nicht durchsetzten können.

Verschiedene Gliederungsschemata wurden für das Holozän in Europa vorgeschlagen. Am gebräuchlichsten ist das von Blytt (1867) und SERnANDER (1894), das auf klimatisch interpretierte paläobotanische Daten aus Mooren in Skandinavien zurückgeht. In chronologischer Reihenfolge wurde das Holozän in folgende Abschnitte unterteilt: Präboreal, Boreal, Atlantikum, Subboreal, Subatlantikum. In Deutschland gliederten Firbas (1949/52) und Overbeck (1975) in Anlehnung an das System von BlytT und Sernander die Nacheiszeit in Vorwärmezeit, Frühe Wärmezeit, Mittlere Wärmezeit, Späte Wärmezeit und Nachwärmezeit. Die Zonierung nach BLYTT und SERNANDER ist im nördlichen Europa noch gebräuchlich. Sie wird aber weitgehend durch Fixierung der Zonengrenzen mittels absoluter Chronologie ersetzt (MANGERUd et al. 1974).

\section{Typuslokalität}

Ein GSSP für die Untergrenze des Holozäns liegt bislang nicht vor. Gegenwärtig wird von der SQS ein Vorschlag vorbereitet, den archivierten Kern der NorthGRIP-Bohrung als GSSP zu nutzen. Als Parastratotyp in N-Deutschland wäre wegen der hohen Präzision die Sequenz von jährlich geschichteten lakustrinen Ablagerungen der Eifelmaare geeignet (LiTT et al. 2001).

\section{Verbreitung}

Das Holozän als chronostratigraphische Einheit ist weltweit gebräuchlich.

\section{Datierung}

In der Bohrung NorthGRIP ist das Alter der Untergrenze des Holozäns auf 11.700 Jahre bestimmt worden (Referenzdatum 2000 AD).

Nach Jahresschichtenzählungen in den Eifelmaaren beginnt das Holozän um 11.590 Warvenjahren v.h. (Referenzdatum 1950, Brauer et al. 1999, Litt \& Stebich 1999). Mittlerweile wurde auch die Grenze zwischen der Jüngeren Dryaszeit und dem Präboreal dendrochronologisch auf 11.570 Jahre v.h. bestimmt (FrIEDRICH et al. 1999). 


\section{Calais-Dünkirchen-Folge (marines Holozän)}

\section{Definition, Erstbeschreibung}

Die Begriffe „Calais“ und „Dunkerque“ wurden zuerst von DuBors (1924) zur lithostratigraphischen Unterteilung des marinen Holozäns in Nordfrankreich benutzt. Die Trennung zwischen den liegenden Calais-Schichten und den hangenden Dunkerque-Schichten wurde dabei in der Regel durch einen weit verbreiteten eingeschalteten Torf gekennzeichnet. Mit der Übernahme der Begriffe nach Belgien, in die Niederlande und nach Deutschland wandelte sich diese ursprünglich rein lithologische Terminologie in eine chronologische, nachdem die hinter diesen Einheiten liegenden Transgressionsphasen immer besser datiert werden konnten.

\section{Typuslokalität, Typusregion}

Typusregion der Grundbegriffe ist das französische marine Holozän im Raum Calais-Dünkirchen. Mit der weiteren Differenzierung beider Folgen in Calais I bis IV und Dünkirchen I-IV kamen zusätzliche Typuslokalitäten in Belgien (bes. TAVERNIER 1948) und den Niederlanden (bes. seit TESCH 1942) hinzu.

\section{Vergleichbare Profile, Verbreitung}

Als übergreifende Begriffe für die Nordsee-Transgressionsphasen sind diese Termini inzwischen als chronostratigraphische Einheiten von Nordfrankreich bis nach Deutschland in Gebrauch. Dabei wurden weitere Untergliederungen vorgenommen, z.B. wurde von MoormanN (1951) zunächst in Belgien eine Dünkirchen 0-Transgression eingefügt, die als älter als der Torf, aber jünger als Calais IV angesehen wurde. In den Niederlanden gilt das Calais-Dünkirchen-System als offizielle Grundlage des Geologischen Dienstes für die Gliederung des Küstenholozäns (DE Jong \& HaGeman 1960, HaGEMAN 1963, später u.a. Vos \& van HEeringen 1997). In Deutschland wurde das Calais-Dünkirchen-System erst spät übernommen (bes. durch MenKe 1988). Auf der Basis des deutschen Küstenholozäns und zahlreicher neuer Datierungen wurde durch BEHRE (2003) eine Neubearbeitung der Calais-Dünkirchen-Folge vorgenommen, bei der die Dünkirchen 0-Transgression in Calais IV eingegliedert wurde und für den mittleren und jüngeren Bereich insgesamt sieben Regressionen zwischen den Transgressionsphasen definiert wurden.

\section{Datierung}

Auf der Basis von Radiokarbondatierungen liegt die Calais-Folge zwischen ca. 7.800 BP (cal. 6.650 v. Chr.) und 3.250 BP (cal. 1.500 v.Chr.), die Dünkirchen-Folge setzt 2.850 BP (cal. 1.000 v. Chr.) ein und reicht bis heute. Die aktuellen Datierungen der zahlreichen Unterabschnitte finden sich bei BEHRE (2003).

\section{Bemerkungen}

Der langsame Wechsel vom ursprünglich lithologischen bis zum heutigen chronologischen Inhalt dieser Termini hat vielfach Verwirrung gestiftet. Eine deutsch-niederländische Übersicht der damals noch überwiegend lithologisch gebrauchten Termini mit neu geschaffenen weiteren Untergliederungen nach Profilen in Deutschland (die dann aber kaum in Gebrauch kamen) lieferten Brand et al. (1965). Eine weitere Komplikation ergab sich daraus, dass man in den Niederlanden lange Zeit von einem stetig steigenden Meeresspiegel ohne Schwankungen ausging, so dass die inzwischen erkannten Regressionsphasen zeitlich in die Transgressionsphasen eingeschlossen waren. Deshalb gibt die Revision von BEHRE (2003) z.T. andere Daten als die älteren Arbeiten aus den Niederlanden. 